\title{
SYSTEMATICS OF THE “GIANT” RICINULEI (RICINOIDIDAE: RICINOIDES) OF WEST AFRICA, WITH DESCRIPTIONS OF FIVE NEW SPECIES AND COMPARATIVE MORPHOLOGY OF THE MALE COPULATORY APPARATUS
}

\author{
RICARDO BOTERO-TRUJILLO \\ Division of Invertebrate Zoology \\ American Museum of Natural History \\ COLBY E. SAIN \\ Division of Invertebrate Zoology \\ American Museum of Natural History \\ Department of Earth and Planetary Sciences \\ University of Tennessee \\ LORENZO PRENDINI \\ Division of Invertebrate Zoology \\ American Museum of Natural History
}

BULLETIN OF THE AMERICAN MUSEUM OF NATURAL HISTORY

Number 448, 68 pp., 34 figures, 5 tables

Issued April 5, 2021 


\section{CONTENTS}

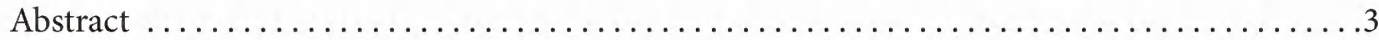

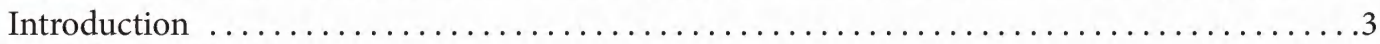

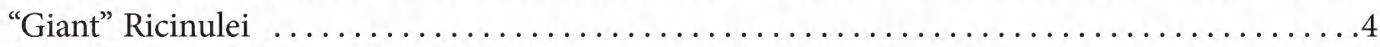

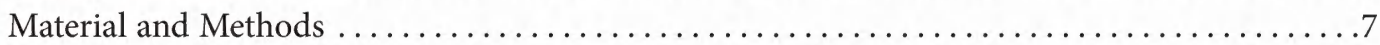

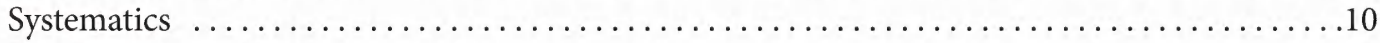

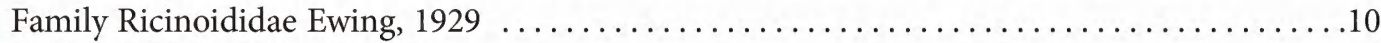

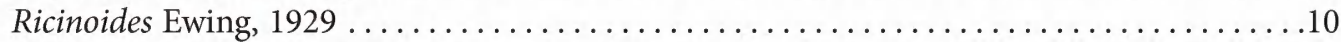

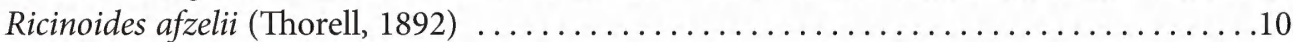

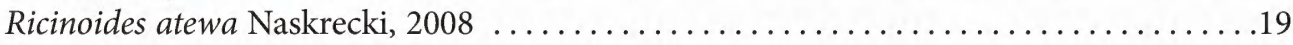

Ricinoides eburneus, sp. nov. ................................29

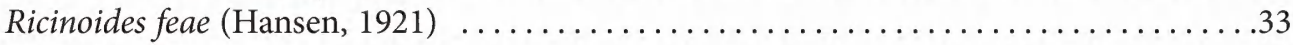

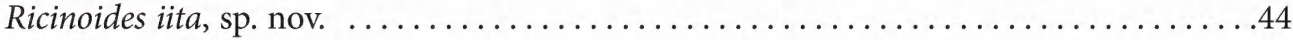

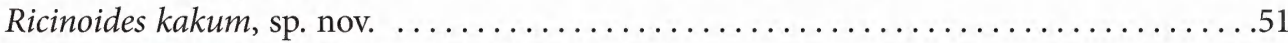

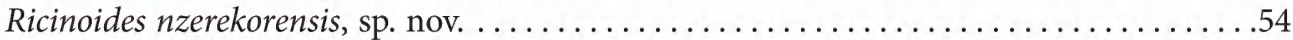

Ricinoides taii, sp. nov. ..................................... 59

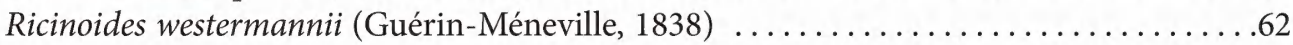

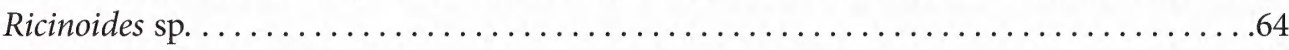

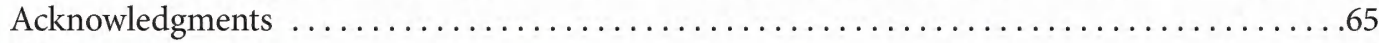

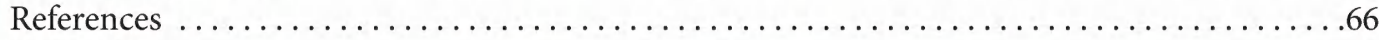




\begin{abstract}
The Ricinulei Thorell, 1876, or "hooded tick-spiders," are among the rarest and least studied arachnid orders. Ricinoides Ewing, 1929, the only Old World genus of extant ricinuleids, with 11 species described from tropical West Africa, is the most neglected of the three genera currently recognized. A lack of attention to the systematics of Ricinoides has created a disparity between its taxonomic diversity and that of the New World genera, Cryptocellus Westwood, 1874, and Pseudocellus Platnick, 1980, in which many new species have been described in recent decades. The present contribution provides a revised diagnosis of Ricinoides, which includes two new, putative synapomorphies for the genus and addresses the systematics and morphology of a group of West African species, which includes the world's largest ricinuleids and the type species of the genus. This group of nine species, referred to as the "giant" Ricinulei, shares a unique combination of characters, many of which appear to be unique to the group, and appears to be monophyletic. Four species of this group are redescribed, with revised diagnoses, based on reexamination of the type material: Ricinoides afzelii (Thorell, 1892), from Sierra Leone; Ricinoides atewa Naskrecki, 2008, from Ghana; Ricinoides feae (Hansen, 1921), from Guinea-Bissau; and Ricinoides westermannii (Guérin-Méneville, 1838), from Togo. Five new species are described, raising the number of species in the genus to 16: Ricinoides eburneus, sp. nov., and Ricinoides taii, sp. nov., from Côte d'Ivoire; Ricinoides iita, sp. nov., from Nigeria; Ricinoides kakum, sp. nov., from Ghana; and Ricinoides nzerekorensis, sp. nov., from Guinea. Comparative illustrations of the adult morphology are presented for all nine species. The male copulatory apparatus is described and illustrated in detail, and new terminology and characters presented. The female spermathecae are described and illustrated for six species in which the females are known, representing the first illustrated comparison of these structures in African ricinuleids. Geographical distribution records are revised and updated for the different species, and their distributions mapped.
\end{abstract}

\section{INTRODUCTION}

Comprising fewer than 100 extant species, the Ricinulei Thorell, 1876, or "hooded tick-spiders," are among the rarest and least studied arachnid orders. Ricinulei are an ancient lineage, the oldest fossils dating to the Upper Carboniferous (ca. 305-319 Ma) of Europe and North America. The extinct ricinuleid fauna of this period was studied in detail by Selden (1992), and an additional new species was recently described (Whalen and Selden, 2020). Fossil ricinuleids from mid-Cretaceous (c. $99 \mathrm{Ma}$ ) Burmese amber deposits were described by Wunderlich $(2012,2015,2017)$.

Extant ricinuleids are presently classified into three genera, and are almost confined to the tropical latitudes, except for a few species that extend slightly beyond (Gertsch and Mulaik, 1939; Gertsch, 1971; Valdez-Mondragón and Francke, 2011). The majority (84.2\%) of the species diversity of Ricinulei occurs in the New World. Cryptocellus Westwood, 1874, comprising
40 valid species, is distributed from Honduras southward to the Brazilian state of Rondônia (Harvey, 2003; Botero-Trujillo and Valdez-Mondragón, 2016; Botero-Trujillo and Flórez, 2017). Pseudocellus Platnick, 1980, also comprising 40 valid species, occurs from southern Texas, in the United States, southward to Panama, and on the island of Cuba (Harvey, 2003; Teruel, 2018; Valdez-Mondragón et al., 2018, 2020; Valdez-Mondragón and Juárez-Sánchez, 2021). The third and least speciose genus, Ricinoides Ewing, 1929, which comprised 11 species at the outset of the present study, is the only group of ricinuleids in the Old World, where it is restricted to tropical Africa, and presently recorded from 14 countries (Harvey, 2003; Naskrecki, 2008; Penney et al., 2009; Murienne et al., 2013; Fernández and Giribet, 2015; table 1).

Although Ricinoides westermannii (GuérinMéneville, 1838), the type species of Ricinoides, was the first described extant species of Ricinulei, knowledge of the Afrotropical Ricinulei has fallen 
far behind the Neotropical Ricinulei, in which many new species, including several highly modified troglobionts (Cokendolpher and Enríquez, 2004; Valdez-Mondragón and Francke, 2011, 2013; Armas, 2017), were described in recent decades. The most comprehensive contributions to the systematics and morphology of Afrotropical Ricinulei to date, are a revision of Ricinoides by Tuxen (1974), when the genus comprised seven species, and a series of publications by Legg (1976a, 1976b, 1977, 1978a, 1978b, 1982). The most recent taxonomic contribution to Ricinoides was the description of Ricinoides atewa Naskrecki, 2008, one of just six Ricinoides species described in the last 100 years (Hansen, 1921; Legg, 1976b, 1978a, 1982; Naskrecki, 2008).

The apparent neglect of Afrotropical Ricinulei, compared with Neotropical Ricinulei, may be attributed to several factors, including limited collecting in tropical Africa in the postcolonial period, due to a paucity of local biologists (compared with Latin America), political instability, and general insecurity in many tropical African countries; limited global expertise on African arachnids in general; and the absence of a systematic revision of historical material in natural history collections. Nevertheless, African ricinuleids recently received some attention as a model for addressing questions concerning Earth history. In the first published molecular phylogeny of the order, Murienne et al. (2013) investigated the biogeography of extant Ricinulei. The phylogeny of Ricinoides was used to test the "refugial speciation model" hypothesis, as compared with the "museums as refugia" hypothesis, in tropical West and Central Africa. Although not all African species were represented in the phylogenetic analysis and the taxonomic resolution of the samples was insufficient for inferring intra-generic relationships (not the primary aim of the study), it was determined that forest refugia played a role in preserving ancient lineages of Ricinulei rather than driving allopatric speciation.

The present contribution provides a revised diagnosis of Ricinoides, which includes two new, putative synapomorphies for the genus, and addresses the systematics and morphology of a group of West African species, which includes the world's largest ricinuleids and the type species of the genus. This group of nine species, referred to as the "giant" Ricinulei, shares a unique combination of characters, many of which appear to be unique to the group, and appears to be monophyletic. Four of these species are redescribed, with revised diagnoses, based on reexamination of the type material: Ricinoides afzelii (Thorell, 1892), from Sierra Leone; Ricinoides atewa Naskrecki, 2008, from Ghana; Ricinoides feae (Hansen, 1921), from Guinea-Bissau; and $R$. westermannii, from Togo. Five are newly described, based on museum material, in some cases very old, raising the number of species in the genus to 16: Ricinoides eburneus, sp. nov., and Ricinoides taii, sp. nov., from Côte d'Ivoire; Ricinoides iita, sp. nov., from Nigeria; Ricinoides kakum, sp. nov., from Ghana; and Ricinoides nzerekorensis, sp. nov., from Guinea. Comparative illustrations of the adult morphology are presented for all nine species. The male copulatory apparatus is described and illustrated in detail, and new terminology and characters presented. The female spermathecae are described and illustrated for six species in which the females are known, representing the first illustrated comparison of these structures in African ricinuleids. Geographical distribution records are revised and updated for the different species, and their distributions mapped. In spite of these advances, African ricinuleids remain poorly known and their diversity is probably vastly underestimated.

\section{“GIANT” RICINULEI}

The "giant" Ricinulei which are the subject of the present contribution (fig. 1), is a group of nine West African Ricinoides species, which share a unique combination of characters, in addition to being the world's largest ricinuleids. The total body length (excluding the cucullus and pygidium) of adults ranges from 6 to 10 $\mathrm{mm}$, with $R$. feae the smallest species of the group, at 6.24-6.45 $\mathrm{mm}$, and $R$. iita the largest, at $9.74 \mathrm{~mm}$. 


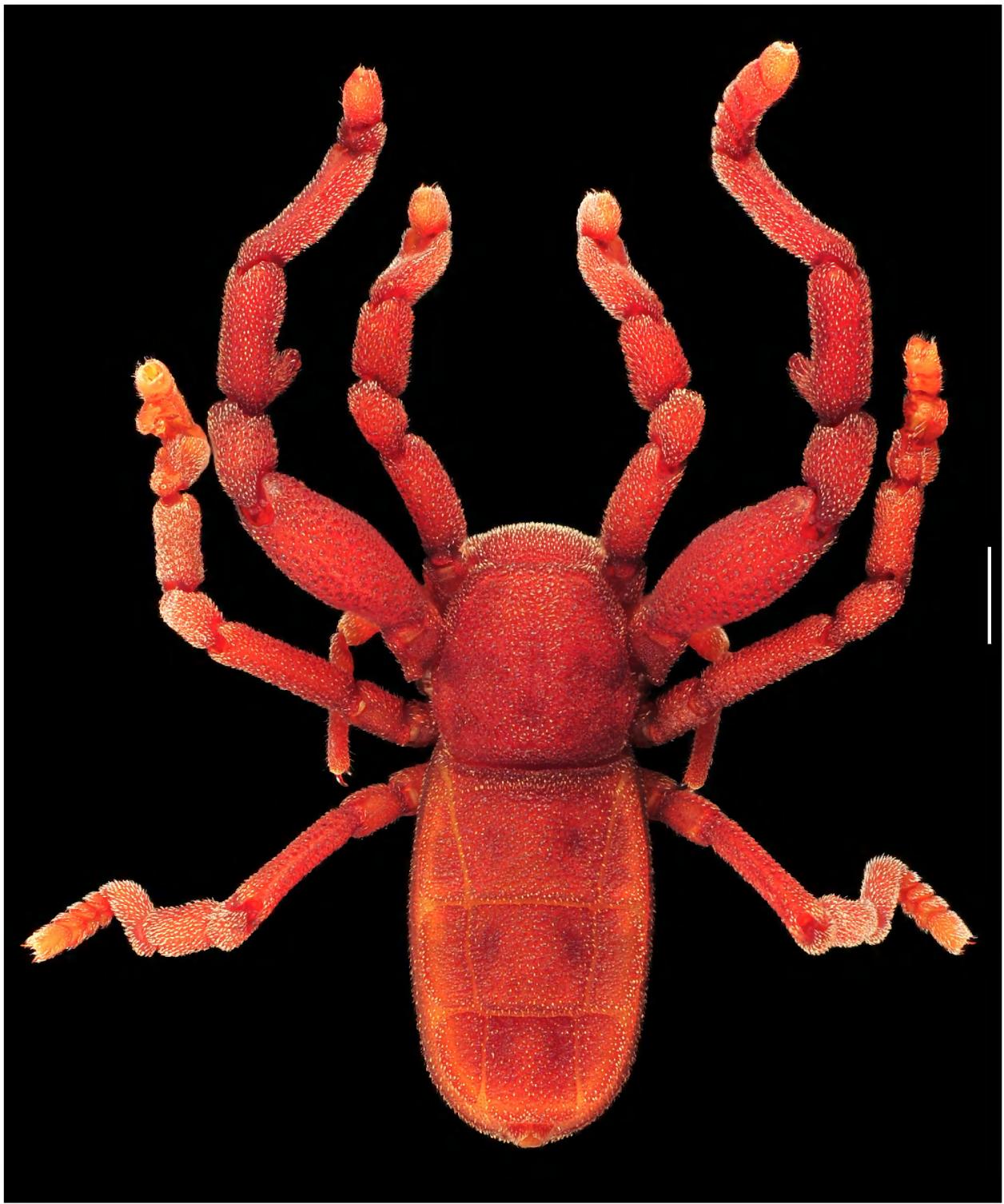

FIGURE 1. "Giant" ricinuleid, Ricinoides feae (Hansen, 1921), paralectotype ơ (MSNG), Rio Cacine, GuineaBissau, habitus, dorsal aspect. Scale bar $=1 \mathrm{~mm}$. Photograph courtesy Elena Babicz.

Except where indicated, all nine species exhibit the following characters in both sexes. Elevated oval tubercles are present distally on the pedipalp tibia (fig. 3C, D). A longitudinal sulcus is present dorsally on the femur of each leg (fig. 4A). A proventral depression is present proximally on the metatarsus of leg $I$ in the male (fig. 4B). A ventromedian apophysis is present on the tibia of leg II in the male of all species except $R$. westermannii. A ventral subproximal depression is present on the metatarsus of leg II in the male (fig. 4C). An acute process is present dorsodistally on the subdistal (third) tarsomere of leg III in the male (fig. 4D). 


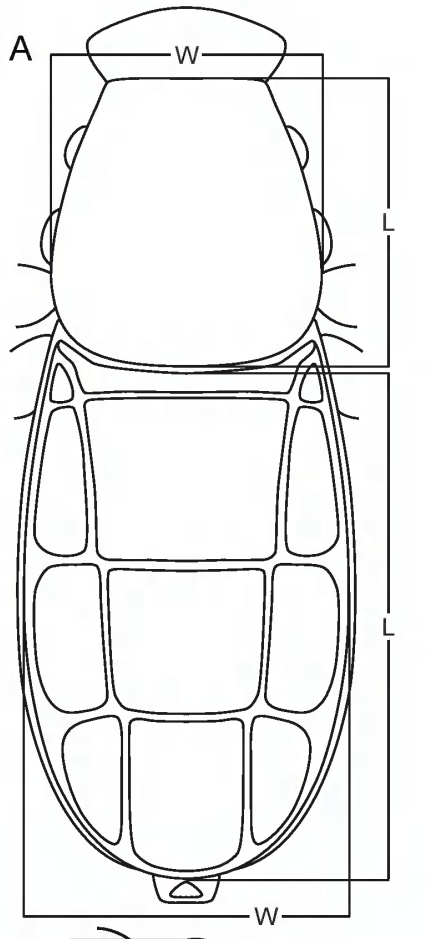

B

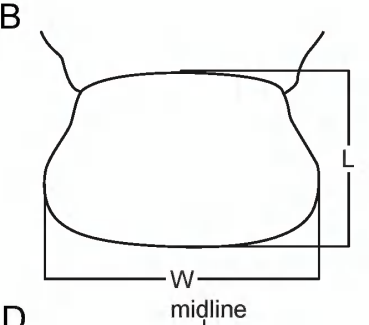

D
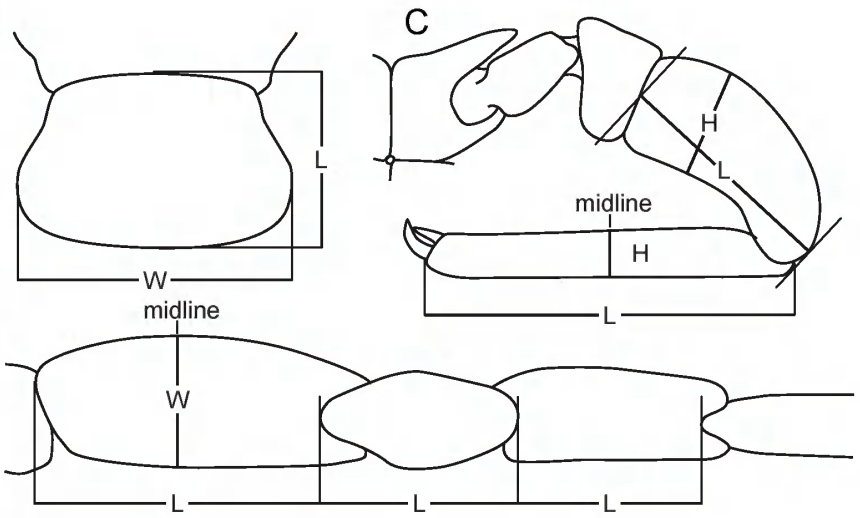

$\mathrm{E}$
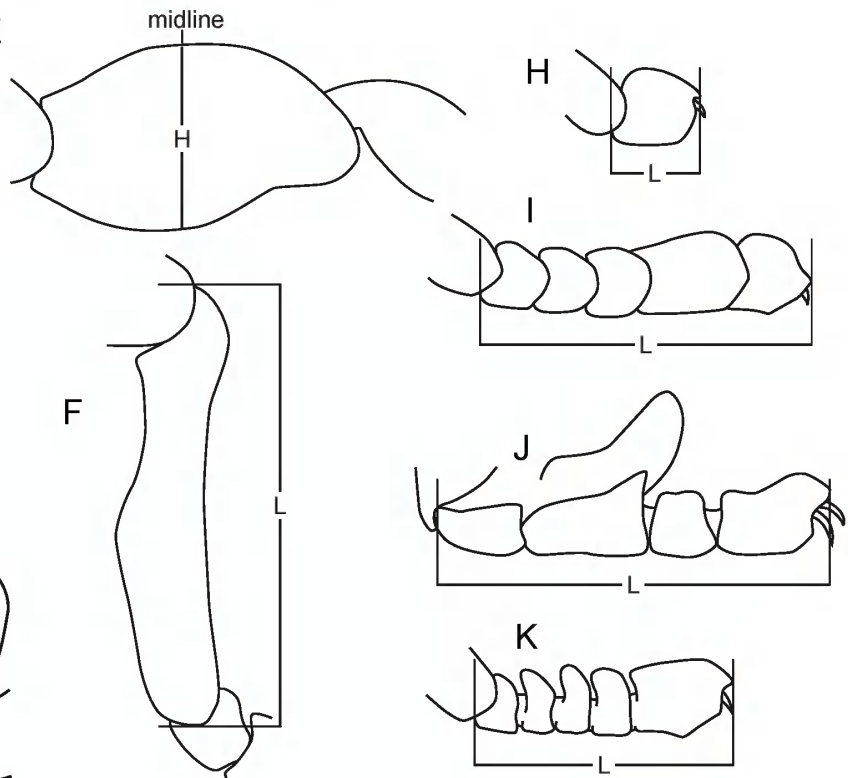

FIGURE 2. Selected measurements recorded for species of Ricinoides Ewing, 1929. A. Soma, dorsal aspect. B. Cucullus, anterior aspect. C. Pedipalp, prolateral aspect. D. Leg II, dorsal aspect. E. Leg II femur, prolateral aspect. F. Leg II metatarsus, prolateral aspect. G. Leg III metatarsus (ð), prolateral aspect. H-K. Tarsi, legs I (H), II (I), III ( $\hat{O}^{\text {) }}(\mathbf{J})$, and IV (K). Abbreviations: L, length; W, width; H, height.

The tergal and pleural membranes of the opisthosoma are granular (fig. 4E). The opening of the pygidium is distinctly narrow, its width two fifths (in $R$. feae and $R$. westermannii only) to one third the lateral width of the segment at its base (fig. 4F). The male copulatory apparatus possesses a fixed process with a lobular region distally, comprising alpha $(\alpha)$, beta $(\beta)$, retrolateral distal $(r d)$ and prolateral distal $(p d)$ lobes.
The beta ( $\beta$ ) lobe is bicuspid (except in $R$. afzelii, in which it is entire). The retrolateral subdistal $(r s d)$ lobe is medium sized.

Although addressing the phylogeny of the "giant" Ricinulei is beyond the scope of this contribution, it is noteworthy that both the molecular phylogeny of Murienne et al. (2013) and unpublished morphological analyses (R.B.-T. and L.P., in prep.) support the monophyly of this 

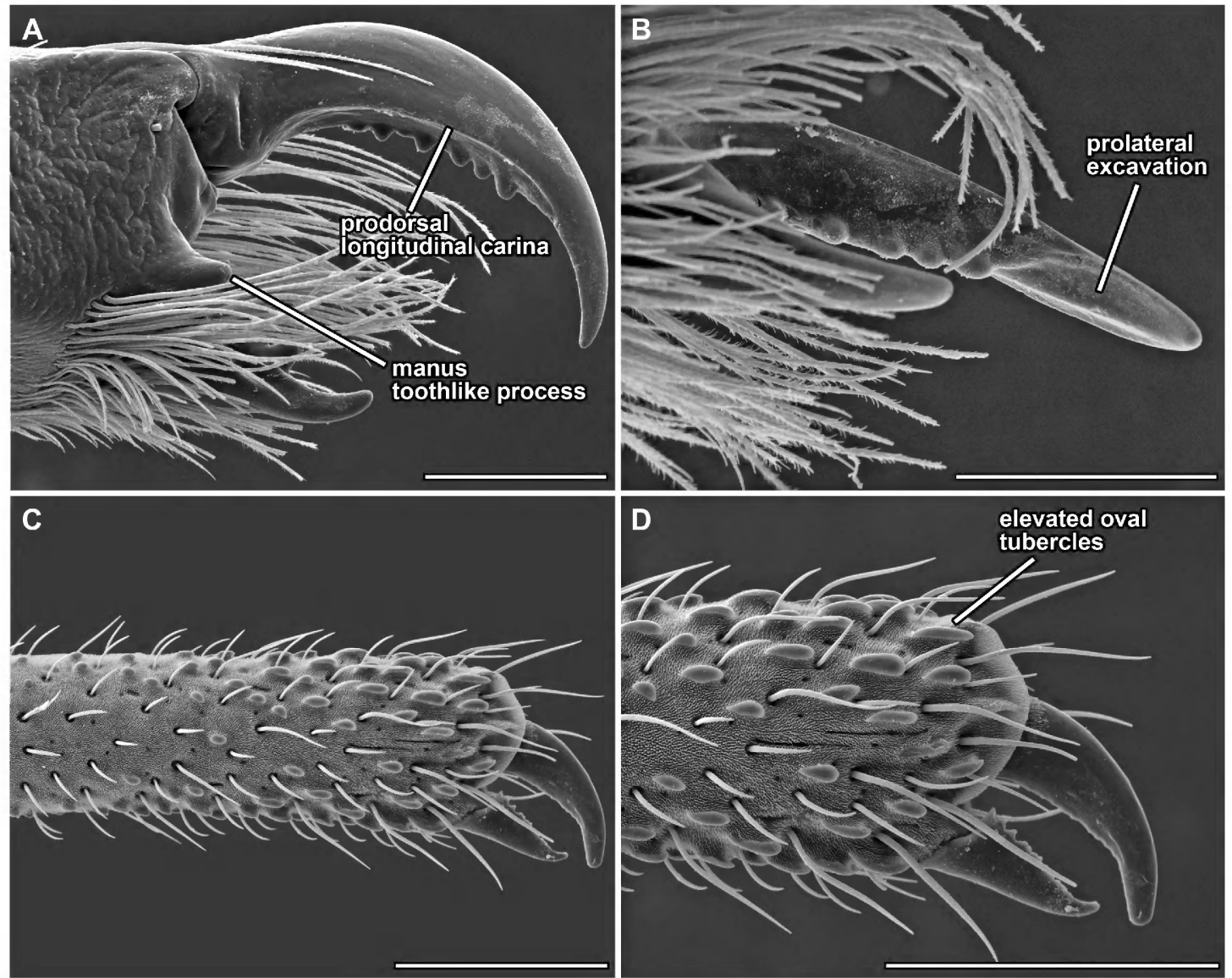

FIGURE 3. Ricinoides sp., tritonymph (AMCC [LP 4664]). A. Chelicera, dorsal aspect. B. Cheliceral movable finger, prolateral aspect. C, D. Pedipalp tibia, distal part, prolateral aspect (C), close up (D). Scale bars $=0.2 \mathrm{~mm}$.

group of species. Future analyses will address the phylogeny of African Ricinulei in more detail.

\section{MATERIAL AND METHODS}

Material AND TAXon SAMPLING: Material is deposited in the following collections: the American Museum of Natural History (AMNH), including the Ambrose Monell Cryocollection for Molecular and Microbial Research (AMCC), New York; the Natural History Museum (BMNH), London; the Field Museum of Natural History (FMNH), Chicago; the Museum of Comparative Zoology (MCZ), Harvard University, Cambridge, MA; the Muséum d'Histoire
Naturelle, Geneva (MHNG); the Musée Royal de l'Afrique Centrale (MRAC), Tervuren, Belgium; the Museo Civico di Storia Naturale "Giacomo Doria" (MSNG), Genoa, Italy; the Naturhistoriska Riksmuseet, Stockholm (NHRS); the U.S. National Museum of Natural History (USNM), Smithsonian Institution, Washington, DC; the Museum für Naturkunde der Humboldt-Universität, Berlin (ZMB); and the Natural History Museum of Denmark, University of Copenhagen (ZMUC).

DiAgnoses AND Descriptions: Comparative diagnoses are presented to separate each species by means of a limited combination of characters. Diagnostic characters were observed in the name- 

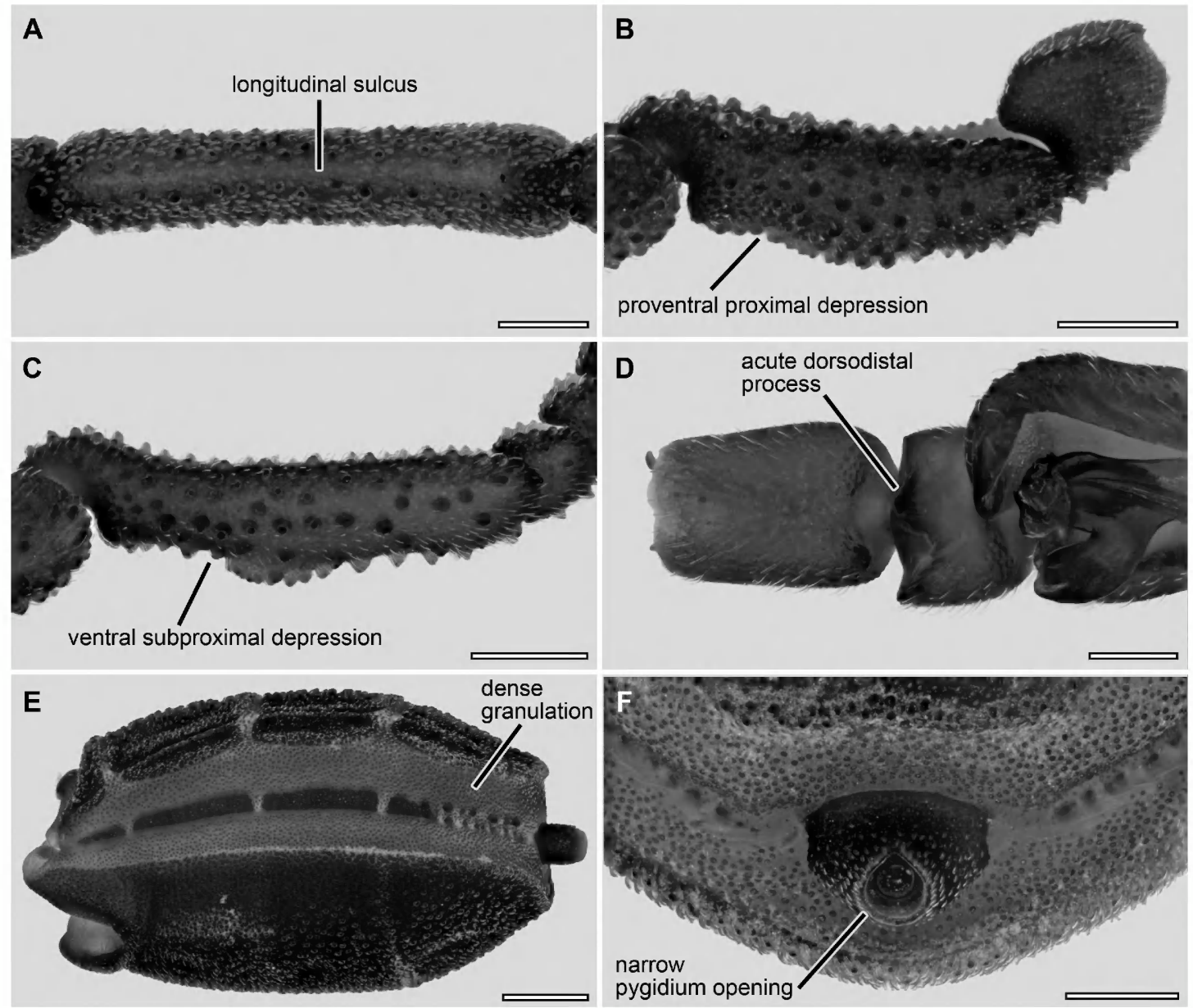

FIGURE 4. Ricinoides Ewing, 1929, selected structures characteristic of "giant" Ricinulei. A. Ricinoides westermannii (Guérin-Méneville, 1838), neotype ơ (ZMB 7013), leg IV femur, dorsal aspect. B. Ricinoides kakum, sp. nov., holotype ơ (MRAC 217.183), leg I metatarsus and tarsus, prolateral aspect. C. Ricinoides feae (Hansen, 1921), lectotype ôे (MSNG), leg II metatarsus, prolateral aspect. D, E. Ricinoides nzerekorensis, sp. nov., D. paratype ô (MRAC 209.286), leg III distal tarsomeres, dorsal aspect, E. paratype $q$ (MRAC 209.267), distended opisthosoma, lateral aspect. F. Ricinoides kakum, holotype ô (MRAC 217.183), posterior end of opisthosoma, pygidium. Scale bars $=0.5 \mathrm{~mm}(\mathbf{A}, \mathbf{B}, \mathbf{C}, \mathbf{F}), 0.25 \mathrm{~mm}(\mathbf{D}), 1 \mathrm{~mm}(\mathbf{E})$.

bearing type of each species and confirmed to be shared by conspecific specimens when available. Descriptions of males address the same characters across all species and include characters that, following examination of all species of Ricinoides, were found to vary interspecifically among males or intersexually in at least one species. Descriptions of males were prepared for the name-bearing type of each species, except in the case of $R$. afzelii, for which the holotype is female. Shorter, supplementary descriptions are provided for females, when available, addressing characters of females that differ from conspecific males and others that, even if similar, were observed to be sexually dimorphic in other species of Ricinoides.

Microscopy, Measurement, and Imaging: Forty-five linear measurements (fig. 2) were recorded using a calibrated ocular micrometer, 
fitted to a Nikon SMZ 1500 stereomicroscope, from specimens submerged in $75 \%$ ethanol, for at least one male and female of each species when both sexes are known. Measurements were recorded from the specimens used to prepare descriptions, unless indicated otherwise. Additional specimens were measured if the description included nontype specimens or when conspecific specimens from geographically distant localities were available. Measurements of the opisthosoma were obtained for the dorsal plate. The lengths of the leg femur, patella, and tibia were measured along the dorsal surface and of the leg metatarsus and tarsus, along the lateral surface. The widths and heights of the leg femora were measured at the midline (not the broadest point), allowing more precise estimates of interspecific and intersexual variation in shape and proportions, especially informative for leg II. For example, incrassate femora exhibit the greatest values of width and height at the midline, whereas unmodified femora often exhibit the greatest values at the proximal and distal ends. Measuring at the midline, even when the femur is narrower at that point, facilitates comparison between homologous regions of the segment.

Digital photomicrographs were taken with a Nikon DS-Ri2 camera adapted to a Nikon SMZ 18 stereomicroscope with a SHR Plan Apo 1× Objective, using NIS-Elements Imaging Software, ver. 4.60 , at the AMNH Microscopy and Imaging Facility. Images and illustrations were prepared from the specimens that were described and measured, unless indicated otherwise. For scanning electron microscopy (SEM), dehydrated sections were gold-palladium coated in a VG Scientific SC 7620 mini sputter-coater. SEM micrographs were taken under high vacuum with a Philips FEI XL30 TMP at the Museo Argentino de Ciencias Naturales "Bernardino Rivadavia” (MACN), Buenos Aires, Argentina. Line drawings were prepared using a camera lucida mounted on the Nikon SMZ 1500 stereomicroscope. Prior to illustration, the female genitalia were dissected and, where necessary, cleared with lacto-phenol solution with glacial acetic acid (BioQuip, Rancho Dominguez, CA).

GeOreferencing and Mapping: Locality records from the material examined were retroactively georeferenced, as required, primarily using Google Earth. A distribution map was produced by plotting the georeferences onto the GMTED2010 digital elevation model (https:// www.usgs.gov/core-science-systems/eros/ coastal-changes-and-impacts/gmted2010?qt-science_support_page_related_con $=0 \#$ qt-science support_page_related_con) using QGIS Geographic Information System 3.14 (Open Source Geospatial Foundation, Beaverton, OR).

Terminology: Terminology of somatic morphology, including the leg segments, largely follows publications on Cryptocellus by the first author (e.g., Botero-Trujillo and Valdez-Mondragón, 2016; Botero-Trujillo and Flórez, 2017). Although this terminology is the most widely used across the taxonomic literature of Ricinulei, several novel terms are introduced herein for structures not previously identified or formally named, including the prodorsal longitudinal carina and prolateral excavation of the cheliceral movable finger, the sublateral longitudinal sulci of the cucullus, and the proventral proximal and ventral subproximal depressions of the metatarsus of legs I and II.

Terminology for the major components of the male copulatory apparatus follows Cokendolpher (2000), according to whom the apparatus comprises three parts, i.e., the base, the fixed process, and the movable process. This differs from the terminology used in previous publications on Ricinoides (e.g., Tuxen, 1974; Legg, 1976b, 1977, 1978a; Naskrecki, 2008), which refer to the copulatory apparatus as the "tarsal process" and to the movable process as an "accessory piece." One problem with applying the term "tarsal process" to the copulatory apparatus is that this is not the only process present on the tarsus of leg III in male ricinuleids-the lamina cyathiformis of the second tarsomere and the acute dorsodistal process of the third tarsomere of "giant" Ricinulei are also tarsal processes, for example. Similarly, the "accessory piece" 
is a broad, unspecific term that also could be applied to other structures. The terminology of Cokendolpher (2000) is preferred because it recognizes three structures by clearly identifying the peduncular base of the apparatus and because it takes into consideration the association (i.e., mobility) that each of the two processes has to the structure from which they arise.

A new nomenclature is presented for the lobes on the fixed process, part of ongoing work to homologize structures across Ricinoides (R.B.-T. and L.P., in prep.). The new nomenclature introduces greater accuracy to particular terms from Tuxen (1974), e.g., prolateral laminar $(P L)$ lobe replaces "lateral lobe"; retrolateral subdistal $(r s d)$ lobe replaces lobe "a"; primary alpha $(\alpha)$ lobe replaces lobe "c"; and primary beta $(\beta)$ lobe replaces lobe "b." Naskrecki (2008: 60, fig. 14) overlooked the rsd lobe and misinterpreted the $\beta$ lobe, which is bicuspid in most species covered herein, as two lobes ("a" and "b"), the former of which was misidentified. Two other lobes, the secondary prolateral distal $(p d)$ and secondary retrolateral distal $(r d)$ lobes, were overlooked by Tuxen (1974) and Naskrecki (2008). Another new term, subdistal emargination, is introduced for the excavated margin which separates the rsd lobe from the distal lobular region bearing the primary and secondary lobes.

The terminology of Dumitresco and JuvaraBalş (1977a) is applied for structures of the female bursa copulatrix.

\section{SYSTEMATICS}

Family Ricinoididae Ewing, 1929

Ricinoides Ewing, 1929

Cryptostemma Guérin-Méneville, 1838: 11 [junior homonym of Cryptostemma Herrich-Schäffer, 1835 (Insecta: Hemiptera)], type species by monotypy: Cryptostemma westermannii Guérin-Méneville, 1838; Gervais, 1844: 130, 131; Karsch, 1892: 30-32; Hansen and Sørensen, 1904: 146.
Ricinoides Ewing, 1929: 586 [replacement name for Cryptostemma Guérin-Méneville, 1838]; Petrunkevitch, 1955: 160; Harvey, 2003: 182.

DiAgnosis: Ricinoides has traditionally been separated from the New World genera, Cryptocellus and Pseudocellus, by the presence of three characters: a pronounced toothlike process, the so-called Ricinoides tooth, on the dorsal surface of the cheliceral manus (fig. 3A); the tarsus of leg I and terminal tarsomere of leg II and, especially, III and IV, sublinear dorsally, covering the ungues; a large lateral lobe, referred to herein as the prolateral laminar $(P L)$ lobe, on the male copulatory apparatus (Tuxen, 1974; Platnick, 1980). Two other, putative synapomorphies of Ricinoides, both on the cheliceral movable finger were identified in the present investigation: a sharp, prodorsal longitudinal carina aligned with the teeth (fig. 3A); and a shallow, prolateral excavation, delimited by two parallel carinae, on the mucron (fig. 3B). These new characters, observed in all known species of Ricinoides, were confirmed absent in the type species of Cryptocellus and Pseudocellus based on examination of the type specimens.

\section{Ricinoides afzelii (Thorell, 1892)}

Figures 5, 6A, 7A, 9A, 11A, 12A, 14A, 15A, 17A, 18A, 20A, 21A, 22A, C, E, G, 28A, C, E, G, I, 33A, 34A, tables 1-3

Cryptostemma afzelii Thorell, 1892: 10-17, figs. 1-8; Hansen and Sørensen, 1904: 150, 151, pl. 8, figs. 2a-g; Petrunkevitch, 1913: 77, fig. 43.

Ricinoides afzelii (Thorell, 1892): Ewing, 1929: 597; Kästner, 1932: 103, fig. 140; Bolívar y Pieltain, 1942: 201; Pollock, 1966: 402-405, unnumbered figs.; 1967: 19-22; Kennaugh, 1968: 394-396, pls. IIb, IIIa, IVb, Vb, VI; Kaestner, 1968: 204, 207; Tuxen, 1974: 91-96 (part, material from Sierra Leone), figs. 5, 8; Savory, 1977: 216, fig. 88; Legg, 1978a: 91, 93, 98; 1978b: 124, 125, figs. 1, 2; 
Harvey, 1984: 209, fig. 10; Dunlop, 1994: 56, unnumbered fig.; 1996: 195, fig. 11 (misidentification); Harvey, 2003: 183 (part); García et al., 2015: 455.

Ricinoides afzeli: Savory, 1964: 198, fig. 101. Ricinoides cf. afzelii: Murienne et al., 2013: 2, figs. 1, 2 (misidentification).

Type Material Examined: Holotype $q$ (NHRS JUST 518, Thorell Collection), SIERRA LEONE, Afzelius. A microvial contains the following detached pieces: sinistral chelicera, dextral pedipalp femur and second trochanter, and two pieces of the tarsi of legs III or IV. The following body regions are missing: cucullus, dextral chelicera, sinistral pedipalp femur and tibia, dextral pedipalp first trochanter and tibia, tarsus of leg III or IV, and second to fifth tarsomeres of both legs II.

Diagnosis: The male of Ricinoides afzelii resembles the males of $R$. atewa, $R$. iita, and $R$. kakum in the modified ventral part of the cucullus. It further resembles the male of $R$. iita in possessing an apical brushlike row of yellowish setae on the proventral surface of the metatarsus of leg III, and in the dimensions of the femur of leg IV, which is wider than the femur of leg III and deeper than the femur of leg I, characters uniquely shared by the two species. On the other hand, the male of $R$. afzelii resembles the males of $R$. atewa and $R$. kakum in the presence of enlarged tubercles on the distal half of the ventral surface of the pedipalp tibia. The male of $R$. afzelii differs from the males of $R$. atewa, R. iita, and R. kakum in the following respects: the cucullus bears a pronounced anteromedian knoblike tubercle (fig. $9 \mathrm{~A})$, the distal retroventral tubercles of the pedipalp tibia are greatly enlarged (fig. 20A), the femur of leg I is wider than the femur of leg IV which, in turn, is wider than the femur of leg III, and the metatarsus of leg I bears a prominent ventral excrescence (fig. 21A). Ricinoides afzelii may further be recognized by the structure of the fixed process of the male copulatory apparatus (figs. $28 \mathrm{~A}, \mathrm{C}, \mathrm{E}, \mathrm{G}, \mathrm{I}, 33 \mathrm{~A}$ ), in which the $\beta$ lobe is entire and the $p d$ lobe dorsoventrally expanded and laterally compressed (table 2).
Description of Male: Based on the male from Bo (BMNH 13588948).

Measurements: Total length $9.68 \mathrm{~mm}$ (table 3)

Coloration: Soma and appendages predominantly dark reddish-brown, almost black. Carapace dorsolateral translucent areas yellowish Opisthosomal tergal and pleural membranes yellow, hyaline. Cheliceral manus yellow; fingers, fin ger dentition, and manus toothlike process dark.

Setation: Surfaces densely covered with short, translucent, bristlelike setae, slightly expanded but not navicular, length similar to height of surrounding tuberose granules (figs. 6A, 14A) Polygonal setae absent.

Tegument surface macrosculpture: Tegument very irregular, without cuticular pits. Carapace, cucullus, opisthosomal sclerites, legs, and, to lesser extent, coxal region covered with coarse, rounded tuberose granules, evenly spaced apart, not clustered together (figs. 6A, 9A, 11A, 14A, 21A, 22A, C, E, G). Opisthosoma, pleural membranes finely and densely granular; tergal membranes more sparsely granular. Pedipalp femur retrolateral surface finely granular, dorsal and prolateral surfaces more coarsely granular; tibia with elevated oval tubercles distally (fig. 20A), tubercles on ventral surface enlarged and arranged into two (proventral and retroventral) rows, distal retroventral tubercles largest.

Carapace: Carapace wider than long, broadest between coxae of legs II and III; trapezoidal, lateral margins curved, narrowing anteriorly (fig. 6A); anterior margin linear in dorsal aspect; posterior margin slightly procurved; median longitudinal sulcus, paired posterior marginal transverse sulci, and paired anterolateral longitudinal sulci distinct; paired lateral depressions present, aligned with coxae of legs II; posteromedian moundlike excrescence absent; dorsolateral translucent areas entirely smooth, medium sized, aligned with intersection between coxae of legs I and II, visible in dorsolateral aspect.

Cucullus: Cucullus broadened laterally, wider than long; ventrolateral margins rounded (fig. 9A); ventral margin predominantly linear in anterior aspect, shallowly bilobate in ventral aspect, poste- 
TABLE 1

Currently Recognized Species of Afrotropical Ricinulei (Ricinoides Ewing, 1929) and Countries of Occurrence

\begin{tabular}{ll}
\hline Species & Distribution \\
\hline Ricinoides afzelii (Thorell, 1892) & Sierra Leone \\
Ricinoides atewa Naskrecki, 2008 & Ghana \\
Ricinoides crassipalpe (Hansen and Sørensen, 1904) & Cameroon, Equatorial Guinea (Bioko Island) \\
Ricinoides eburneus, sp. nov. & Côte d'Ivoire \\
Ricinoides feae (Hansen, 1921) & Guinea-Bissau \\
Ricinoides hanseni Legg, 1976 & Sierra Leone \\
Ricinoides iita, sp. nov. & Nigeria \\
Ricinoides kakum, sp. nov. & Ghana \\
Ricinoides karschii (Hansen and Sørensen, 1904) & Cameroon, Congo, Gabon \\
Ricinoides leonensis Legg, 1978 & Sierra Leone \\
Ricinoides megahanseni Legg, 1982 & Côte d'Ivoire \\
Ricinoides nzerekorensis, sp. nov. & Guinea \\
Ricinoides olounoua Legg, 1978 & Cameroon \\
Ricinoides sjostedtii (Hansen and Sørensen, 1904) & Cameroon, Nigeria \\
Ricinoides taii, sp. nov. & Côte d’Ivoire \\
Ricinoides westermannii (Guérin-Méneville, 1838) & Togo \\
\hline
\end{tabular}

rior surface, median row of denticulations worn; anterior surface shallowly convex, without ventral compressed surface; pair of moderately developed sublateral longitudinal sulci; ventral part with pronounced knoblike tubercle anteromedially.

Chelicerae: Manus dorsal surface with large toothlike process distally. Movable finger longer than fixed finger, tooth row comprising eight small teeth; sharp prodorsal longitudinal carina parallel to tooth row (opposite fixed finger); mucron with shallow but distinct prolateral excavation (opposite fixed finger) delimited by two parallel longitudinal carinae. Fixed finger tooth row comprising five small teeth.

Coxosternal region: Tritosternum very small, barely visible, not abutting coxae of legs I (fig. 11A); coxae of legs II-IV abutting one another medially along entire length; coxae of legs II, anterior and posterior margins subparallel, not perpendicular to median axis, inclined anteriorly; coxae of legs II, posterior margins U-shaped medially; suture between coxae of legs II approximately $2.5 \times$ length of suture between coxae of legs III and IV.
Opisthosoma: Opisthosoma oval, longer than wide, broadest at tergite XII. Posterodorsal and posteroventral margins without spiniform granules (figs. 14A, 17A). Tergites X-XIII each comprising median and lateral sclerites; median sclerites of tergites XI-XIII each with paired, shallow submedian depressions near anterior margins; lateral margins of median sclerites converging posteriorly on tergite XI, subparallel on XII, slightly converging anteriorly on XIII; median sclerites of tergites XI and XII wider than long, of XIII approximately as wide as long, square; margins of lateral sclerites adjacent to tergal longitudinal membranes predominantly linear, tergal membranes narrow. Sternites XI-XIII each with pair of shallow submedian depressions similar to tergites (fig. 17A). Pygidium, basal segment parallel to longitudinal axis of opisthosoma; opening very narrow, subcircular, width approximately one third lateral width of segment at its base; posterior border narrow; dorsal surface with V-shaped notch; ventral surface entire.

Pedipalps: Femur globose, length approximately $2 \times$ depth. Tibia longer than femur; pre- 


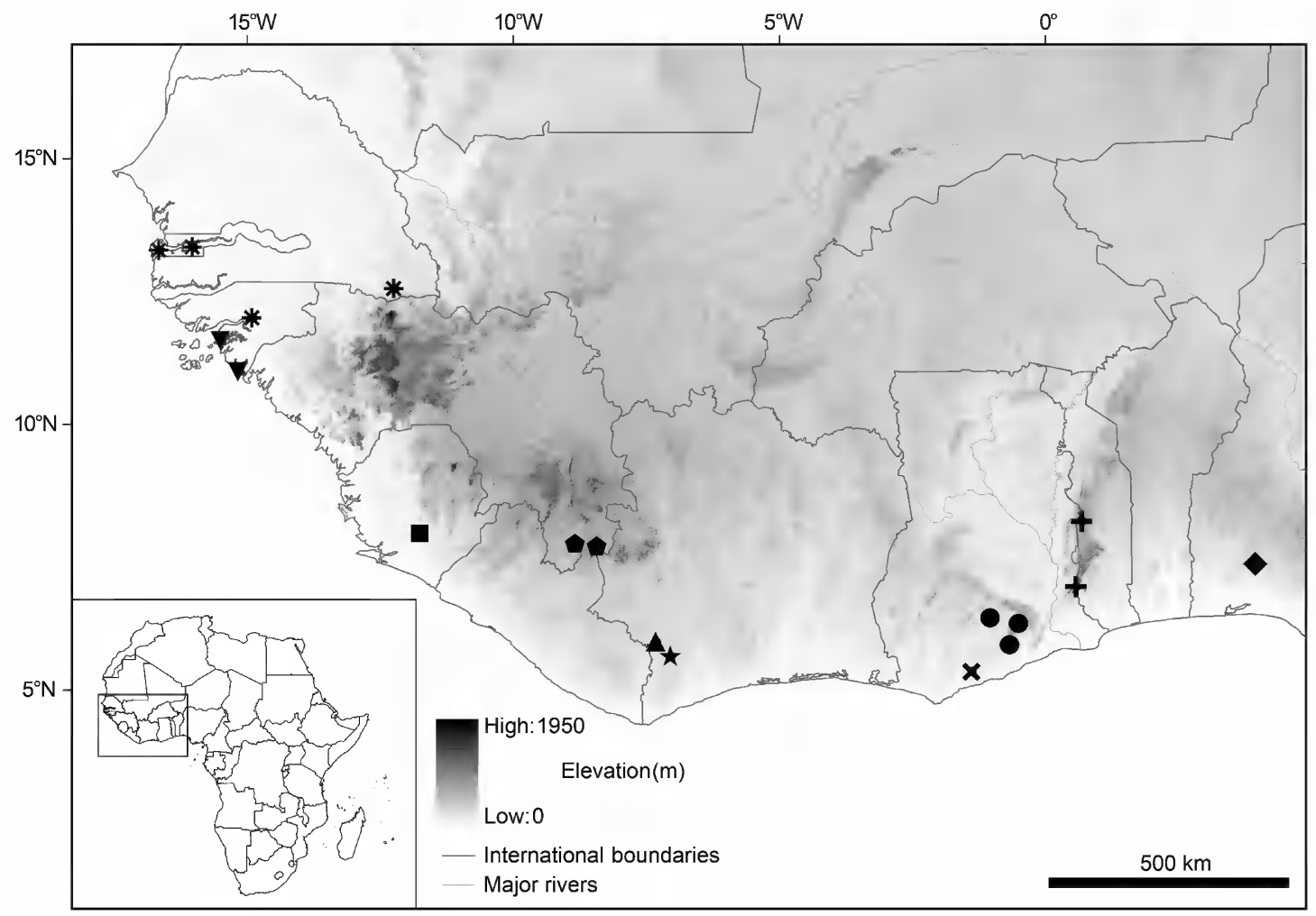

FIGURE 5. Map of West Africa, plotting known locality records of species of "giant" Ricinulei (Ricinoides Ewing, 1929), based on material examined and verified identifications: Ricinoides afzelii (Thorell, 1892) (square); Ricinoides atewa Naskrecki, 2008 (circle); Ricinoides eburneus, sp. nov. (triangle); Ricinoides feae (Hansen, 1921) (inverted triangle); Ricinoides iita, sp. nov. (diamond); Ricinoides kakum, sp. nov. (×); Ricinoides nzerekorensis, sp. nov. (pentagon); Ricinoides taii, sp. nov. (star); Ricinoides westermannii (Guérin-Méneville, 1838) (+); Ricinoides sp. (asterisk).

dominantly linear, slightly curved ventrally (fig. $20 \mathrm{~A})$; robust along entire length, margins parallel in dorsal and lateral aspects; apical longitudinal carinae absent. Movable finger approximately $2 \times$ length of fixed finger.

Legs: Leg II longest, femur markedly incrassate (figs. 22A, C). Femora width (at midline) increasing in order leg III $<$ IV $<$ I $<<$ II; dorsal surface with longitudinal sulcus most distinct on leg IV. Leg I tibia without ventral apophyses; metatarsus subcircular in cross-section, with deep proventral depression in proximal third and prominent ventral excrescence (fig. 21A). Leg II tibia with very large ventromedian apophysis proximally (fig. 22E), markedly hook shaped, with acute apex, entirely covered with tuberose granules; tibia and metatarsus without pad of long translucent setae ventrally; metatarsus without ventrosubmedian concavity, with shallow subproximal depression and moderate submedian excrescence ventrally (fig. 22G); first to third tarsomeres short, subequal, fourth approximately $2 \times$ length of preceding tarsomeres; all tarsomeres movable. Leg III metatarsus not swollen, with moderate concavity dorsodistally; proventral surface with apical brushlike row of yellowish setae; prodorsal proximal sulcus present; metatarsus, metatarsal process, and tarsus precisely fitting together to completely encase copulatory apparatus when tarsus retracted; 


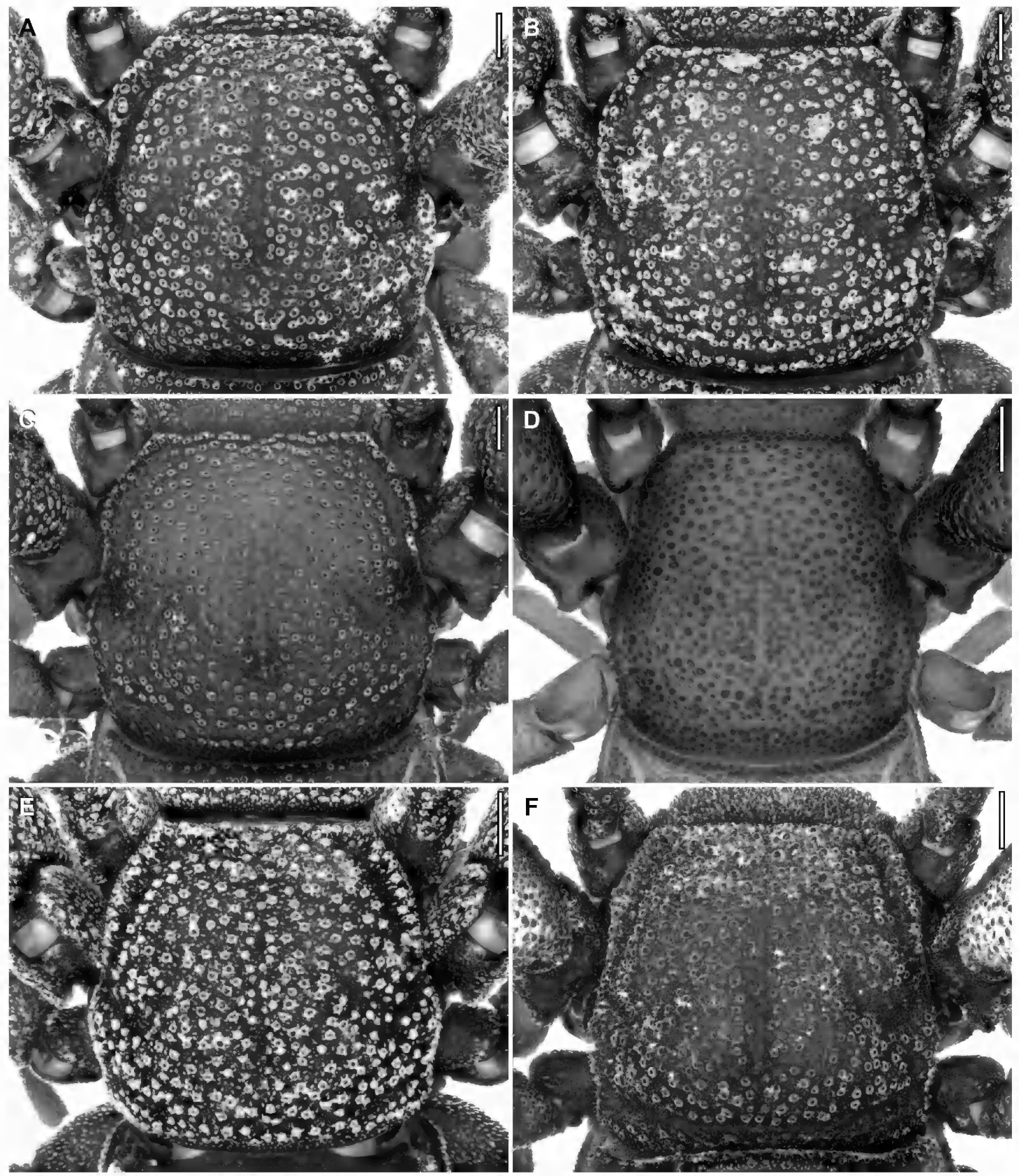

FIGURE 6. Ricinoides Ewing, 1929, carapace, dorsal aspect. A. Ricinoides afzelii (Thorell, 1892), ơ (BMNH 13588948). B. Ricinoides atewa Naskrecki, 2008, holotype ô (AMNH IZC 324855). C. Ricinoides eburneus, sp. nov., holotype $\widehat{\partial}$ (MRAC 230.162). D. Ricinoides feae (Hansen, 1921), lectotype ô (MSNG). E. Ricinoides iita, sp. nov., holotype $\delta$ (USNM). F. Ricinoides kakum, sp. nov., holotype $\delta$ (MRAC 217.183). Scale bars $=$ $1 \mathrm{~mm}$. 


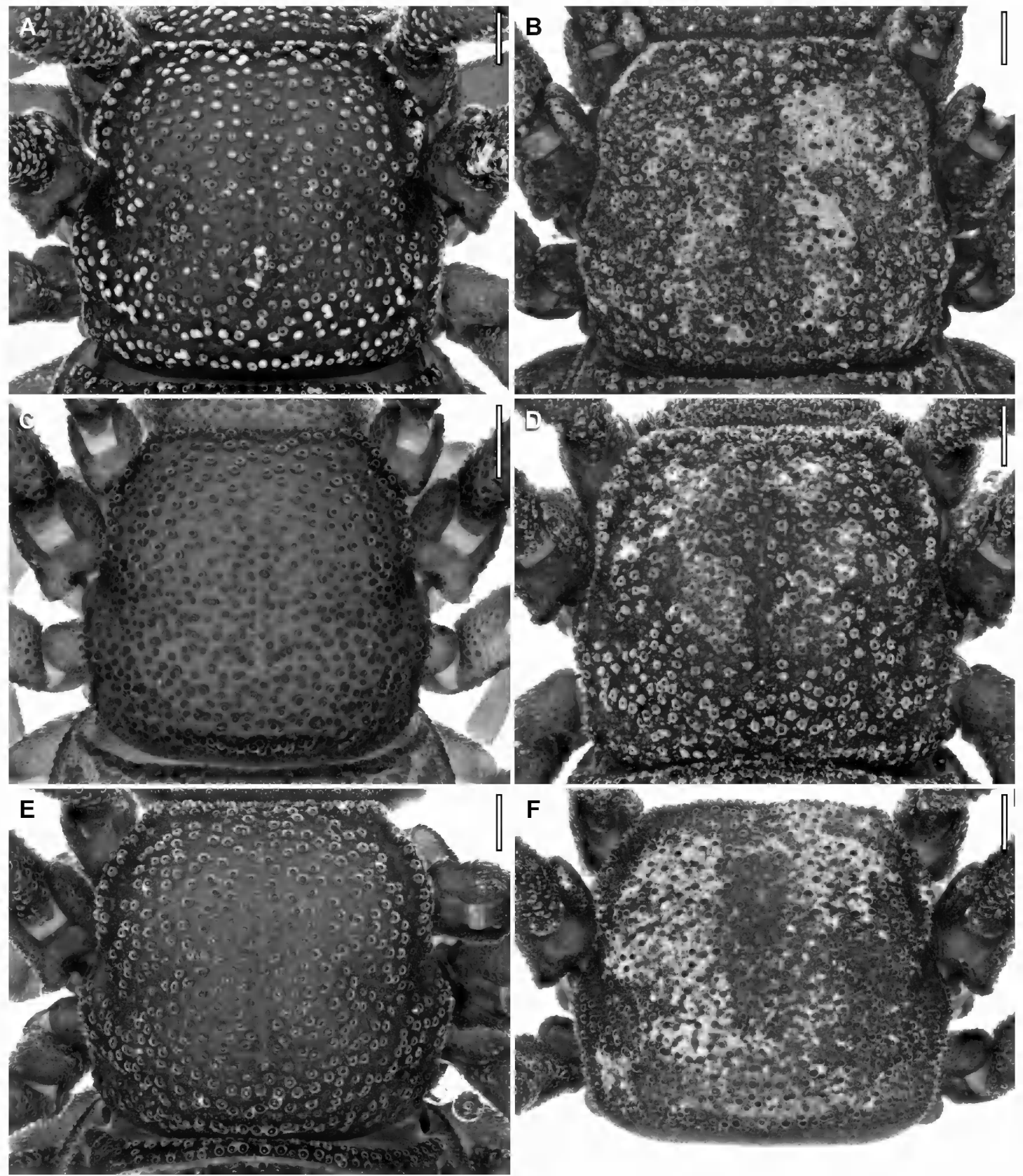

FIGURE 7. Ricinoides Ewing, 1929, carapace, dorsal aspect. A. Ricinoides afzelii (Thorell, 1892), ㅇ (BMNH 13588949). B. Ricinoides atewa Naskrecki, 2008, \& (AMNH IZC 324883). C. Ricinoides feae (Hansen, 1921), paralectotype + (MSNG), Rio Cacine, Guinea-Bissau. D. Ricinoides kakum, sp. nov., paratype + (MRAC 217.183). E. Ricinoides nzerekorensis, sp. nov., paratype + (MRAC 209.267). F. Ricinoides taii, sp. nov., paratype + (MRAC 233.482). Scale bars $=1 \mathrm{~mm}$. 


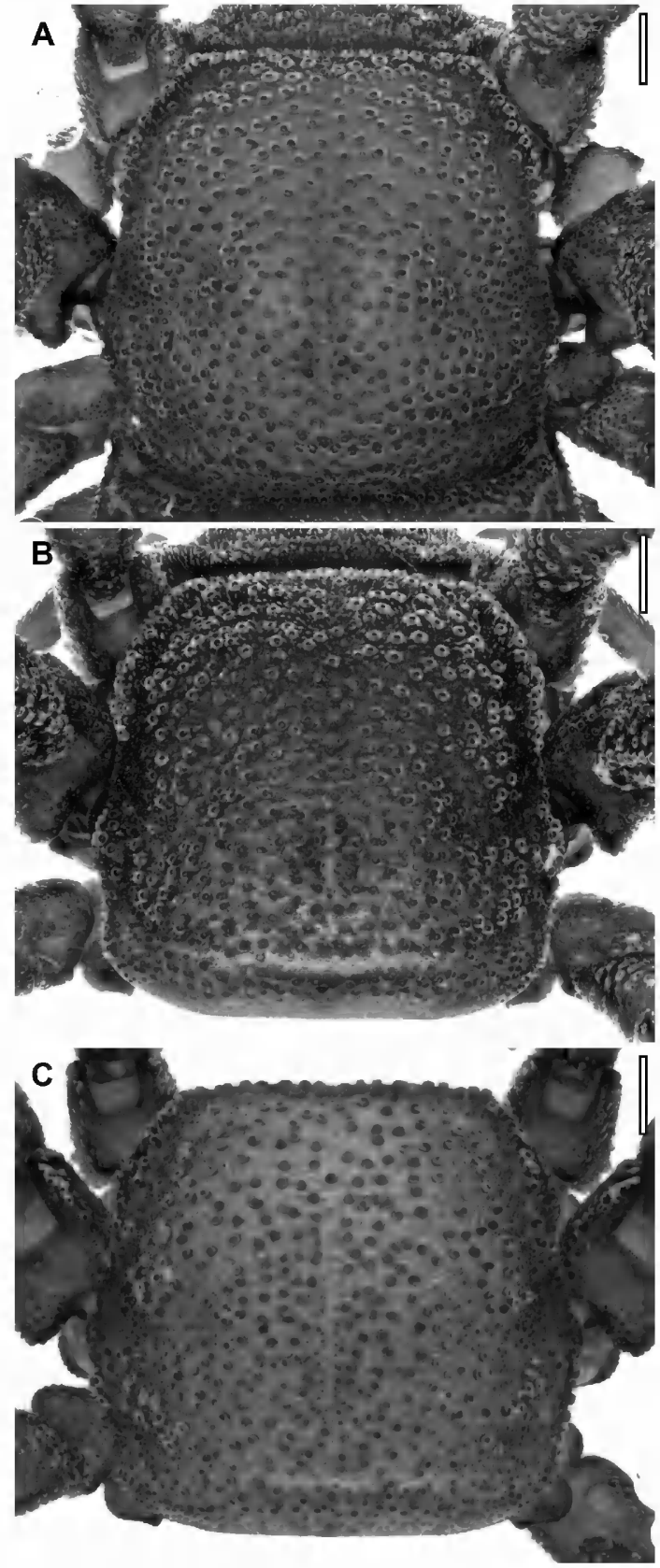

FIGURE 8. Ricinoides Ewing, 1929, carapace, dorsal aspect. A. Ricinoides nzerekorensis, sp. nov., holotype of (MRAC 209.266). B. Ricinoides taii, sp. nov., holotype ô (MRAC 233.458). C. Ricinoides westermannii (Guérin-Méneville, 1838), neotype ô (ZMB 7013). Scale bars $=1 \mathrm{~mm}$. metatarsal process situated basally near tibia, robust, tapering and slightly laterally compressed, longitudinal axis sinuous, apex pointing retrolaterally; lamina cyathiformis of second tarsomere approximately as deep as long, with pointed apex; subdistal (third) tarsomere with acute dorsodistal process. Leg IV tarsus unmodified. Legs III and IV terminal tarsomere apex, dorsal margin sublinear, covering ungues. Leg I tarsus and legs II-IV terminal tarsomeres without ventrodistal papillae.

Copulatory apparatus: Fixed process, $P L$ lobe moderately expanded and dorsoventrally compressed (figs. 28C, G). Distal lobular region, primary a lobe very long, narrow, and dorsoventrally compressed (figs. 28A, C, E, G, I, 33A); origin submedial, curving toward prolateral surface; prolateral and retrolateral margins slightly irregular. Primary $\beta$ lobe medium sized, entire. $r s d$ lobe medium sized, pronounced, associated with distinct subdistal emargination. Secondary $p d$ and $r d$ lobes well developed; $p d$ dorsoventrally expanded and laterally compressed, with rounded margin; $r d$ pointed. Movable process slender, slightly flexible, narrowing distally; apex simple, entire.

Supplementary Description of Female: Based on the holotype (NHRS JUST 518) and the female from Bo (BMNH 13588949). Resembles male except as noted.

Measurements: Total length 8.70-9.68 mm (table 3).

Tegument surface macrosculpture: Pedipalp femur retrolateral surface finely granular, dorsal and prolateral surfaces coarsely granular; tibia, ventral surface without distinct rows of oval tubercles, distal retroventral tubercles not noticeably enlarged.

Carapace: Posteromedian moundlike excrescence absent (fig. 7A).

Cucullus: Ventral part without knoblike tubercle anteromedially; ventrolateral margins rounded; ventral margin predominantly linear in anterior aspect.

Coxosternal region: Coxae of legs II-IV abutting one another medially along entire length (fig. 12A); coxae of legs II, posterior margin V-shaped medially. 
TABLE 2

Morphology of Lobes of the Male Copulatory Apparatus of “Giant" Ricinulei (Ricinoides Ewing, 1929)

\begin{tabular}{|c|c|c|c|c|c|}
\hline & $P L$ lobe $^{1}$ & a lobe $^{2}$ & $\beta$ lobe $^{3}$ & $p d$ lobe $^{4}$ & $r d$ lobe $^{4}$ \\
\hline $\begin{array}{l}\text { Ricinoides afzelii } \\
\text { (figs. } 28 \mathrm{~A}, \mathrm{C}, \mathrm{E}, \mathrm{G}, \\
\text { I, 33A) }\end{array}$ & $\begin{array}{l}\text { Moderately } \\
\text { expanded }\end{array}$ & $\begin{array}{l}\text { Very long; DV compressed; origin } \\
\text { submedial; curving prolaterally; } \mathrm{pl}, \mathrm{rl} \\
\text { slightly irregular }\end{array}$ & Entire & $\begin{array}{l}\text { Well developed; DV } \\
\text { expanded, laterally } \\
\text { compressed }\end{array}$ & $\begin{array}{l}\text { Well } \\
\text { developed; } \\
\text { pointed }\end{array}$ \\
\hline $\begin{array}{l}\text { Ricinoides atewa } \\
\text { (figs. 28B, D, F, H, } \\
\text { J, 33B) }\end{array}$ & $\begin{array}{l}\text { Greatly } \\
\text { expanded }\end{array}$ & $\begin{array}{l}\text { Very long; DV compressed; origin } \\
\text { submedial; curving ventrally; pl } \\
\text { smooth, rl serrated }\end{array}$ & $\begin{array}{l}\text { Bicuspid; } \beta_{1} \text { and } \beta_{2} \\
\text { pointed }\end{array}$ & $\begin{array}{l}\text { Well developed; } \\
\text { pointed }\end{array}$ & $\begin{array}{l}\text { Well } \\
\text { developed; } \\
\text { pointed }\end{array}$ \\
\hline $\begin{array}{l}\text { Ricinoides eburneus } \\
\text { (figs. 29A, C, E, G, } \\
\text { I, 33C) }\end{array}$ & $\begin{array}{l}\text { Greatly } \\
\text { expanded }\end{array}$ & $\begin{array}{l}\text { Very long; DV compressed (slightly); } \\
\text { origin submedial; curving ventrally } \\
\mathrm{pl}, \mathrm{rl} \text { smooth; rl sinuous }\end{array}$ & $\begin{array}{l}\text { Bicuspid; } \beta_{1} \text { and } \beta_{2} \\
\text { pointed }\end{array}$ & $\begin{array}{l}\text { Well developed; } \\
\text { pointed }\end{array}$ & $\begin{array}{l}\text { Well } \\
\text { developed; } \\
\text { pointed }\end{array}$ \\
\hline $\begin{array}{l}\text { Ricinoides feae } \\
\text { (figs. 29B, D, F, H, } \\
\text { J, 33D) }\end{array}$ & $\begin{array}{l}\text { Relatively } \\
\text { narrow }\end{array}$ & $\begin{array}{l}\text { Long; laterally compressed; origin } \\
\text { slightly prolateral; curving ventrally; } \\
\text { d smooth, v slightly irregular }\end{array}$ & $\begin{array}{l}\text { Bicuspid; } \beta_{1} \text { and } \\
\beta_{2} \text { pointed; widely } \\
\text { separated from one } \\
\text { another }\end{array}$ & $\begin{array}{l}\text { Broad elevated } \\
\text { surface }\end{array}$ & $\begin{array}{l}\text { Cluster of } \\
\text { small spines }\end{array}$ \\
\hline $\begin{array}{l}\text { Ricinoides iita } \\
\text { (figs. 30A, C, E, G, } \\
\text { I, 33E) }\end{array}$ & $\begin{array}{l}\text { Moderately } \\
\text { expanded }\end{array}$ & $\begin{array}{l}\text { Very long; subcircular; origin slightly } \\
\text { prolateral; curving retrolaterally; } \\
\text { margins smooth }\end{array}$ & $\begin{array}{l}\text { Bicuspid; } \beta_{1} \text { pointed; } \\
\beta_{2} \text { larger, fingerlike }\end{array}$ & $\begin{array}{l}\text { Well developed; } \\
\text { pointed }\end{array}$ & $\begin{array}{l}\text { Well } \\
\text { developed; } \\
\text { pointed }\end{array}$ \\
\hline $\begin{array}{l}\text { Ricinoides kakum } \\
\text { (figs. 30B, D, F, H, } \\
\text { J, 33F) }\end{array}$ & $\begin{array}{l}\text { Greatly } \\
\text { expanded }\end{array}$ & $\begin{array}{l}\text { Very long; DV compressed distally } \\
\text { (to lesser extent proximally); origin } \\
\text { submedial; curving ventrally; pl } \\
\text { smooth, } \mathrm{rl} \text { serrated }\end{array}$ & $\begin{array}{l}\text { Bicuspid; } \beta_{1} \text { and } \beta_{2} \\
\text { pointed }\end{array}$ & $\begin{array}{l}\text { Well developed; } \\
\text { pointed }\end{array}$ & $\begin{array}{l}\text { Well } \\
\text { developed; } \\
\text { pointed }\end{array}$ \\
\hline $\begin{array}{l}\text { Ricinoides } \\
\text { nzerekorensis } \\
\text { (figs. } 31 \mathrm{~A}, \mathrm{C}, \mathrm{E}, \mathrm{G}, \\
\mathrm{I}, 33 \mathrm{G} \text { ) }\end{array}$ & $\begin{array}{l}\text { Moderately } \\
\text { expanded }\end{array}$ & $\begin{array}{l}\text { Long, thumb shaped; DV } \\
\text { compressed; origin submedial; } \\
\text { curving ventrally; pl smooth, } \\
\text { rl slightly irregular; pl sinuous, } \\
\text { expanded }\end{array}$ & $\begin{array}{l}\text { Bicuspid; } \beta_{1} \text { and } \beta_{2} \\
\text { pointed }\end{array}$ & Small but evident & $\begin{array}{l}\text { Small but } \\
\text { evident }\end{array}$ \\
\hline $\begin{array}{l}\text { Ricinoides taii } \\
\text { (figs. 31B, D, F, H, J, } \\
33 \mathrm{H} \text { ) }\end{array}$ & $\begin{array}{l}\text { Moderately } \\
\text { expanded }\end{array}$ & $\begin{array}{l}\text { Long, thumb shaped; DV } \\
\text { compressed; origin submedial; } \\
\text { curving ventrally } \\
\text { pl, rl slightly irregular; pl sinuous, } \\
\text { expanded }\end{array}$ & $\begin{array}{l}\text { Bicuspid; } \beta_{1} \text { and } \beta_{2} \\
\text { pointed }\end{array}$ & $\begin{array}{l}\text { Vestigial; elevated } \\
\text { ridge }\end{array}$ & $\begin{array}{l}\text { Vestigial; } \\
\text { elevated } \\
\text { ridge }\end{array}$ \\
\hline $\begin{array}{l}\text { Ricinoides } \\
\text { westermannii } \\
\text { (figs. 32, 33I) }\end{array}$ & $\begin{array}{l}\text { Moderately } \\
\text { expanded }\end{array}$ & Unknown (lobe broken) & $\begin{array}{l}\text { Bicuspid; } \beta_{1} \text { and } \beta_{2} \\
\text { pointed; } \beta_{1} \text { larger }\end{array}$ & $\begin{array}{l}\text { Well developed; } \\
\text { pointed }\end{array}$ & $\begin{array}{l}\text { Well } \\
\text { developed; } \\
\text { pointed }\end{array}$ \\
\hline
\end{tabular}

${ }^{1}$ Prolateral laminar $(P L)$ lobe: degree of expansion in dorsal or ventral aspects.

${ }^{2}$ Primary a lobe: length; shape in cross section (DV, dorsoventrally); origin (position) on fixed process; axis of curvature; margins (d, dorsal; pl, prolateral; rl, retrolateral; $\mathrm{v}$, ventral).

${ }^{3}$ Primary $\beta$ lobe: shape; when bicuspid, $\beta_{1}$ and $\beta_{2}$.

${ }^{4}$ Secondary prolateral distal $(p d)$ and retrolateral distal $(r d)$ lobes: development; shape (DV, dorsoventrally); retrolateral subdistal $(r s d)$ lobe excluded.

Opisthosoma: Opisthosoma oval (figs. 15A, 18A). Tergites XI-XIII, median sclerites wider than long. Opening of basal segment of pygidium very narrow, subcircular.

Pedipalps: Tibia entirely linear.

Legs: Leg I metatarsus without prominent ventral excrescence or proximal depression proventrally. Leg II femur unmodified, longer than but similar in shape to femora of other legs; tibia with- out ventromedian apophysis; metatarsus without subproximal depression or submedian excrescence ventrally. Leg III metatarsus without apical brushlike row of setae proventrally.

Spermathecae: Anterior wall of bursa copulatrix with pair of large, slightly pigmented, rounded areas. Anterior surface with 24 hard, sacculiform structures, variable in size, 12 on either side, arranged into two L-shaped rows (fig. 


\section{TABLE 3}

Measurements (mm) for Three Species of West African Ricinulei: Ricinoides afzelii (Thorell, 1892), Ricinoides atewa Naskrecki, 2008, and Ricinoides eburneus, sp. nov.

Material deposited in the American Museum of Natural History (AMNH), New York, the Natural History Museum (BMNH), London, the Naturhistoriska Riksmuseet, Stockholm (NHRS), and the Musée Royal de l'Afrique Centrale (MRAC), Tervuren, Belgium. Abbreviations: L, length; W, width; $\mathrm{H}$, height.

\begin{tabular}{|c|c|c|c|c|c|c|c|}
\hline \multirow{4}{*}{$\begin{array}{l}\text { Type/sex } \\
\text { Collection }\end{array}$} & & \multicolumn{3}{|c|}{ R. afzelii } & \multicolumn{2}{|c|}{ R. atewa } & \multirow{4}{*}{$\begin{array}{c}\text { R. eburneus } \\
\text { Holotype } \delta \\
\text { MRAC } \\
230.162 \\
\end{array}$} \\
\hline & & 0 & $q$ & Holotype $q$ & Holotype $\delta^{\star}$ & $q$ & \\
\hline & & BMNH & BMNH & NHRS & AMNH & AMNH & \\
\hline \multirow{2}{*}{\multicolumn{2}{|c|}{ Total body $\mathrm{L}^{1}$}} & & & & & & \\
\hline & & 9.7 & 8.7 & 9.7 & 9.6 & 9.2 & 8.9 \\
\hline \multirow[t]{2}{*}{ Cucullus } & $\mathrm{L}$ & 2.2 & 2.0 & - & 2.3 & 2.4 & 2.2 \\
\hline & $\mathrm{W}^{2}$ & 3.3 & 2.9 & - & 3.5 & 3.0 & 3.0 \\
\hline \multirow[t]{2}{*}{ Carapace } & $\mathrm{L}$ & 3.8 & 3.3 & 3.8 & 3.5 & 3.3 & 3.4 \\
\hline & $\mathrm{W}^{2}$ & 4.0 & 3.6 & 4.1 & 3.9 & 3.8 & 3.6 \\
\hline \multirow[t]{2}{*}{ Opisthosoma } & $\mathrm{L}^{1}$ & 5.9 & 5.4 & $5.9^{5}$ & 6.1 & 5.9 & 5.4 \\
\hline & $\mathrm{W}^{2}$ & 4.5 & 4.6 & $4.8^{5}$ & 4.8 & 5.0 & 4.1 \\
\hline \multirow[t]{2}{*}{ Median sclerite XI } & $\mathrm{L}$ & 1.9 & 1.7 & 2.0 & 2.2 & 2.0 & 1.8 \\
\hline & $\mathrm{W}^{2}$ & 3.0 & 3.3 & 3.5 & 3.3 & 3.3 & 2.7 \\
\hline \multirow[t]{2}{*}{ Median sclerite XII } & $\mathrm{L}$ & 1.6 & 1.5 & 1.7 & 1.8 & 1.7 & 1.6 \\
\hline & $\mathrm{W}^{2}$ & 2.5 & 2.6 & 2.7 & 2.7 & 2.7 & 2.3 \\
\hline \multirow[t]{2}{*}{ Median sclerite XIII } & $\mathrm{L}$ & 2.0 & 1.7 & 2.0 & 2.0 & 1.8 & 1.8 \\
\hline & $\mathrm{W}^{2}$ & 2.1 & 1.9 & 2.1 & 2.1 & 2.1 & 1.7 \\
\hline \multirow[t]{4}{*}{ Pedipalp } & Femur L & 1.7 & 1.6 & 1.6 & 1.6 & 1.9 & 1.6 \\
\hline & Femur $\mathrm{H}^{3}$ & 0.8 & 0.7 & 0.8 & 0.8 & 0.8 & 0.8 \\
\hline & Tibia L & 2.6 & 2.4 & - & 2.5 & 2.6 & 2.5 \\
\hline & Tibia $\mathrm{H}^{4}$ & 0.4 & 0.3 & - & 0.4 & 0.4 & 0.4 \\
\hline \multirow[t]{7}{*}{ Leg I } & Femur L & 2.0 & 1.5 & 1.8 & 2.1 & 1.8 & 2.0 \\
\hline & Femur $\mathrm{W}^{4}$ & 1.0 & 0.7 & 0.8 & 0.9 & 0.7 & 0.9 \\
\hline & Femur $\mathrm{H}^{4}$ & 1.0 & 0.6 & 0.8 & 1.0 & 0.8 & 1.0 \\
\hline & Patella L & 1.7 & 1.4 & 1.6 & 1.6 & 1.4 & 1.7 \\
\hline & Tibia L & 1.2 & 1.1 & 1.3 & 1.5 & 1.3 & 1.2 \\
\hline & Metatarsus L & 2.2 & 1.9 & 2.2 & 2.3 & 2.2 & 2.2 \\
\hline & Tarsus L & 0.8 & 0.7 & 0.8 & 0.9 & 0.8 & 0.8 \\
\hline \multirow[t]{7}{*}{ Leg II } & Femur L & 3.5 & 2.7 & 3.2 & 3.9 & 3.3 & 3.6 \\
\hline & Femur $\mathrm{W}^{4}$ & 1.6 & 0.6 & 0.8 & 1.8 & 0.6 & 1.6 \\
\hline & Femur $\mathrm{H}^{4}$ & 2.2 & 0.8 & 1.0 & 2.0 & 0.8 & 2.3 \\
\hline & Patella L & 2.3 & 1.7 & 2.1 & 2.4 & 1.9 & 2.2 \\
\hline & Tibia L & 2.2 & 1.9 & 2.3 & 2.4 & 2.2 & 2.0 \\
\hline & Metatarsus L & 3.2 & 2.6 & 3.1 & 3.3 & 3.0 & 3.0 \\
\hline & Tarsus L & 2.7 & 2.4 & - & 2.9 & 2.7 & 2.8 \\
\hline \multirow[t]{7}{*}{ Leg III } & Femur L & 2.5 & 1.9 & 2.3 & 2.7 & 2.2 & 2.3 \\
\hline & Femur $\mathrm{W}^{4}$ & 0.8 & 0.6 & 0.7 & 0.7 & 0.7 & 0.6 \\
\hline & Femur $\mathrm{H}^{4}$ & 0.8 & 0.7 & 0.8 & 0.8 & 0.7 & 0.6 \\
\hline & Patella L & 1.6 & 1.4 & 1.6 & 1.7 & 1.5 & 1.5 \\
\hline & Tibia L & 1.6 & 1.1 & 1.3 & 1.6 & 1.4 & 1.3 \\
\hline & Metatarsus L & 2.2 & 1.7 & 2.0 & 2.3 & 1.8 & 2.0 \\
\hline & Tarsus L & 2.9 & 1.6 & - & 2.7 & 1.6 & 2.7 \\
\hline \multirow[t]{7}{*}{ Leg IV } & Femur L & 2.8 & 2.3 & 2.7 & 2.9 & 2.6 & 2.5 \\
\hline & Femur $\mathrm{W}^{4}$ & 0.9 & 0.5 & 0.6 & 0.7 & 0.5 & 0.6 \\
\hline & Femur $\mathrm{H}^{4}$ & 1.1 & 0.7 & 0.8 & 1.0 & 0.7 & 0.7 \\
\hline & Patella L & 1.7 & 1.5 & 1.7 & 1.9 & 1.5 & 1.5 \\
\hline & Tibia L & 1.3 & 1.1 & 1.5 & 1.5 & 1.4 & 1.2 \\
\hline & Metatarsus L & 2.1 & 1.9 & 2.2 & 2.2 & 2.1 & 2.0 \\
\hline & Tarsus L & 2.1 & 1.8 & - & 2.0 & 1.7 & 2.0 \\
\hline
\end{tabular}

${ }^{1}$ Excludes pygidium and cucullus.

${ }^{2}$ Maximum width.

${ }^{3}$ Maximum height.

${ }^{4}$ Midline.

${ }^{5}$ Approximate (opisthosomal dorsal sclerites collapsed). 
34A). Spermathecae follicular, each comprising soft, elongate tube terminating in tapering duct, situated submedially on anterior surface of bursa copulatrix adjacent to dorsal margin. Posterior genital lip as in figure 34A.

Distribution: This species is known only from Bo in the Southern Province of Sierra Leone (fig. 5), where it is codistributed with Ric inoides leonensis Legg, 1978. Records of this species from Guinea (Tuxen, 1974; Harvey, 2003; Naskrecki, 2008) are referred to R. nzerekorensis. Reports of $R$. afzelii from Ghana (Dunlop, 1996; Harvey, 2003) are probably also misidentifications given the narrow geographical distribution of most ricinuleid species and the geographical distance between the two countries.

REMARKs: The type locality in Sierra Leone is unknown. In 1964-1965, J. Pollock collected a large series of ricinuleids at Bo, comprising specimens identified by Pollock (1967) as $R$. afzelii and others, later described by Legg (1978a) as $R$. leonensis. Subsequent publications cited Bo as a locality record for R. afzelii (Legg, 1978a, 1978b; Harvey, 1984). Ricinoides afzelii was erroneously reported from several localities in Guinea (Tuxen, 1974; Harvey, 2003; Naskrecki, 2008). Tuxen (1974) redescribed the species based mostly on specimens from Nzérékoré. Reexamination of the holotype of $R$. afzelii and material from Bo and Nzérékoré, during the present investigation, confirmed that the material from Bo is conspecific with the holotype, whereas the material from Nzérékoré represents a new species, described below as $R$. nzerekorensis.

A female from Mount Gangra, Guinea, identified as Ricinoides cf. afzelii by Murienne et al. (2013), and placed outside the clade comprising other "giant" ricinuleids in their molecular phylogeny, evidently belongs to a different group of species, not the "giant" Ricinulei covered in the present contribution.

Additional Material Examined: SIERRA LEONE: E.E. Austen, 1 \& (BMNH 13588947). Southern Province: Bo $\left[07^{\circ} 57^{\prime} \mathrm{N} 11^{\circ} 44^{\prime} \mathrm{W}\right]$, vi-x.1964, J. Pollock, beneath log, 1 oे (BMNH 13588948), same data, except: viii.1965, 2 ○े (BMNH 13588950), 1 ○े (BMNH
13588953), 3 ㅇ (BMNH 13588949, 13588951, 13588952), 1 tritonymph (BMNH 13588954), 2 deutonymphs (BMNH 13588958), 1 deutonymph (BMNH 13588956), 1 protonymph (BMNH 13588955), 1 larva (BMNH 13588957), same data, except: 19.x.1965, 1 우 (AMNH IZC 324954).

\section{Ricinoides atewa Naskrecki, 2008}

Figures 5, 6B, 7B, 9B, 10B, 11B, 12B, 14B, 15B, 17B, 18B, 20B, 21B, 22B, D, F, H, 28B, D, F, H, J, 33B, 34B, tables 1-3

Ricinoides westermannii (Guérin-Méneville, 1838): Harvey, 1984: 205-207, figs. 1-9 (misidentification); 2003: 184 (misidentification, material from Ghana).

Ricinoides atewa Naskrecki, 2008: 58-64, figs. 1-13, 20-28; Murienne et al., 2013: 2, 6, figs. 1, 2; Sharma et al., 2014: 2966, figs. 1f, 2, 3, 6, 8, 11; Fernández and Giribet, 2015: 3, 7, 8, figs. 1a, 2b, 3a-c; Sharma et al., 2015: 4, fig. 2c; Santibáñez-López, 2018: 8, fig. 1a; Sharma et al., 2018: 40, fig. 2; Ballesteros and Sharma, 2019: 902, fig. 1; Ballesteros et al., 2019: 3, 6, fig. 1a, 3a, c.

Type MATERIAl: Holotype $\delta$ (AMNH IZC 324855), GHANA: Eastern Region: Atewa Range Forest Reserve, Asiakwa, main road, $06^{\circ} 15^{\prime} 00.7^{\prime \prime} \mathrm{N}$ $00^{\circ} 33^{\prime} 53.7^{\prime \prime} \mathrm{W}, 817 \mathrm{~m}, 7-11 . x i i .2007$ [reported as “06 ${ }^{\circ} 15^{\prime} 43.9^{\prime \prime} \mathrm{N} \mathrm{00} 33^{\prime} 16.5^{\prime \prime} \mathrm{W}, 827 \mathrm{~m}$, 8.xii.2007” in original description], P. Naskrecki, V. AwotwePratt, and N. Jengre [examined]. The vial containing the holotype includes a microvial with the detached dextral copulatory apparatus. Paratypes: 1 o, 2 (AMNH/MCZ), same data as holotype; 1 \& (MCZ), same data as original description, except: 11-16.vi.2006, P. Naskrecki; 2 우 (AMNH/MCZ), same data, except: along main reserve road, $06^{\circ} 15^{\prime} 00.7^{\prime \prime} \mathrm{N} 00^{\circ} 33^{\prime} 53.7^{\prime \prime} \mathrm{W}$, 817 m, 7-11.xii.2007, P. Naskrecki, V. AwotwePratt, and N. Jengre. Ajenjua Bepo Forest Reserve, $06^{\circ} 22^{\prime} 02.3^{\prime \prime} \mathrm{N} 01^{\circ} 01^{\prime} 58^{\prime \prime} \mathrm{W}, 300-330 \mathrm{~m}$, 26-30.viii.2006, P. Naskrecki, 4 ㅇ (AMNH/ MCZ). Only the holotype, two males, and one 

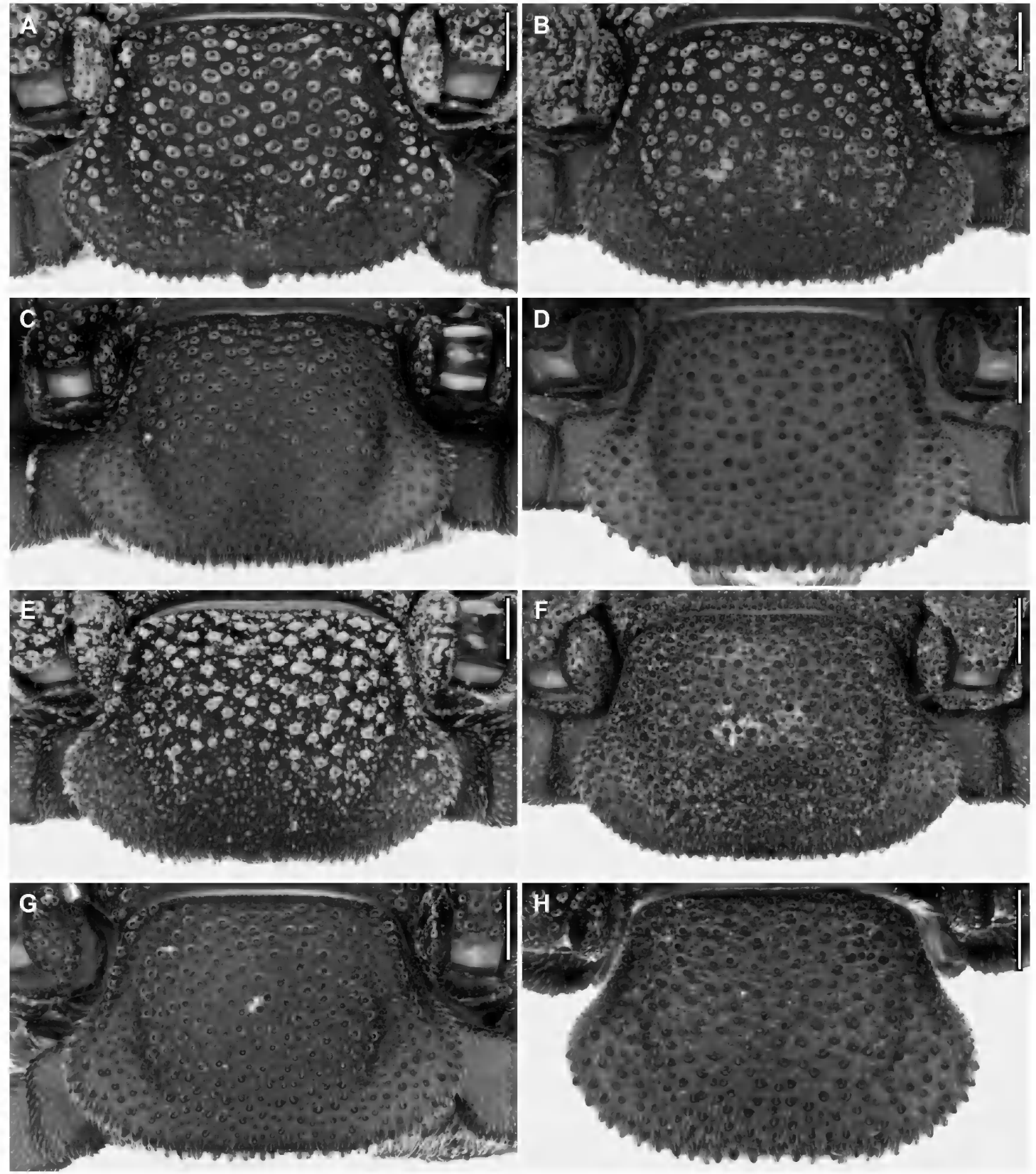

FIGURE 9. Ricinoides Ewing, 1929, cucullus, anterior aspect. A. Ricinoides afzelii (Thorell, 1892), ô (BMNH 13588948). B. Ricinoides atewa Naskrecki, 2008, holotype ô (AMNH IZC 324855). C. Ricinoides eburneus, sp. nov., holotype ô (MRAC 230.162). D. Ricinoides feae (Hansen, 1921), lectotype ơ (MSNG). E. Ricinoides iita, sp. nov., holotype ô (USNM). F. Ricinoides kakum, sp. nov., holotype ô (MRAC 217.183). G. Ricinoides nzerekorensis, sp. nov., holotype ô (MRAC 209.266). H. Ricinoides taii, sp. nov., holotype ô (MRAC 233.458). Scale bars $=0.5 \mathrm{~mm}$. 

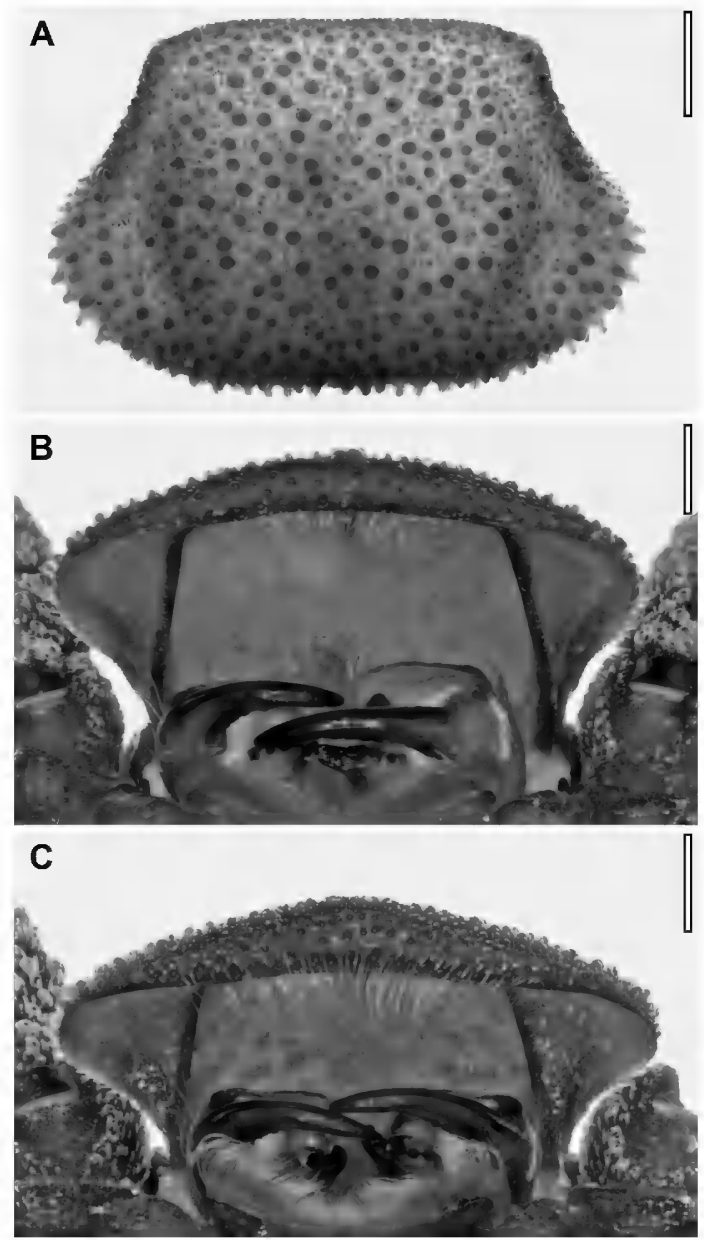

FIGURE 10. Ricinoides Ewing, 1929, cucullus, anterior (A) and posteroventral (B, C) aspects. A. Ricinoides westermannii (Guérin-Méneville, 1838), neotype 0 (ZMB 7013). B. Ricinoides atewa Naskrecki, 2008, holotype ơ (AMNH IZC 324855). C. Ricinoides iita, sp. nov., holotype ơ (USNM). Scale bars $=0.5 \mathrm{~mm}$.

female, labelled as paratypes although not listed as such in the original description (see Additional Material Examined), are present in the AMNH and there is no record that additional specimens were deposited.

Diagnosis: Ricinoides atewa most closely resembles $R$. kakum. The males of both species share several characters, including a group of slightly elevated granules anteromedially on the ventral part of the cucullus (fig. 10B), and moderately enlarged tubercles in the distal half of the ventral surface of the pedipalp tibia (fig. 20B). The fixed process of the male copulatory apparatus of $R$. atewa resembles that of $R$. kakum in the laterally expanded $P L$ lobe (figs. $28 \mathrm{D}, \mathrm{H}$ ), a character also shared by R. eburneus, and the distinct subdistal serrations on the retrolateral margin of the a lobe (figs. 28D, H, J), which is unique to $R$. atewa and R. kakum (table 2). The lateral sclerites of tergite $\mathrm{X}$ are well developed and the tergal membranes narrow in $R$. atewa (figs. 14B, 15B), whereas the lateral sclerites of tergite $\mathrm{X}$ are obsolete and the tergal membranes broad, in $R$. kakum. Additionally, the moderately enlarged tubercles in the distal half of the ventral surface of the pedipalp tibia comprise two (proventral and retroventral) rows in the male of $R$. atewa, unlike the male of $R$. kakum, in which the tubercles comprise a single retroventral row.

Redescription of MALE: Based on the holotype (AMNH IZC 324855).

Measurements: Total length $9.63 \mathrm{~mm}$ (table 3).

Coloration: Soma and appendages predominantly dark reddish brown, almost black. Carapace dorsolateral translucent areas yellowish. Opisthosomal tergal and pleural membranes yellow, hyaline. Cheliceral manus yellow; fingers, finger dentition, and manus toothlike process dark.

Setation: Surfaces densely covered with short, translucent, bristlelike setae, slightly expanded but not navicular, length similar to height of surrounding tuberose granules (figs. 6B, 14B). Polygonal setae absent.

Tegument surface macrosculpture: Tegument very irregular, without cuticular pits. Carapace, cucullus, opisthosomal sclerites, legs, and, to lesser extent, coxal region covered with coarse, rounded tuberose granules, evenly spaced apart, not clustered together (figs. 6B, 9B, 11B, 14B, 21B, 22B, D, F, H). Opisthosoma, pleural membranes finely and densely granular; tergal membranes more sparsely granular. Pedipalp femur dorsal, prolateral, and retrolateral surfaces finely granular; tibia with elevated oval 


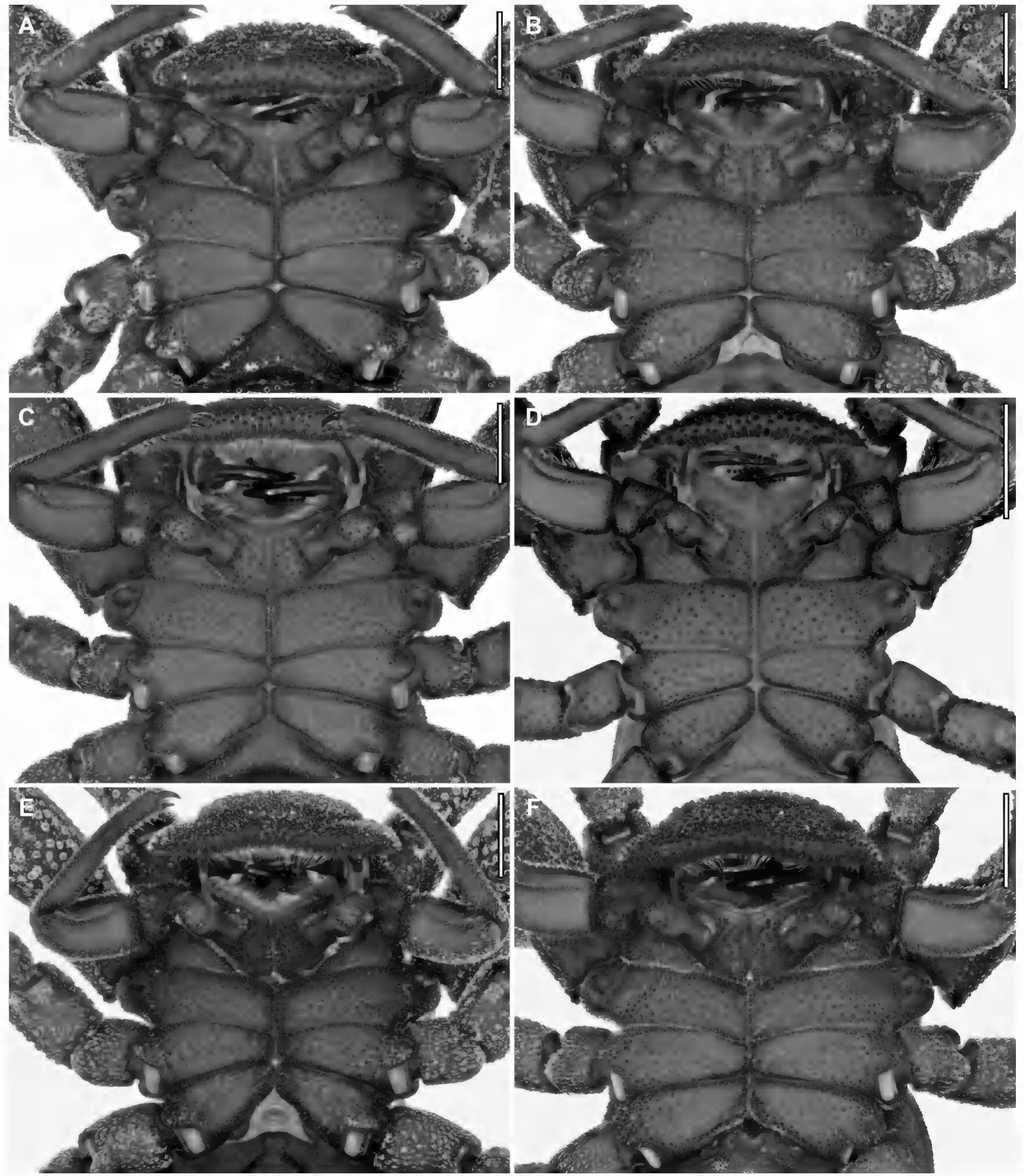

FIGURE 11. Ricinoides Ewing, 1929, coxosternal region, ventral aspect. A. Ricinoides afzelii (Thorell, 1892), ô (BMNH 13588948). B. Ricinoides atewa Naskrecki, 2008, holotype ơ (AMNH IZC 324855). C. Ricinoides eburneus, sp. nov., holotype ô (MRAC 230.162). D. Ricinoides feae (Hansen, 1921), lectotype ơ (MSNG). E. Ricinoides iita, sp. nov., holotype ơ (USNM). F. Ricinoides kakum, sp. nov., holotype ơ (MRAC 217.183). Scale bars $=1 \mathrm{~mm}$. 


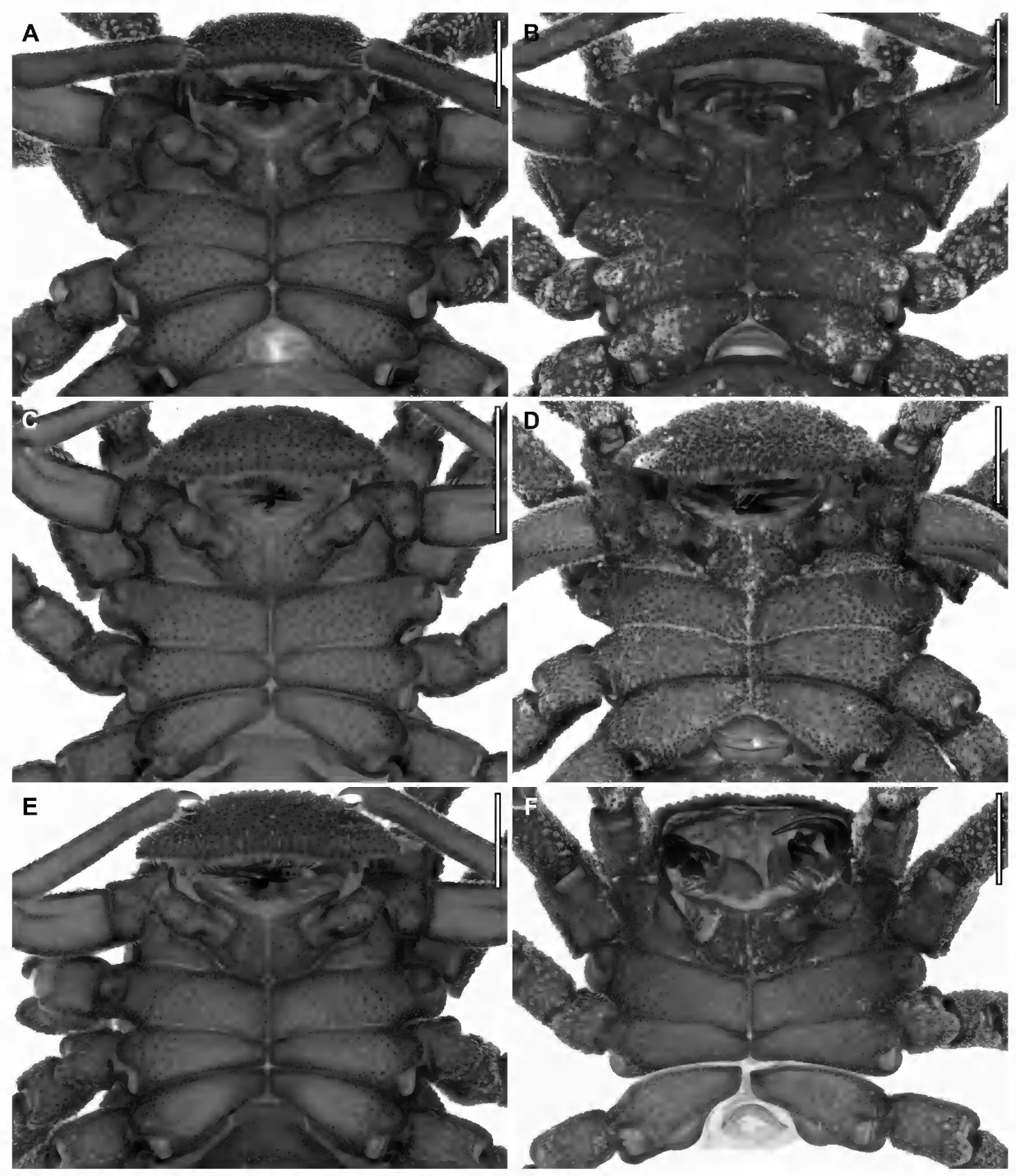

FIGURE 12. Ricinoides Ewing, 1929, coxosternal region, ventral aspect. A. Ricinoides afzelii (Thorell, 1892), q (BMNH 13588949). B. Ricinoides atewa Naskrecki, 2008, $q$ (AMNH IZC 324883). C. Ricinoides feae (Hansen, 1921), paralectotype + (MSNG), Rio Cacine, Guinea-Bissau. D. Ricinoides kakum, sp. nov., paratype (MRAC 217.183). E. Ricinoides nzerekorensis, sp. nov., paratype $q$ (MRAC 209.267). F. Ricinoides taii, sp. nov., paratype + (MRAC 233.482). Scale bars $=1 \mathrm{~mm}$. 


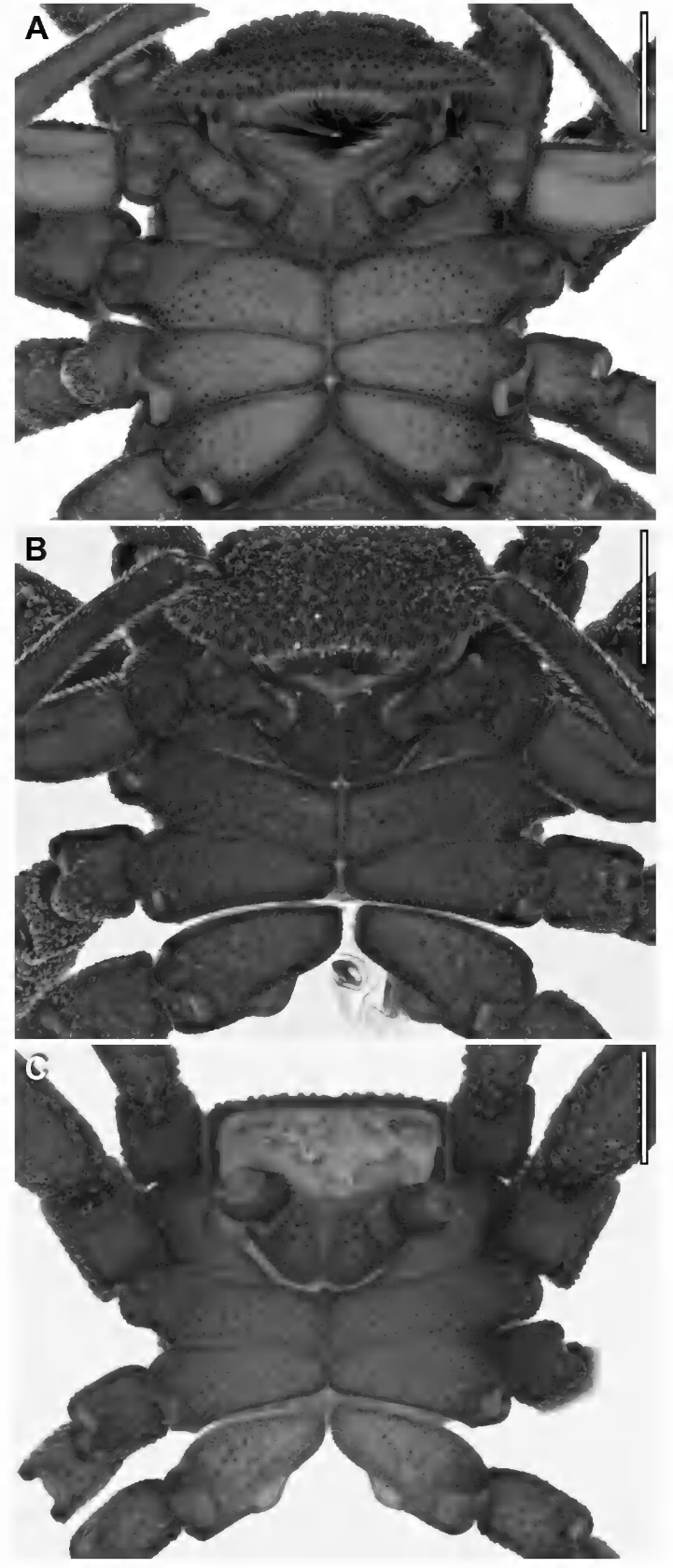

FIGURE 13. Ricinoides Ewing, 1929, coxosternal region, ventral aspect. A. Ricinoides nzerekorensis, sp. nov., holotype ơ (MRAC 209.266). B. Ricinoides taii, sp. nov., holotype ơ (MRAC 233.458). C. Ricinoides westermannii (Guérin-Méneville, 1838), neotype $\delta$ (ZMB 7013). Scale bars $=1 \mathrm{~mm}$. tubercles distally (fig. 20B), tubercles on ventral surface moderately enlarged and arranged into two (proventral and retroventral) rows.

Carapace: Carapace wider than long, broadest between coxae of legs II and III; trapezoidal, lateral margins curved, narrowing anteriorly (fig. $6 \mathrm{~B})$; anterior margin linear in dorsal aspect; posterior margin slightly procurved; median longitudinal sulcus, paired posterior marginal transverse sulci, and paired anterolateral longitudinal sulci distinct; paired lateral depressions aligned with coxae of legs II; posteromedian moundlike excrescence absent; dorsolateral translucent areas entirely smooth, medium sized, aligned with intersection between coxae of legs I and II, visible in dorsolateral aspect.

Cucullus: Cucullus broadened laterally, wider than long; ventrolateral margins rounded (fig. 9B); ventral margin predominantly linear in anterior aspect, shallowly bilobate in ventral aspect, posterior surface, median row of denticulations worn; anterior surface shallowly convex, without ventral compressed surface; pair of moderately developed sublateral longitudinal sulci; ventral part with group of slightly elevated granules anteromedially (fig. 10B), without knoblike tubercle or elevation anteromedially.

Chelicerae: Manus dorsal surface with large toothlike process distally. Movable finger longer than fixed finger, tooth row comprising six or seven small teeth; sharp prodorsal longitudinal carina parallel to tooth row (opposite fixed finger); mucron with shallow but distinct prolateral excavation (opposite fixed finger) delimited by two parallel longitudinal carinae. Fixed finger tooth row comprising four small teeth.

Coxosternal region: Tritosternum very small, barely visible, not abutting coxae of legs I (fig. 11B); coxae of legs II-IV abutting one another medially along entire length; coxae of legs II, anterior and posterior margins almost parallel, slightly narrowing medially, not perpendicular to median axis, inclined anteriorly; coxae of legs II, posterior margins $\mathrm{V}$-shaped medially; suture between coxae of legs II approximately $2 \times$ length of suture between coxae of legs III and IV. 
Opisthosoma: Opisthosoma oval, longer than wide, broadest at tergite XII. Posterodorsal and posteroventral margins without spiniform granules (figs. 14B, 17B). Tergites X-XIII each comprising median and lateral sclerites; median sclerites of tergites XI-XIII each with paired, shallow submedian depressions near anterior margins; lateral margins of median sclerites converging posteriorly on tergite XI and, to lesser extent, XII, subparallel on XIII; median sclerites of tergites XI and XII wider than long, of XIII approximately as wide as long, square; margins of lateral sclerites adjacent to tergal longitudinal membranes predominantly linear, tergal membranes narrow. Sternites XI-XIII each with pair of shallow submedian depressions similar to tergites (fig. 17B). Pygidium, basal segment parallel to longitudinal axis of opisthosoma; opening very narrow, slightly compressed laterally, width approximately one third lateral width of segment at its base; posterior border narrow; dorsal surface with V-shaped notch; ventral surface entire.

Pedipalps: Femur globose, length approximately $2 \times$ depth. Tibia longer than femur; entirely linear (fig. 20B); robust along entire length, margins parallel in dorsal and lateral aspects; apical longitudinal carinae absent. Movable finger approximately $2 \times$ length of fixed finger.

Legs: Leg II longest, femur markedly incrassate (figs. 22B, D). Legs III and IV femora narrowest and similar in width, femora width (at midline) increasing in order leg IV $=$ III $<$ I $<<$ II; dorsal surface with longitudinal sulcus most distinct on leg IV. Leg I tibia without ventral apophyses; metatarsus subcircular in cross section, with deep proventral depression in proximal half and without prominent ventral excrescence (fig. 21B). Leg II tibia with large ventromedian apophysis proximally (fig. 22F), not markedly hook shaped, with pointed apex, entirely covered with tuberose granules; tibia and metatarsus without pad of long translucent setae ventrally; metatarsus with shallow subproximal depression but without ventrosubmedian concavity or excres- cence (fig. 22H); first to third tarsomeres short, subequal, fourth approximately $2 \times$ length of preceding tarsomeres; all tarsomeres movable. Leg III metatarsus not swollen, with moderate concavity dorsodistally; proventral surface without apical brushlike row of setae; prodorsal proximal sulcus present; metatarsus, metatarsal process, and tarsus precisely fitting together to completely encase copulatory apparatus when tarsus retracted; metatarsal process situated basally near tibia, robust, tapering and slightly laterally compressed, longitudinal axis sinuous, apex pointing retrolaterally; lamina cyathiformis of second tarsomere slightly longer than deep, with pointed apex; subdistal (third) tarsomere with acute dorsodistal process. Leg IV tarsus not swollen. Legs III and IV terminal tarsomere apex, dorsal margin sublinear, covering ungues. Leg I tarsus and legs II-IV terminal tarsomeres without ventrodistal papillae.

Copulatory apparatus: Fixed process, $P L$ lobe greatly expanded and dorsoventrally compressed (figs. 28D, H). Distal lobular region, primary a lobe very long, narrow, and dorsoventrally compressed (figs. 28B, D, F, H, J, 33B); origin submedial, curving toward ventral surface; prolateral margin smooth, retrolateral margin with distinct subdistal serrations. Primary $\beta$ lobe medium sized, distinctly bicuspid, with $\beta_{1}$ and $\beta_{2}$ pointed. rsd lobe medium sized and pronounced, associated with distinct subdistal emargination. Secondary $p d$ and $r d$ lobes well developed, pointed. Movable process slender, slightly flexible, narrowing distally; apex simple, entire.

Supplementary Description of Female: Based on the female from Mamang Forest Reserve (AMNH IZC 324883). Resembles male unless otherwise noted.

Measurements: Total length $9.19 \mathrm{~mm}$ (table 3).

Tegument surface macrosculpture: Pedipalp tibia with oval tubercles on ventral surface smaller than in male.

Carapace: Posteromedian moundlike excrescence absent (fig. 7B).

Cucullus: Ventral part without group of elevated granules anteromedially; ventrolateral 

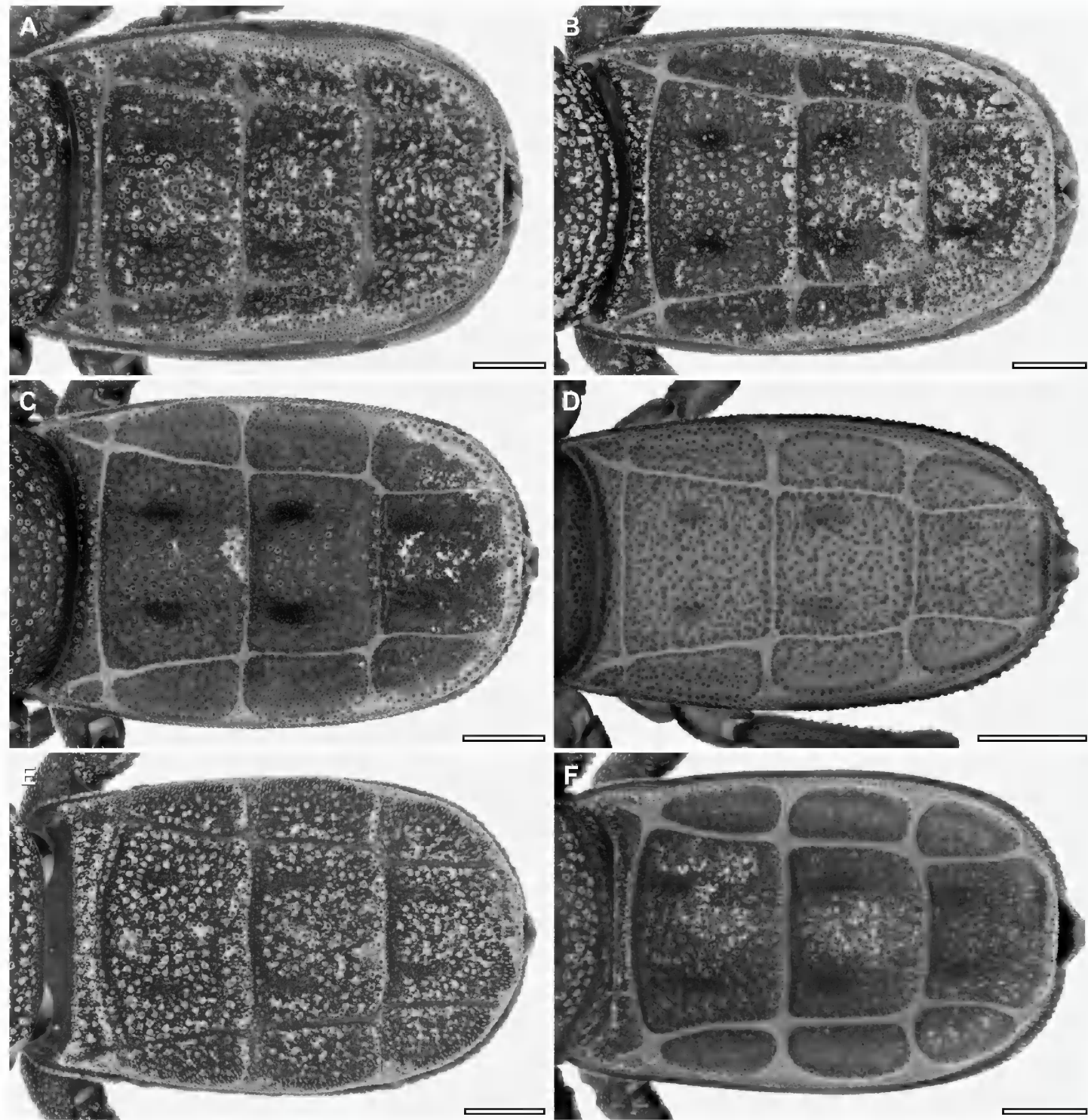

FIGURE 14. Ricinoides Ewing, 1929, opisthosoma, dorsal aspect. A. Ricinoides afzelii (Thorell, 1892), ठิ (BMNH 13588948). B. Ricinoides atewa Naskrecki, 2008, holotype ô (AMNH IZC 324855). C. Ricinoides eburneus, sp. nov., holotype ô (MRAC 230.162). D. Ricinoides feae (Hansen, 1921), lectotype đo (MSNG). E. Ricinoides iita, sp. nov., holotype ô (USNM). F. Ricinoides kakum, sp. nov., holotype ơ (MRAC 217.183). Scale bars $=1 \mathrm{~mm}$. 

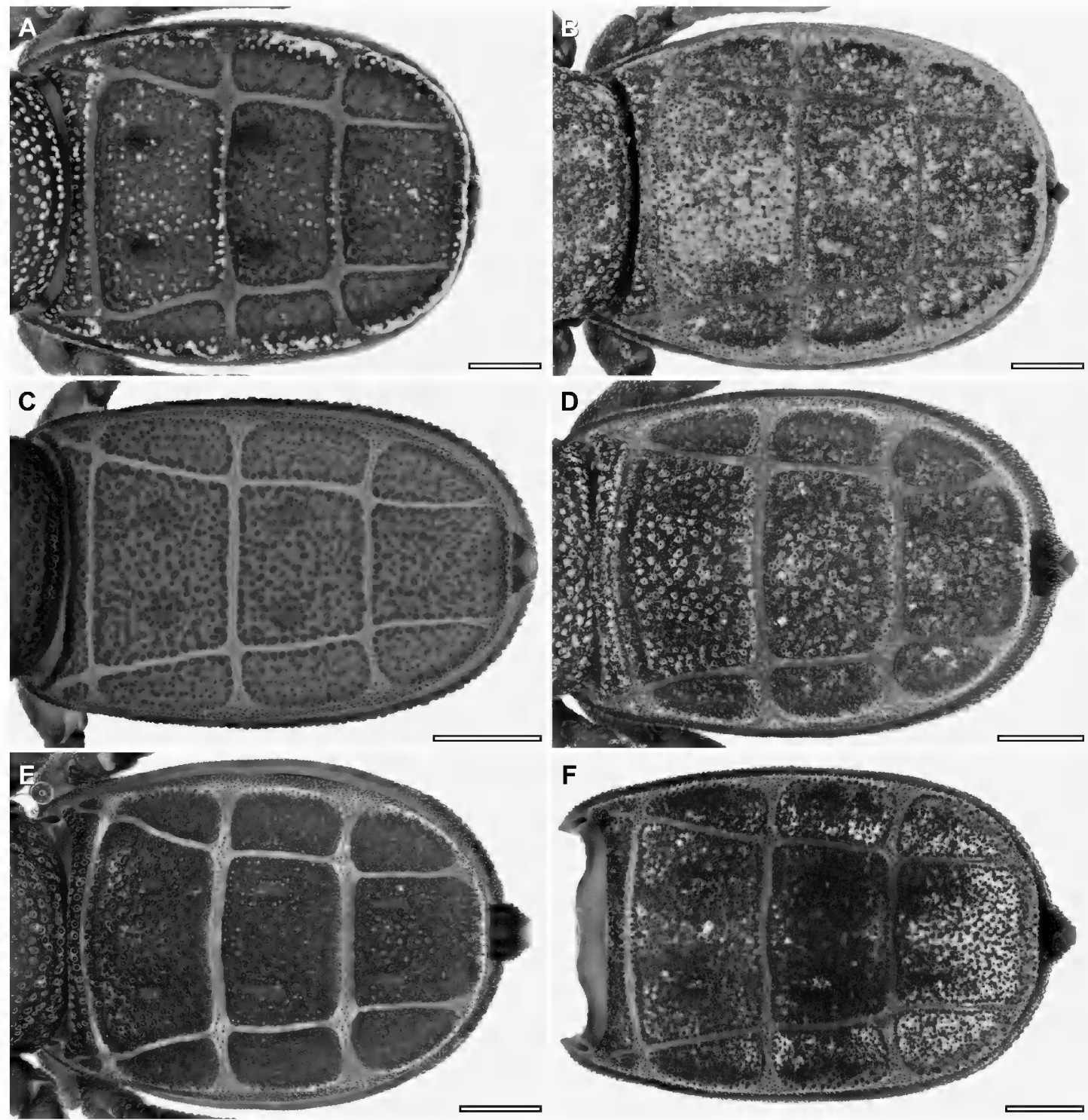

FIGURE 15. Ricinoides Ewing, 1929, opisthosoma, dorsal aspect. A. Ricinoides afzelii (Thorell, 1892), $q$ (BMNH 13588949). B. Ricinoides atewa Naskrecki, 2008, q (AMNH IZC 324883). C. Ricinoides feae (Hansen, 1921), paralectotype + (MSNG), Rio Cacine, Guinea-Bissau. D. Ricinoides kakum, sp. nov., paratype + (MRAC 217.183). E. Ricinoides nzerekorensis, sp. nov., paratype + (MRAC 209.267). F. Ricinoides taii, sp. nov., paratype \& (MRAC 233.482). Scale bars $=1 \mathrm{~mm}$. 

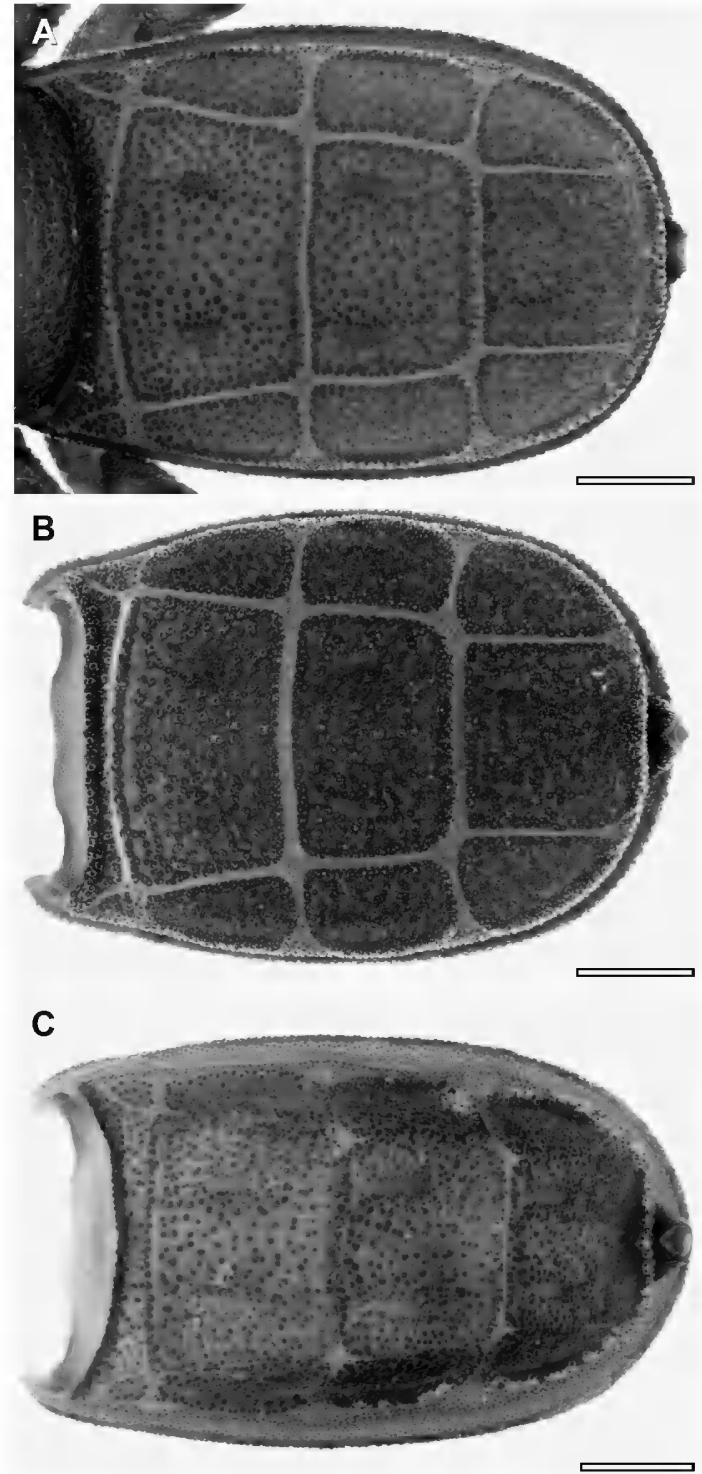

FIGURE 16. Ricinoides Ewing, 1929, opisthosoma, dorsal aspect. A. Ricinoides nzerekorensis, sp. nov., holotype of (MRAC 209.266). B. Ricinoides taii, sp. nov., holotype $\delta$ (MRAC 233.458). C. Ricinoides westermannii (Guérin-Méneville, 1838), neotype $\widehat{\sigma}$ (ZMB 7013). Scale bars $=1 \mathrm{~mm}$. margins rounded; ventral margin predominantly linear in anterior aspect.

Coxosternal region: Coxae of legs II and IV abutting one another medially along entire length, coxae of legs III abutting along anterior two thirds (fig. 12B); coxae of legs II, posterior margin $\mathrm{V}$-shaped medially.

Opisthosoma: Opisthosoma oval (figs. 15B, 18B). Tergites XI-XIII, median sclerites wider than long. Opening of basal segment of pygidium very narrow, compressed laterally.

Legs: Leg I metatarsus without proximal depression proventrally. Leg II femur unmodified, longer than but similar in shape to femora of other legs; tibia without ventromedian apophysis; metatarsus without subproximal depression ventrally.

Spermathecae: Anterior wall of bursa copulatrix with pair of medium-sized, slightly pigmented, rounded areas. Anterior surface with nine hard sacculiform structures sinistrally and seven dextrally, variable in size, some markedly elongate (fig. 34B). Spermathecae follicular, each comprising soft, elongate tube terminating in tapering duct, situated submedially on anterior surface of bursa copulatrix adjacent to dorsal margin. Posterior genital lip as in fig. 34B.

Distribution: This species is known from several localities south of Lake Volta in the Eastern Region of Ghana (fig. 5).

Remarks: Harvey's $(1984,2003)$ record of $R$. westermannii from Mt. Atewa, Ghana, the type locality of $R$. atewa, is probably conspecific with the latter.

Additional Material Examined: GHANA: Eastern Region: Akim Abuakwa region, NW of Asiakwa $\left[06^{\circ} 16^{\prime} \mathrm{N} 00^{\circ} 30^{\prime} \mathrm{W}\right]$, Kibi hills, Pusa Pusa River, vii.1968, N.D. Jaga, 1 ô, 1 ㅇ (FMNH INS 3821310); Asamankese $\left[05^{\circ} 51^{\prime} \mathrm{N} \quad 00^{\circ} 40^{\prime} \mathrm{W}\right], 21 . x i i .1969, \mathrm{D}$. Leston, in rotten wood, dense shade on edge of coeva farm, 1 o (AMNH IZC 324885); Mamang Forest Reserve, camp 2, $06^{\circ} 15^{\prime} 01.4^{\prime \prime} \mathrm{N} 01^{\circ} 02^{\prime} 25.4^{\prime \prime} \mathrm{W}, 130 \mathrm{~m}$, 30.viii-5.ix.2006, P. Naskrecki and V. Awotwe-Pratt, 1 ๙, 1 (AMNH IZC 324883) [labeled "paratypes" but not mentioned in original description].

None of the following specimens, mentioned in the original description (Naskrecki, 2008), were located in 
the AMNH and there is no record they were ever deposited: GHANA: Eastern Region: Atewa Range Forest Reserve, Asiakwa, along main reserve road, $06^{\circ} 15^{\prime} 00.7^{\prime \prime} \mathrm{N}$ $00^{\circ} 33^{\prime} 53.7^{\prime \prime} \mathrm{W}, 817 \mathrm{~m}, 7-11 . x i i .2007$, P. Naskrecki, V. Awotwe-Pratt, and N. Jengre, 4 o, 6 tritonymphs, 3 deutonymphs (AMNH/MCZ), same data, except: $06^{\circ} 15^{\prime} 43.9^{\prime \prime} \mathrm{N} \quad 00^{\circ} 33^{\prime} 16.5^{\prime \prime} \mathrm{W}, 827 \mathrm{~m}$, 8.xii.2007, 2 tritonymphs, 1 deutonymph (AMNH/MCZ). Ajenjua Bepo Forest Reserve, $06^{\circ} 22^{\prime} 02.3^{\prime \prime} \mathrm{N} 01^{\circ} 01^{\prime} 58^{\prime \prime} \mathrm{W}, 300-330$ m, 26-30.viii.2006, P. Naskrecki, 3 ô, 2 tritonymphs, 1 deutonymph, 1 protonymph (AMNH/MCZ) [ 1 o (AMNH IZC 324951), labeled "paratype" but not mentioned as such in original description, examined].

\section{Ricinoides eburneus, sp. nov.}

Figures 5, 6C, 9C, 11C, 14C, 17C, 20C, 21C, 23A, C, E, G, 29A, C, E, G, I, 33C, tables 1-3

Type Material: Holotype $\hat{o}$ (MRAC 230.162), CÔTE D'IVOIRE: Montagnes and Bas-Sassandra Districts: Forêt de Taï [Taï National Park, $05^{\circ} 41^{\prime} \mathrm{N} 06^{\circ} 56^{\prime}$ W], C.R.E., road near Chimpanzee Camp, 20.ii.2010, M. Diarassouba, forest across river, on clayey soil, near pitfalls III, manual capture. Two microvials contain the following detached pieces: sinistral leg I and dextral copulatory apparatus.

Diagnosis: Ricinoides eburneus resembles $R$. nzerekorensis in possessing a distinct pad of bristlelike setae on the ventral surfaces of the tibia and metatarsus of leg II in the male (fig. 23E, G), and $R$. atewa and $R$. kakum in the laterally expanded $P L$ lobe of the male copulatory apparatus (figs. 29C, G). The ventromedian apophysis on the tibia of leg II is smooth dorsally and prolaterally in the male of R. eburneus (fig. 23E) unlike all other species, in which the apophysis is entirely covered with granules (the apophysis is absent in $R$. westermannii). Ricinoides eburneus differs further from $R$. nzerekorensis in the structure of the ventral pad of setae on the tibia of leg II in the male, which is more distinct and comprises longer setae, more than half the depth of the metatarsus of leg II (fig. 23E). Other differences among the four species are evident in the structure of the male copulatory apparatus (table 2).
Eтymology: The specific epithet is a latinized adjective for "ivory," as in Côte d'Ivoire (or Ivory Coast), the country in which this species has been recorded, and also alludes to the large, partially smooth apophysis on the leg II tibia of the male.

Description of Male: Based on the holotype (MRAC 230.162).

Measurements: Total length $8.87 \mathrm{~mm}$ (table 3).

Coloration: Soma and appendages dark red. Carapace dorsolateral translucent areas yellowish. Opisthosomal tergal and pleural membranes yellow, hyaline. Cheliceral manus yellow; fingers, finger dentition, and manus toothlike process dark.

Setation: Surfaces densely covered with short, translucent, bristlelike setae, slightly expanded but not navicular, length similar to height of surrounding tuberose granules (figs. 6C, 14C). Polygonal setae absent.

Tegument surface macrosculpture: Tegument very irregular, without cuticular pits. Carapace, cucullus, opisthosomal sclerites, legs, and, to lesser extent, coxal region covered with coarse, rounded tuberose granules, evenly spaced apart, not clustered together (figs. 6C, 9C, 11C, 14C, 21C, 23A, C, E, G). Opisthosoma, pleural membranes finely and densely granular; tergal membranes more sparsely granular. Pedipalp femur dorsal, prolateral, and retrolateral surfaces finely granular; tibia with elevated oval tubercles distally (fig. 20C), not noticeably enlarged or arranged in distinct rows.

Carapace: Carapace wider than long, broadest between coxae of legs II and III; trapezoidal, lateral margins curved, narrowing anteriorly (fig. $6 \mathrm{C})$; anterior margin linear in dorsal aspect; posterior margin slightly procurved; median longitudinal sulcus, paired posterior marginal transverse sulci, and paired anterolateral longitudinal sulci distinct; paired lateral depressions aligned with coxae of legs II; posteromedian moundlike excrescence absent; dorsolateral translucent areas entirely smooth, medium sized, aligned with intersection between coxae of legs I and II, visible in dorsolateral aspect.

Cucullus: Cucullus broadened laterally, wider than long; ventrolateral margins rounded (fig. 


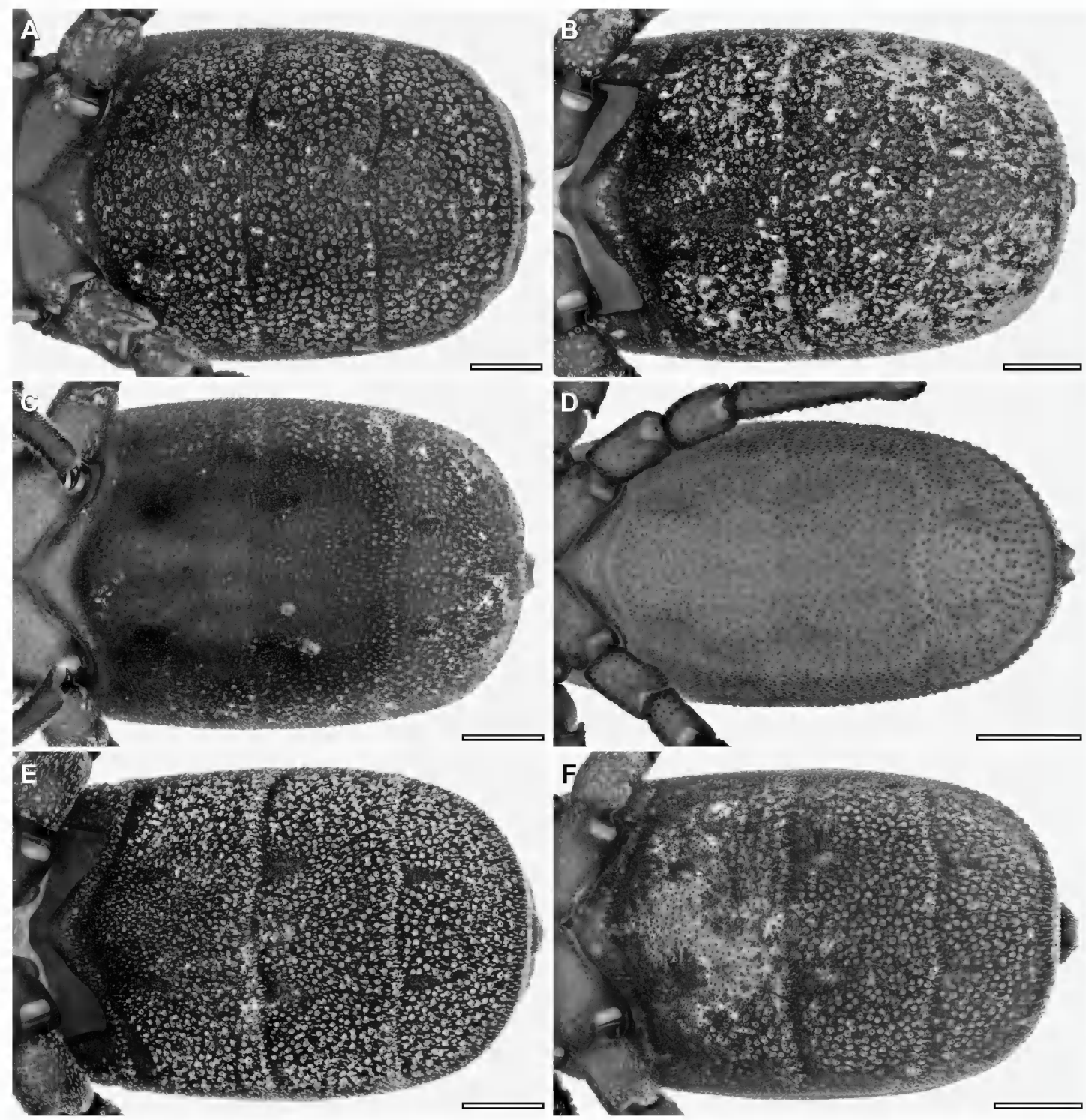

FIGURE 17. Ricinoides Ewing, 1929, opisthosoma, ventral aspect. A. Ricinoides afzelii (Thorell, 1892), ô (BMNH 13588948). B. Ricinoides atewa Naskrecki, 2008, holotype ô (AMNH IZC 324855). C. Ricinoides eburneus, sp. nov., holotype ơ (MRAC 230.162). D. Ricinoides feae (Hansen, 1921), lectotype o (MSNG). E. Ricinoides iita, sp. nov., holotype ô (USNM). F. Ricinoides kakum, sp. nov., holotype ô (MRAC 217.183). Scale bars $=1 \mathrm{~mm}$. 

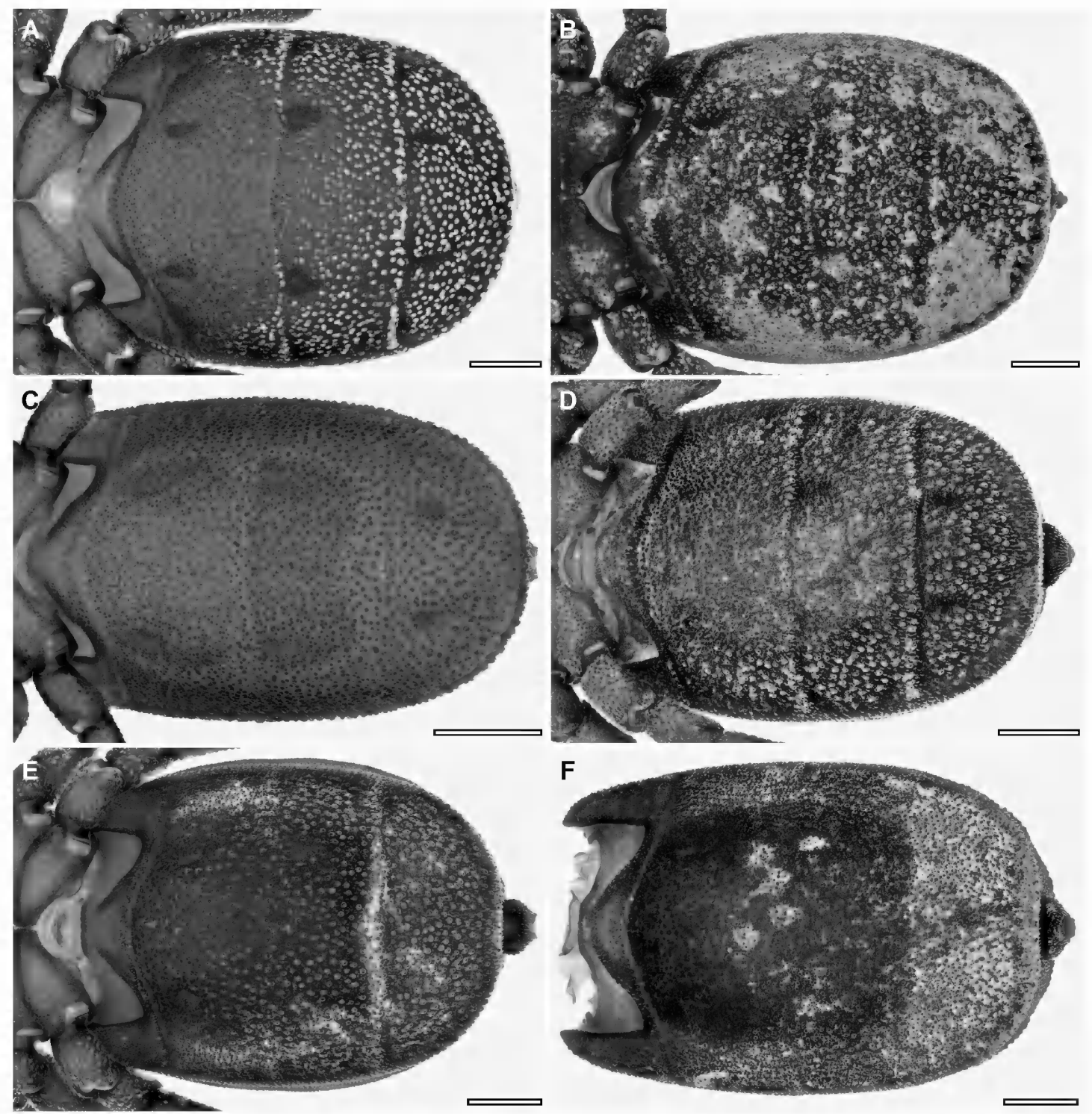

FIGURE 18. Ricinoides Ewing, 1929, opisthosoma, ventral aspect. A. Ricinoides afzelii (Thorell, 1892), o (BMNH 13588949). B. Ricinoides atewa Naskrecki, 2008, ๆ (AMNH IZC 324883). C. Ricinoides feae (Hansen, 1921), paralectotype + (MSNG), Rio Cacine, Guinea-Bissau. D. Ricinoides kakum, sp. nov., paratype $ᄋ$ (MRAC 217.183). E. Ricinoides nzerekorensis, sp. nov., paratype + (MRAC 209.267). F. Ricinoides taii, sp. nov., paratype + (MRAC 233.482). Scale bars $=1 \mathrm{~mm}$. 


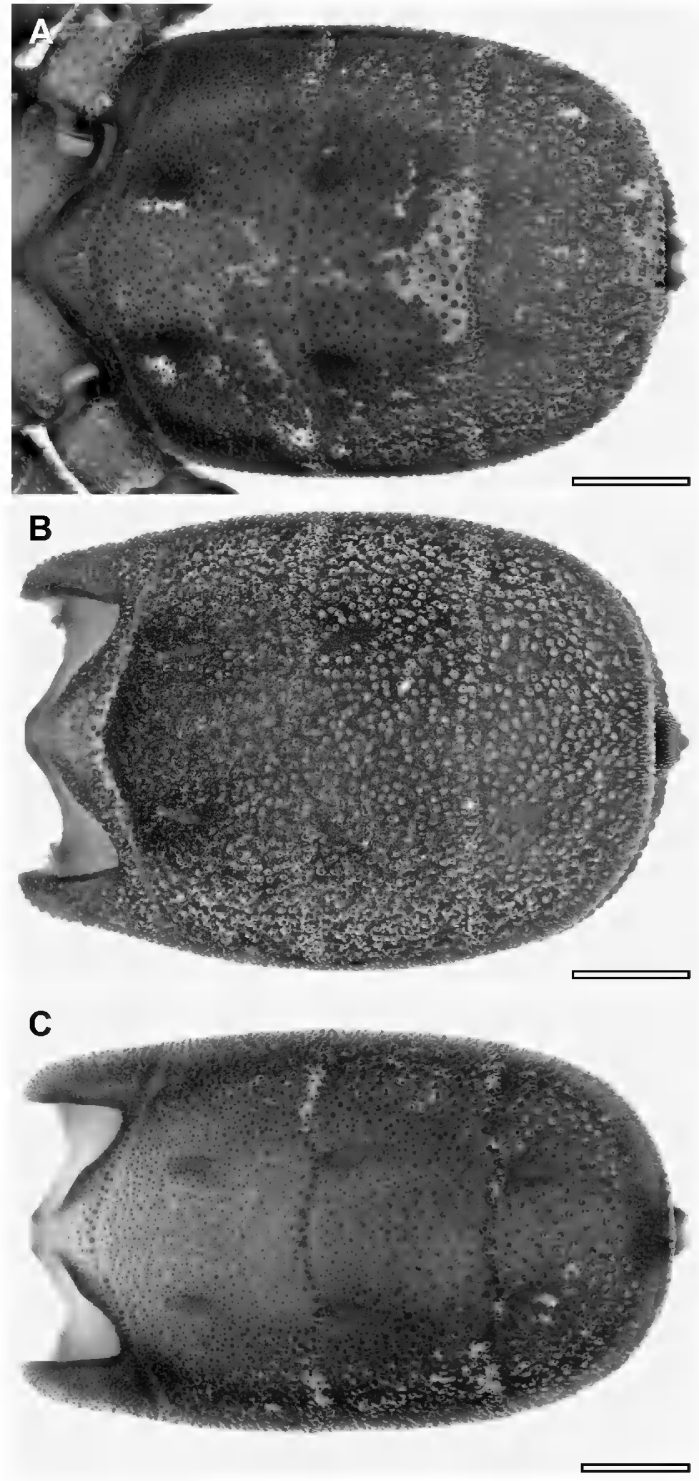

FIGURE 19. Ricinoides Ewing, 1929, opisthosoma, ventral aspect. A. Ricinoides nzerekorensis, sp. nov., holotype 0 (MRAC 209.266). B. Ricinoides taii, sp. nov., holotype ơ (MRAC 233.458). C. Ricinoides westermannii (Guérin-Méneville, 1838), neotype $\delta$ (ZMB 7013). Scale bars $=1 \mathrm{~mm}$.
9C); ventral margin predominantly linear in anterior aspect, shallowly bilobate in ventral aspect, posterior surface with median row of small denticulations; anterior surface shallowly convex, without ventral compressed surface; pair of moderately developed sublateral longitudinal sulci; ventral part unmodified anteromedially.

Chelicerae: Manus dorsal surface with large toothlike process distally (shorter, presumably deformed, on sinistral chelicera). Movable finger longer than fixed finger, tooth row comprising six small teeth; sharp prodorsal longitudinal carina parallel to tooth row (opposite fixed finger); mucron with shallow but distinct prolateral excavation (opposite fixed finger) delimited by two parallel longitudinal carinae. Fixed finger tooth row comprising four or five small teeth.

Coxosternal region: Tritosternum very small, barely visible, not abutting coxae of legs I (fig. 11C); coxae of legs II-IV abutting one another medially along entire length; coxae of legs II, anterior and posterior margins subparallel, not perpendicular to median axis, inclined anteriorly; coxae of legs II, posterior margin V-shaped medially; suture between coxae of legs II approximately $4 \times$ length of suture between coxae of legs III and $3 \times$ length of suture between coxae of legs IV.

Opisthosoma: Opisthosoma oval, longer than wide, broadest at tergite XII. Posterodorsal and posteroventral margins without spiniform granules (figs. 14C, 17C). Tergites X-XIII each comprising median and lateral sclerites; median sclerites of tergites XI-XIII each with paired, shallow submedian depressions near anterior margins; lateral margins of median sclerites converging posteriorly on tergite XI and, to lesser extent, XII, subparallel on XIII; median sclerites of tergites XI and XII wider than long, of XIII approximately as wide as long, square; margins of lateral sclerites adjacent to tergal longitudinal membranes predominantly linear, tergal membranes narrow. Sternites XI-XIII each with pair of shallow submedian depressions similar to tergites (fig. 17C). Pygidium, basal segment parallel to longitudinal axis of opisthosoma; opening very narrow, compressed laterally, width approx- 
imately one third lateral width of segment at its base; posterior border narrow; dorsal surface with V-shaped notch; ventral surface entire.

Pedipalps: Femur globose, length approximately $2 \times$ depth. Tibia longer than femur; entirely linear (fig. 20C); robust along entire length, margins parallel in dorsal and lateral aspects; apical longitudinal carinae absent. Movable finger approximately $2 \times$ length of fixed finger.

Legs: Leg II longest, femur markedly incrassate (figs. 23A, C). Femora width (at midline) increasing in order leg IV $<$ III $<$ I $<<$ II; dorsal surface with longitudinal sulcus most distinct on leg IV. Leg I tibia without ventral apophyses; metatarsus subcircular in cross section, with deep proventral depression in proximal half and without prominent ventral excrescence (fig. 21C). Leg II tibia with very large ventromedian apophysis proximally (fig. 23E), markedly hook shaped, with acute apex, smooth dorsally and prolaterally, and covered with tuberose granules on other surfaces; tibia and metatarsus with distinct pad of long, translucent bristlelike setae (longer than half depth of metatarsus) ventrally (figs. 23E, G); metatarsus with shallow subproximal depression but without ventrosubmedian concavity or excrescence (fig. 23G); first to third tarsomeres short, subequal, fourth approximately $2 \times$ length of preceding tarsomeres; all tarsomeres movable. Leg III metatarsus not swollen, with moderate concavity dorsodistally; proventral surface without apical brushlike row of setae; prodorsal proximal sulcus present; metatarsus, metatarsal process, and tarsus precisely fitting together to completely encase copulatory apparatus when tarsus retracted; metatarsal process situated basally near tibia, robust, tapering and slightly laterally compressed, longitudinal axis sinuous, apex pointing retrolaterally; lamina cyathiformis of second tarsomere approximately as deep as long, with pointed apex; subdistal (third) tarsomere with acute dorsodistal process. Leg IV tarsus not swollen. Legs III and IV terminal tarsomere apex, dorsal margin sublinear, covering ungues. Leg I tarsus and legs II-IV terminal tarsomeres without ventrodistal papillae.

Copulatory apparatus: Fixed process, PL lobe long, greatly expanded and dorsoventrally com- pressed (figs. 29C, G). Distal lobular region, primary a lobe very long, narrow, and slightly dorsoventrally compressed (figs. 29A, C, E, G, I, 33C); origin submedial, curving toward ventral surface; prolateral margin sublinear, smooth; retrolateral margin sinuous, smooth, or slightly irregular subdistally. Primary $\beta$ lobe medium sized, distinctly bicuspid, with $\beta_{1}$ and $\beta_{2}$ pointed. rsd lobe medium sized, pronounced, associated with distinct subdistal emargination. Secondary $p d$ and $r d$ lobes well developed, pointed. Movable process slender, slightly flexible, narrowing distally; apex simple, entire.

FeMALE: Unknown.

Distribution: Ricinoides eburneus is known only from the type locality, Tai National Park, in the Montagnes and Bas-Sassandra districts of Côte d'Ivoire (fig. 5). It is one of three ricinuleid species recorded in the national park, the others being Ricinoides megahanseni Legg, 1982, and R. taii.

\section{Ricinoides feae (Hansen, 1921)}

Figures $1,4 \mathrm{C}, 5,6 \mathrm{D}, 7 \mathrm{C}, 9 \mathrm{D}, 11 \mathrm{D}, 12 \mathrm{C}, 14 \mathrm{D}$, 15C, 17D, 18C, 20D, 21D, 23B, D, F, H, 29B, D, F, H, J, 33D, 34C, tables 1, 2, 4

Cryptostemma feae Hansen, 1921: 26-31, pl. 2, figs. 3a-c, pl. 3, figs. 1a-i; 1930: unpaginated, pl.1, fig. 11, unpaginated, pl. 15, fig. $9 \mathrm{~b}$.

Ricinoides feae (Hansen, 1921): Kästner, 1932: 113, fig. 153; Bolívar y Pieltain, 1942: 201; Millot, 1945a: 72-74, figs. 1-3; 1945b: 1-29, figs. 1-34; 1949a: figs. 54a-c, 62, 79, 83, 90, 92; 1949b: 744-757, figs. 529-551; Zakhvatkin, 1952: 43, fig. 29b; Dubinin, 1962: 443, fig. 1287; Tuxen, 1974: 96-98, figs. 18-23; Dumitresco and Juvara-Balş, 1977a: 260, fig. 1; 1977b: 176, 177, figs. 12a, b, 13a-e; Selden and Dunlop, 1998: 305, fig. 7.1; Harvey, 2003: 183.

Type Material Examined: Cryptostemma feae: Lectotype ồ (MSNG) [here designated], GUINEA- 
BISSAU: Rio Cassine [Tombali Region: Rio Cacine, $\left.11^{\circ} 00^{\prime} \mathrm{N} 15^{\circ} 09^{\prime} \mathrm{W}\right]$, Guinea Portoghese, i-iv. 1900 , L. Fea. The vial containing the lectotype includes a microvial with the detached sinistral copulatory apparatus. Paralectotypes: 9 ô, 13 \&, 27 tritonymphs, 3 deutonymphs, 3 protonymphs (MSNG), same data as lectotype; 4 o, 6 ․, 12 tritonymphs, 13 deutonymphs, 8 protonymphs (MSNG), Bolama [Bolama Region: $11^{\circ} 34^{\prime} 37^{\prime \prime} \mathrm{N}$ $\left.15^{\circ} 28^{\prime} 44^{\prime \prime} \mathrm{W}\right]$, Guinea Portoghese, vi-xii.1899, L. Fea; 2 larvae (MSNG), Bolama, Guinea Portoghese, L. Fea; 2 đ, 4 tritonymphs, 1 deutonymph, 1 protonymph (ZMUC), Rio Cacine, Guinea Portoghese, i-iv.1900, L. Fea; 1 tritonymph (ZMUC), Rio Cacine, Guinea Portoghese, i-iv.1900, L. Fea; 1 ô (ZMUC), Rio Cacine, Guinea Portoghese, iiv.1900, L. Fea; 1 ㅇ (ZMUC), Rio Cacine, Guinea Portoghese, i-iv.1900, L. Fea; 1 đ (MSNG), Rio Cacine, Guinea Portoghese, i-iv.1900, L. Fea.

Diagnosis: Ricinoides feae differs from the other eight species in the unique structure of the fixed process of the male copulatory apparatus (figs. 29B, D, F, H, J, 33D), which features several distinctive characters, including the laterally compressed $\alpha$ lobe, the wide separation of $\beta_{1}$ and $\beta_{2}$ of the $\beta$ lobe, the $p d$ lobe expressed as a moderately broad elevated surface, and the $r d$ lobe comprising a cluster of small spines (table 2 ), none of which is shared with the other species. Additionally, $R$. feae is the only species in which the median sclerite of tergite XIII is noticeably longer than wide (figs. 14D, 15C), the sclerite being wider than long or as long as wide in the other species. Ricinoides feae differs further from all other species, except $R$. westermannii, in the relatively unmodified pedipalp tibia (fig. 20D), which is markedly robust in the other species, and in the width of the opening of the pygidium basal segment, which is approximately two fifths the lateral width of the segment at its base, but narrower laterally in the other species. The male of $R$. feae differs from the male of $R$. westermannii in several respects, including the presence of a large ventromedian apophysis on the tibia of leg II in $R$. feae (fig. $23 \mathrm{~F}$ ), which is absent in $R$. westermannii.
Redescription of Male: Based on the lectotype (MSNG).

Measurements: Total length $6.45 \mathrm{~mm}$ (table 4).

Coloration: Soma and appendages red (fig. 1). Carapace dorsolateral translucent areas yellowish. Opisthosomal tergal and pleural membranes yellow, hyaline. Cheliceral manus yellow; fingers, finger dentition, and manus toothlike process dark.

Setation: Surfaces densely covered with short, translucent, bristlelike setae, length similar to height of surrounding tuberose granules (figs. 6D, 14D). Polygonal setae absent.

Tegument surface macrosculpture: Tegument moderately irregular, without cuticular pits. Carapace, cucullus, lateral margins of opisthosomal tergites, legs (except for prolateral and retrolateral surfaces of leg II femur), and, to lesser extent, coxal region covered with coarse, rounded tuberose granules, evenly spaced apart, not clustered together (figs. 6D, 9D, 11D, 14D, 21D, 23B, D, F, H). Opisthosoma without distinct tubercles; entire dorsal surface and sternite XIII coarsely granular, some granules grouped together or touching others but not distinctly clustered (figs. 14D, 17D); remainder of opisthosomal ventral surface, leg II femur prolateral and retrolateral surfaces, and pleural membranes finely and densely granular; tergal membranes more sparsely granular. Pedipalp femur dorsal, prolateral, and retrolateral surfaces finely granular; tibia with elevated oval tubercles distally (fig. 20D), not noticeably enlarged or arranged in distinct rows.

Carapace: Carapace longer than wide, broadest between coxae of legs II and III; trapezoidal, lateral margins curved, narrowing anteriorly (fig. $6 \mathrm{D})$; anterior margin linear in dorsal aspect; posterior margin slightly procurved; median longitudinal sulcus, paired posterior marginal transverse sulci, and paired anterolateral longitudinal sulci distinct; paired lateral depressions aligned with coxae of legs II; posteromedian moundlike excrescence absent; dorsolateral translucent areas entirely smooth, medium sized, aligned with intersection between coxae of legs I and II, visible in dorsolateral aspect. 


\section{TABLE 4}

Measurements (mm) for Three Species of West African Ricinulei: Ricinoides feae (Hansen, 1921), Ricinoides iita, sp. nov., and Ricinoides kakum, sp. nov.

Material deposited in the Museo Civico di Storia Naturale "Giacomo Doria" (MSNG), Genoa, Italy, the U.S. National Museum of Natural History (USNM), Smithsonian Institution, Washington, DC, and the Musée Royal de l'Afrique Centrale (MRAC), Tervuren, Belgium. Abbreviations: L, length; W, width; $\mathrm{H}$, height.

\begin{tabular}{|c|c|c|c|c|c|c|}
\hline \multirow[b]{2}{*}{$\begin{array}{l}\text { Type / sex } \\
\text { Collection }\end{array}$} & & \multicolumn{2}{|c|}{ R. feae } & \multirow{2}{*}{$\begin{array}{c}R \text {. iita } \\
\text { Holotype ôे } \\
\text { USNM }\end{array}$} & \multicolumn{2}{|c|}{ R. kakum } \\
\hline & & $\begin{array}{c}\text { Lectotype } \delta \\
\text { MSNG }\end{array}$ & $\begin{array}{c}\text { Paralectotype } q \\
\text { MSNG }\end{array}$ & & $\begin{array}{c}\text { Holotype } \delta \\
\text { MRAC } \\
217.183 \\
\end{array}$ & $\begin{array}{c}\text { Paratype } 9 \\
\text { MRAC } \\
217.183 \\
\end{array}$ \\
\hline Total body $\mathrm{L}^{1}$ & & 6.4 & 6.2 & 9.7 & 8.1 & 8.0 \\
\hline \multirow[t]{2}{*}{ Cucullus } & $\mathrm{L}$ & 1.3 & 1.2 & 2.3 & 1.8 & 1.8 \\
\hline & $\mathrm{W}^{2}$ & 1.9 & 1.8 & 3.4 & 2.9 & 2.8 \\
\hline \multirow[t]{2}{*}{ Carapace } & $\mathbf{L}$ & 2.4 & 2.2 & 3.3 & 2.9 & 2.9 \\
\hline & $\mathrm{W}^{2}$ & 2.3 & 2.4 & 3.5 & 3.2 & 3.3 \\
\hline \multirow[t]{2}{*}{ Opisthosoma } & $\mathbf{L}^{1}$ & 4.0 & 4.0 & 6.4 & 5.2 & 5.1 \\
\hline & $W^{2}$ & 2.7 & 2.9 & 4.6 & 3.7 & 4.0 \\
\hline \multirow[t]{2}{*}{ Median sclerite XI } & $\mathbf{L}$ & 1.3 & 1.2 & 2.2 & 1.8 & 1.7 \\
\hline & $W^{2}$ & 1.7 & 1.9 & 3.3 & 2.4 & 2.8 \\
\hline \multirow[t]{2}{*}{ Median sclerite XII } & $\mathrm{L}$ & 1.3 & 1.1 & 2.0 & 1.6 & 1.5 \\
\hline & $\mathrm{W}^{2}$ & 1.3 & 1.5 & 2.7 & 2.1 & 2.3 \\
\hline \multirow[t]{2}{*}{ Median sclerite XIII } & $L$ & 1.2 & 1.3 & 2.0 & 1.5 & 1.5 \\
\hline & $\mathrm{W}^{2}$ & 1.0 & 1.1 & 2.0 & 1.8 & 1.8 \\
\hline \multirow[t]{4}{*}{ Pedipalp } & Femur L & 1.1 & 1.1 & 1.4 & 1.4 & 1.4 \\
\hline & Femur $\mathrm{H}^{3}$ & 0.5 & 0.5 & 0.7 & 0.7 & 0.6 \\
\hline & Tibia L & 1.7 & 1.7 & 2.2 & 2.2 & 2.2 \\
\hline & Tibia $\mathrm{H}^{4}$ & 0.2 & 0.2 & 0.3 & 0.3 & 0.3 \\
\hline \multirow[t]{7}{*}{ Leg I } & Femur L & 1.3 & 1.1 & 2.0 & 1.7 & 1.6 \\
\hline & Femur $\mathrm{W}^{4}$ & 0.6 & 0.4 & 0.9 & 0.7 & 0.6 \\
\hline & Femur $\mathrm{H}^{4}$ & 0.7 & 0.5 & 1.0 & 0.8 & 0.6 \\
\hline & Patella L & 1.2 & 0.9 & 1.6 & 1.3 & 1.3 \\
\hline & Tibia L & 0.8 & 0.8 & 1.1 & 1.1 & 1.2 \\
\hline & Metatarsus L & 1.4 & 1.3 & 2.1 & 1.9 & 1.9 \\
\hline & Tarsus L & 0.6 & 0.5 & 0.7 & 0.6 & 0.6 \\
\hline \multirow[t]{7}{*}{ Leg II } & Femur L & 2.5 & 2.1 & 3.4 & 3.4 & 2.9 \\
\hline & Femur $\mathrm{W}^{4}$ & 1.0 & 0.4 & 1.3 & 1.4 & 0.5 \\
\hline & Femur $\mathrm{H}^{4}$ & 1.6 & 0.6 & 1.6 & 1.7 & 0.7 \\
\hline & Patella L & 1.6 & 1.3 & 2.1 & 2.0 & 1.6 \\
\hline & Tibia L & 1.4 & 1.4 & 2.0 & 2.0 & 2.0 \\
\hline & Metatarsus L & 2.2 & 2.1 & 3.1 & 2.8 & 2.7 \\
\hline & Tarsus L & 2.2 & 2.0 & 2.6 & 2.6 & 2.4 \\
\hline \multirow[t]{7}{*}{ Leg III } & Femur L & 1.7 & 1.4 & 2.7 & 2.3 & 2.0 \\
\hline & Femur $\mathrm{W}^{4}$ & 0.5 & 0.4 & 0.9 & 0.6 & 0.5 \\
\hline & Femur $\mathrm{H}^{4}$ & 0.5 & 0.5 & 0.9 & 0.6 & 0.6 \\
\hline & Patella L & 1.0 & 0.9 & 1.6 & 1.4 & 1.2 \\
\hline & Tibia L & 0.9 & 0.7 & 1.5 & 1.5 & 1.2 \\
\hline & Metatarsus L & 1.3 & 1.2 & 2.0 & 1.9 & 1.6 \\
\hline & Tarsus L & 1.9 & 1.1 & 2.2 & 2.4 & 1.5 \\
\hline \multirow[t]{7}{*}{ Leg IV } & Femur L & 1.8 & 1.7 & 2.7 & 2.4 & 2.3 \\
\hline & Femur $\mathrm{W}^{4}$ & 0.5 & 0.3 & 0.9 & 0.6 & 0.4 \\
\hline & Femur $\mathrm{H}^{4}$ & 0.5 & 0.4 & 1.1 & 0.7 & 0.6 \\
\hline & Patella L & 1.0 & 1.0 & 1.6 & 1.4 & 1.3 \\
\hline & Tibia L & 0.8 & 0.8 & 1.3 & 1.2 & 1.3 \\
\hline & Metatarsus L & 1.3 & 1.3 & 1.9 & 1.7 & 1.9 \\
\hline & Tarsus L & 1.4 & 1.2 & 1.8 & 1.7 & 1.6 \\
\hline
\end{tabular}

${ }^{1}$ Excludes pygidium and cucullus

${ }^{2}$ Maximum width.

${ }^{3}$ Maximum height.

${ }^{4}$ Midline. 
A

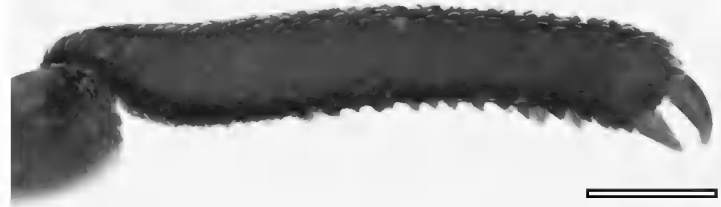

C

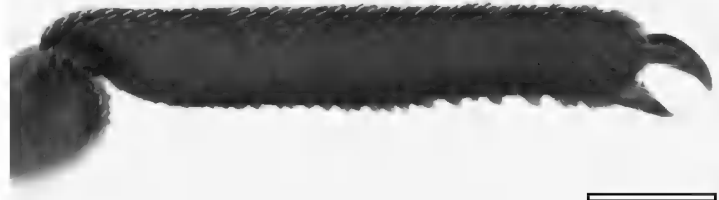

E
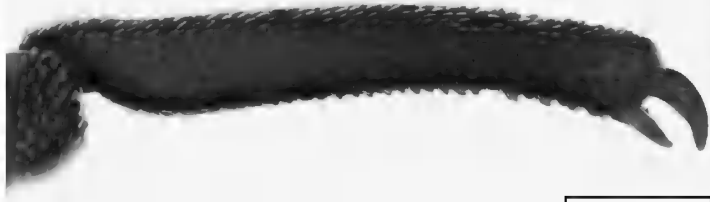

G

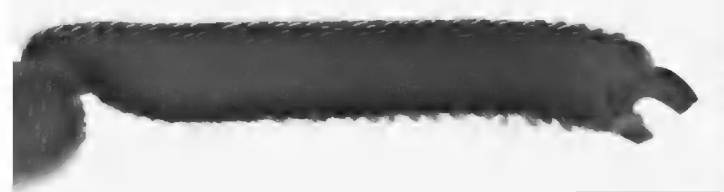

I
B

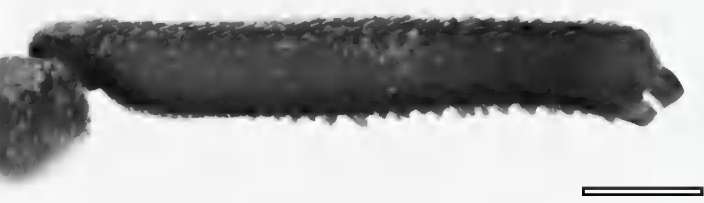

D

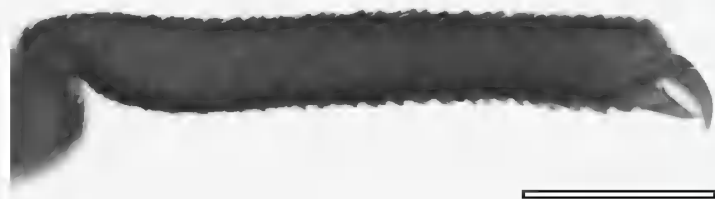

$\mathbf{F}$

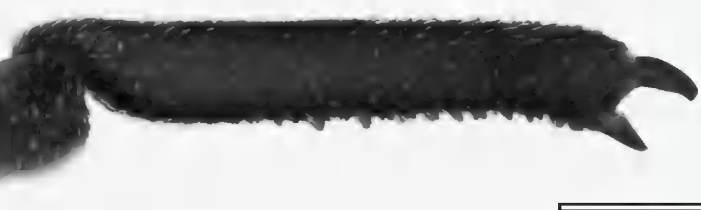

H

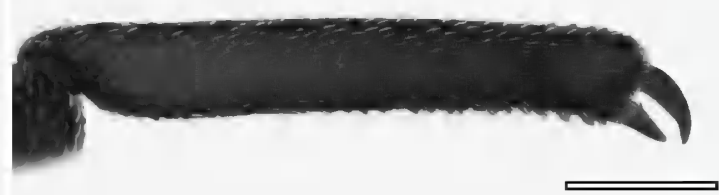

FIGURE 20. Ricinoides Ewing, 1929, pedipalp tibia, prolateral aspect. A. Ricinoides afzelii (Thorell, 1892), $\widehat{0}$ (BMNH 13588948). B. Ricinoides atewa Naskrecki, 2008, holotype ơ (AMNH IZC 324855). C. Ricinoides eburneus, sp. nov., holotype $\delta$ (MRAC 230.162). D. Ricinoides feae (Hansen, 1921), lectotype $\delta$ (MSNG). E. Ricinoides iita, sp. nov., holotype ô (USNM). F. Ricinoides kakum, sp. nov., holotype ôे (MRAC 217.183). G. Ricinoides nzerekorensis, sp. nov., holotype ô (MRAC 209.266). H. Ricinoides taii, sp. nov., holotype ô (MRAC 233.458). I. Ricinoides westermannii (Guérin-Méneville, 1838), neotype ô (ZMB 7013). Scale bars $=0.5 \mathrm{~mm}$. 
A
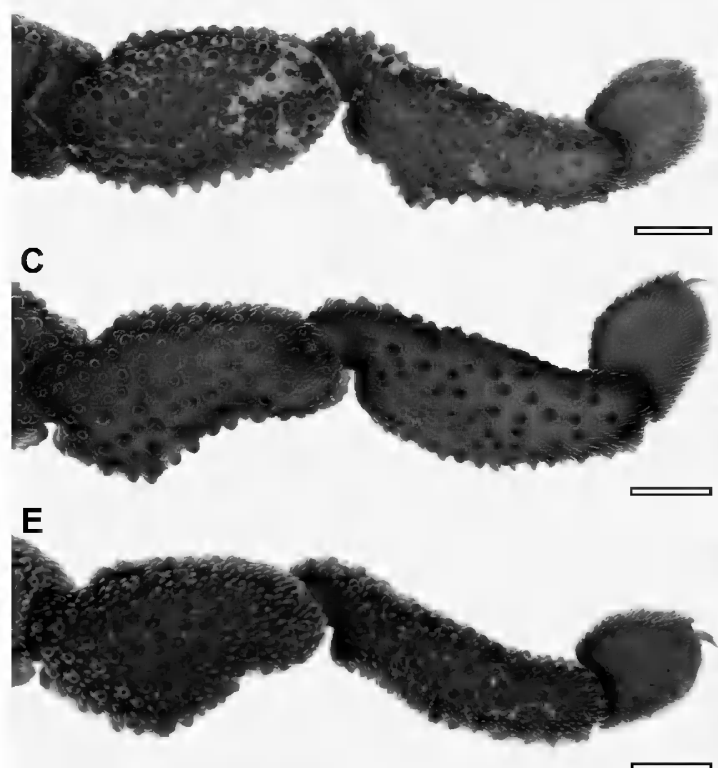

G
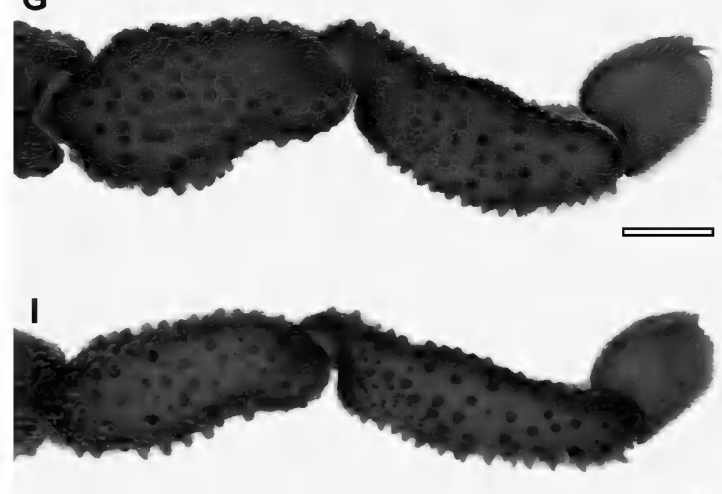

B
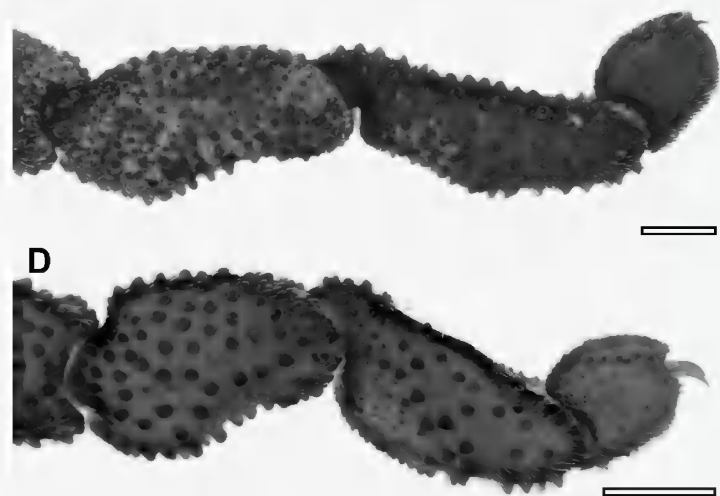

$\mathbf{F}$

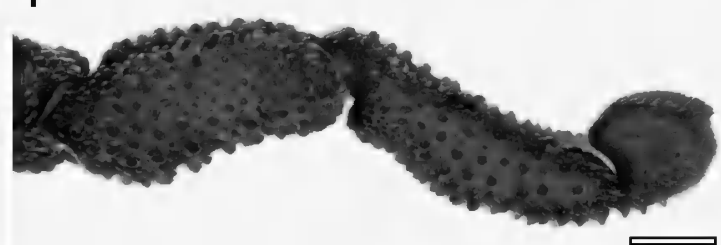

H

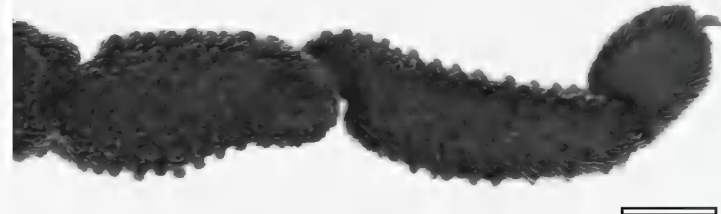

FIGURE 21. Ricinoides Ewing, 1929, leg I distal segments, prolateral aspect. A. Ricinoides afzelii (Thorell, 1892), ơ (BMNH 13588948). B. Ricinoides atewa Naskrecki, 2008, holotype ơ (AMNH IZC 324855). C. Ricinoides eburneus, sp. nov., holotype ô (MRAC 230.162). D. Ricinoides feae (Hansen, 1921), lectotype $\widehat{\delta}$ (MSNG). E. Ricinoides iita, sp. nov., holotype ơ (USNM). F. Ricinoides kakum, sp. nov., holotype ô (MRAC 217.183). G. Ricinoides nzerekorensis, sp. nov., holotype $\delta$ (MRAC 209.266). H. Ricinoides taii, sp. nov., holotype ô (MRAC 233.458). I. Ricinoides westermannii (Guérin-Méneville, 1838), neotype ô (ZMB 7013). Scale bars $=0.5 \mathrm{~mm}$. 

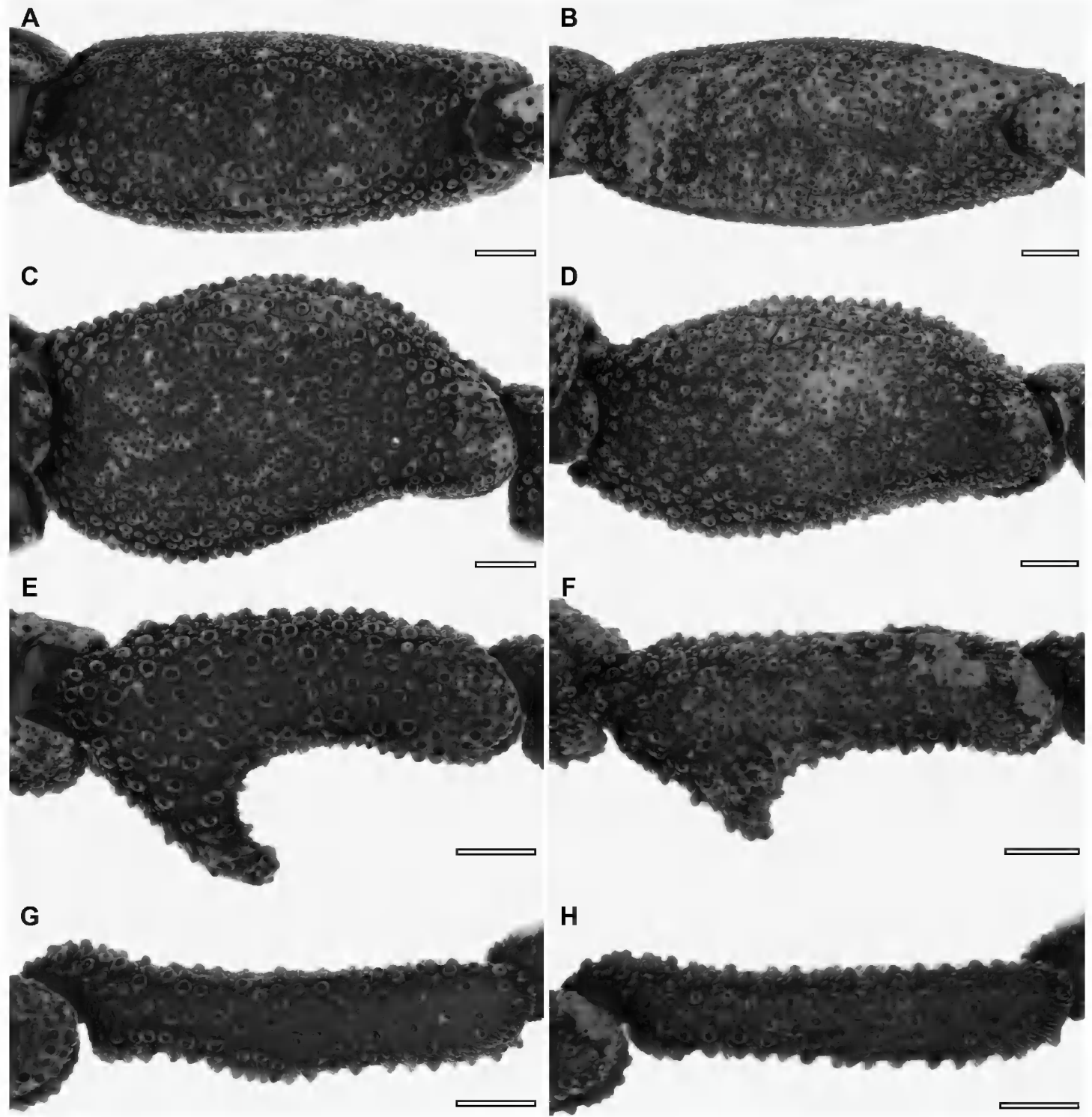

FIGURE 22. Ricinoides Ewing, 1929, leg II femur, dorsal (A, B) and prolateral (C, D) aspects, tibia, prolateral aspect (E, F), and metatarsus, prolateral aspect (G, H). A, C, E, G. Ricinoides afzelii (Thorell, 1892), ồ (BMNH 13588948). B, D, F, H. Ricinoides atewa Naskrecki, 2008, holotype ô (AMNH IZC 324855). Scale bars $=0.5 \mathrm{~mm}$. 


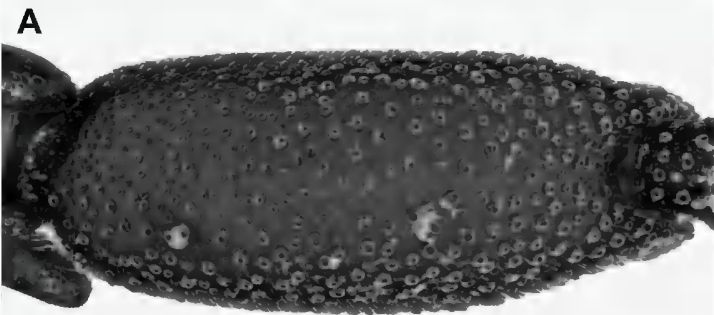

B
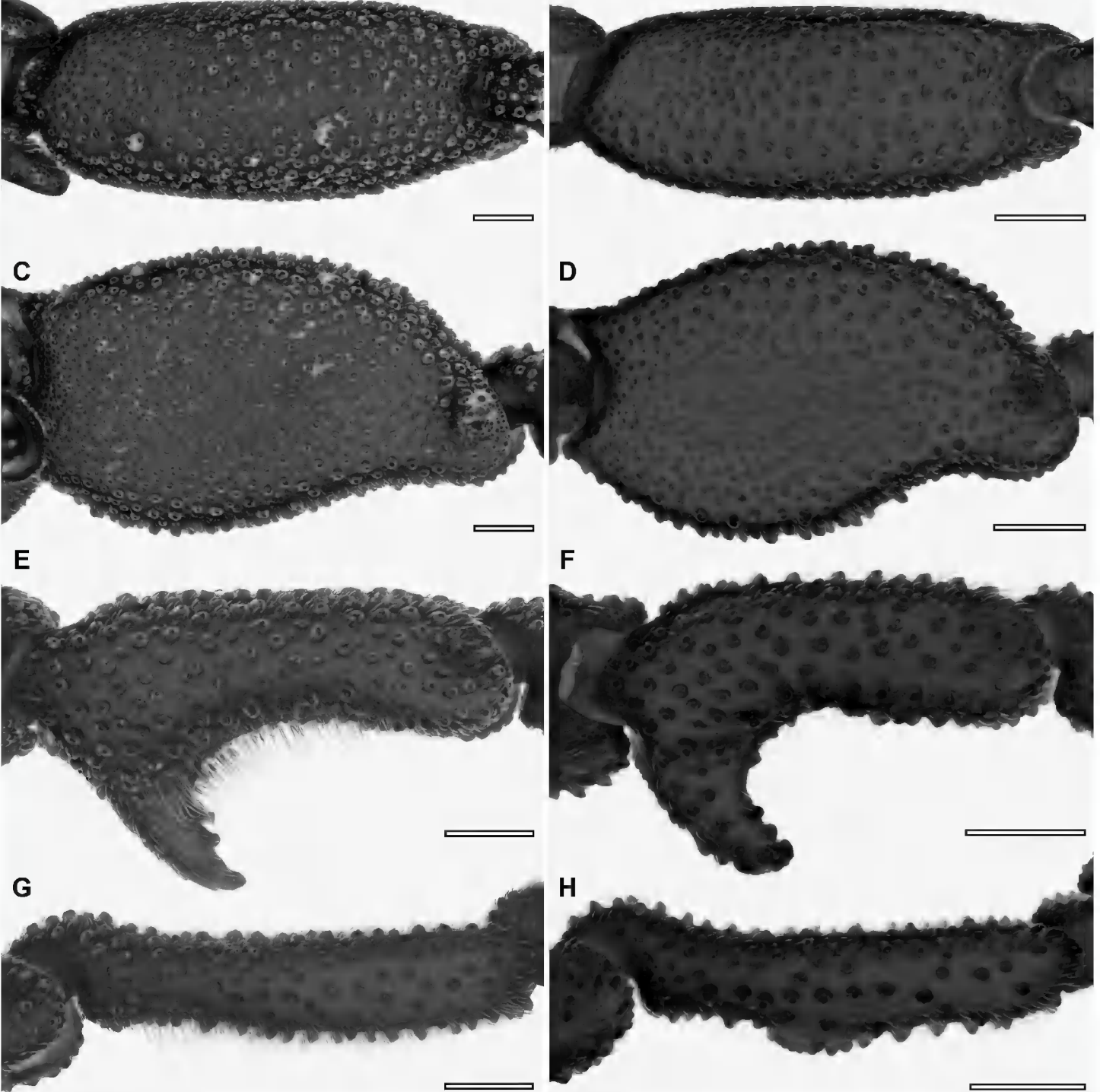

FIGURE 23. Ricinoides Ewing, 1929, leg II femur, dorsal (A, B) and prolateral (C, D) aspects, tibia, prolateral aspect (E, F), and metatarsus, prolateral aspect (G, H). A, C, E, G. Ricinoides eburneus, sp. nov., holotype $\delta$ (MRAC 230.162). B, D, F, H. Ricinoides feae (Hansen, 1921), lectotype ơ (MSNG). Scale bars $=0.5 \mathrm{~mm}$. 

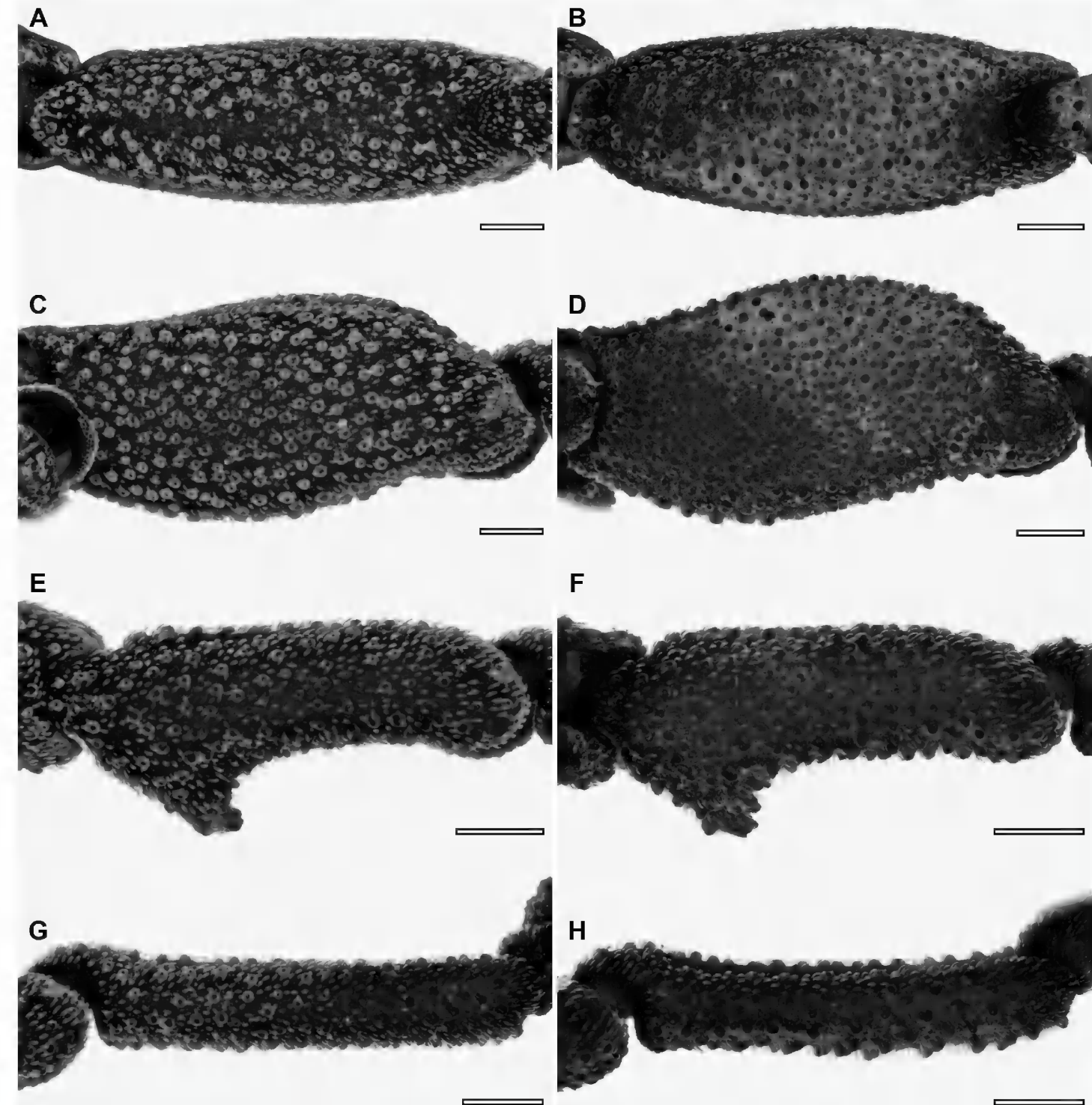

$\mathbf{F}$
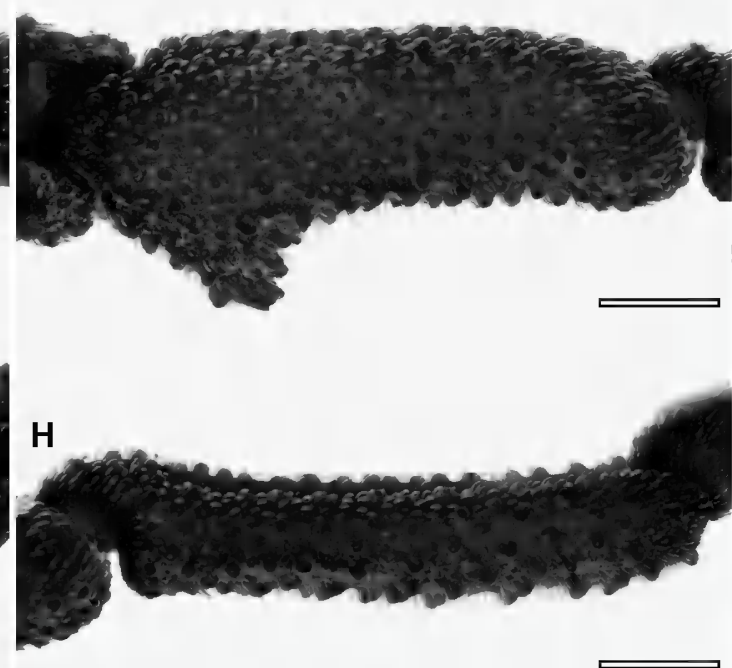

FIGURE 24. Ricinoides Ewing, 1929, leg II femur, dorsal (A, B) and prolateral (C, D) aspects, tibia, prolateral aspect $(\mathbf{E}, \mathbf{F})$, and metatarsus, prolateral aspect $(\mathbf{G}, \mathbf{H}) . \mathbf{A}, \mathbf{C}, \mathbf{E}, \mathbf{G}$. Ricinoides iita, sp. nov., holotype $\sigma^{\hat{\sigma}}$ (USNM). B, D, F, H. Ricinoides kakum, sp. nov., holotype ô (MRAC 217.183). Scale bars $=0.5 \mathrm{~mm}$. 

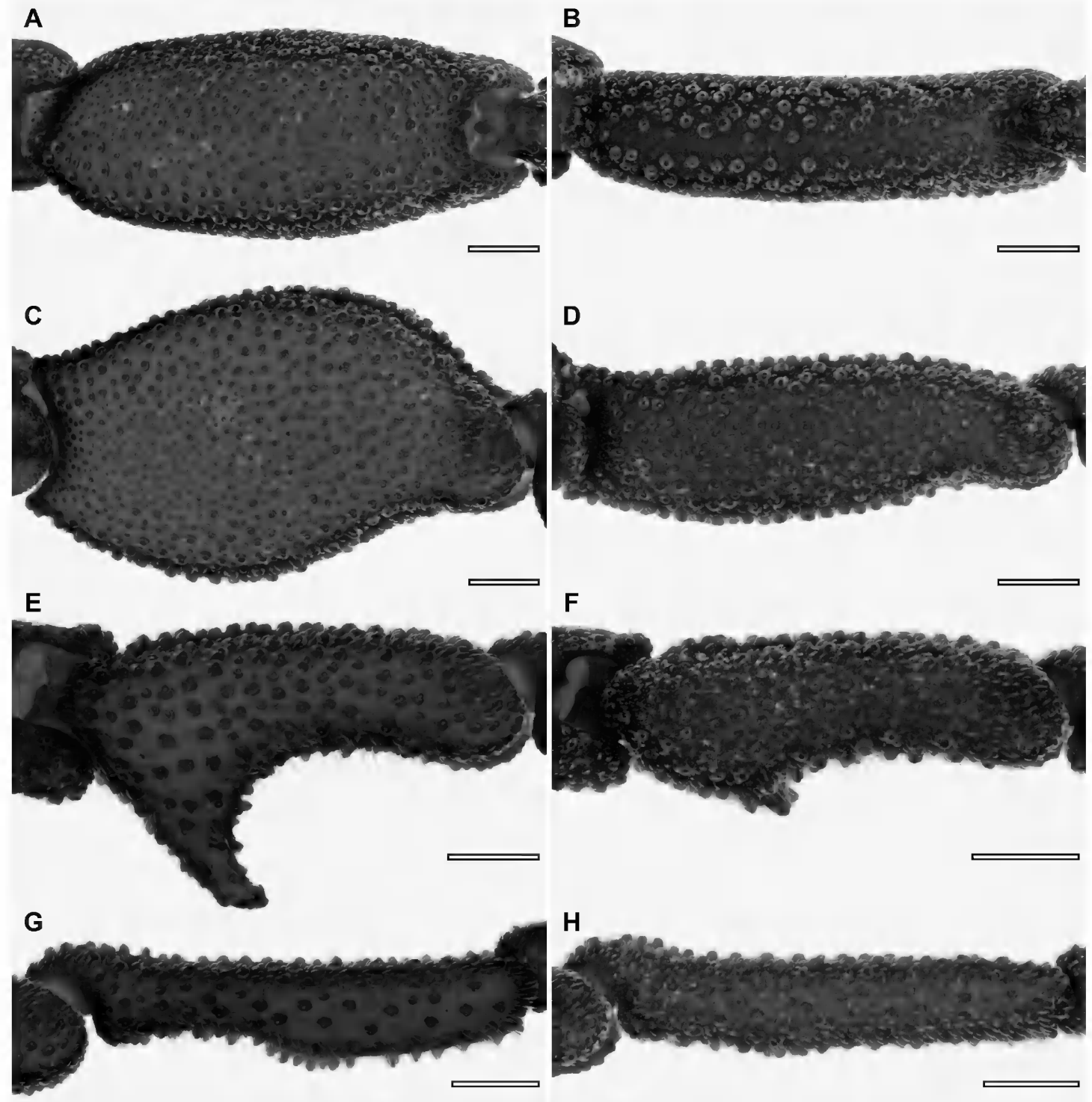

FIGURE 25. Ricinoides Ewing, 1929, leg II femur, dorsal (A, B) and prolateral (C, D) aspects, tibia, prolateral aspect (E, F), and metatarsus, prolateral aspect (G, H). A, C, E, G. Ricinoides nzerekorensis, sp. nov., holotype to (MRAC 209.266). B, D, F, H. Ricinoides taii, sp. nov., holotype ô (MRAC 233.458). Scale bars $=0.5 \mathrm{~mm}$. 


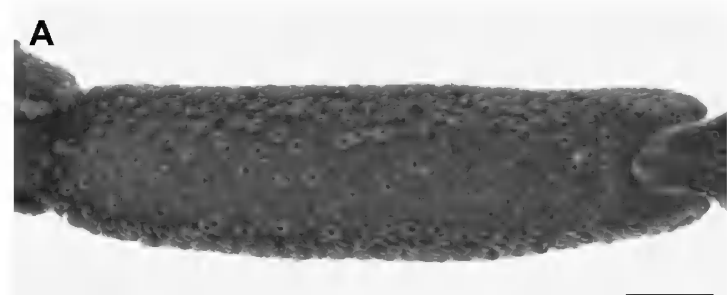

B
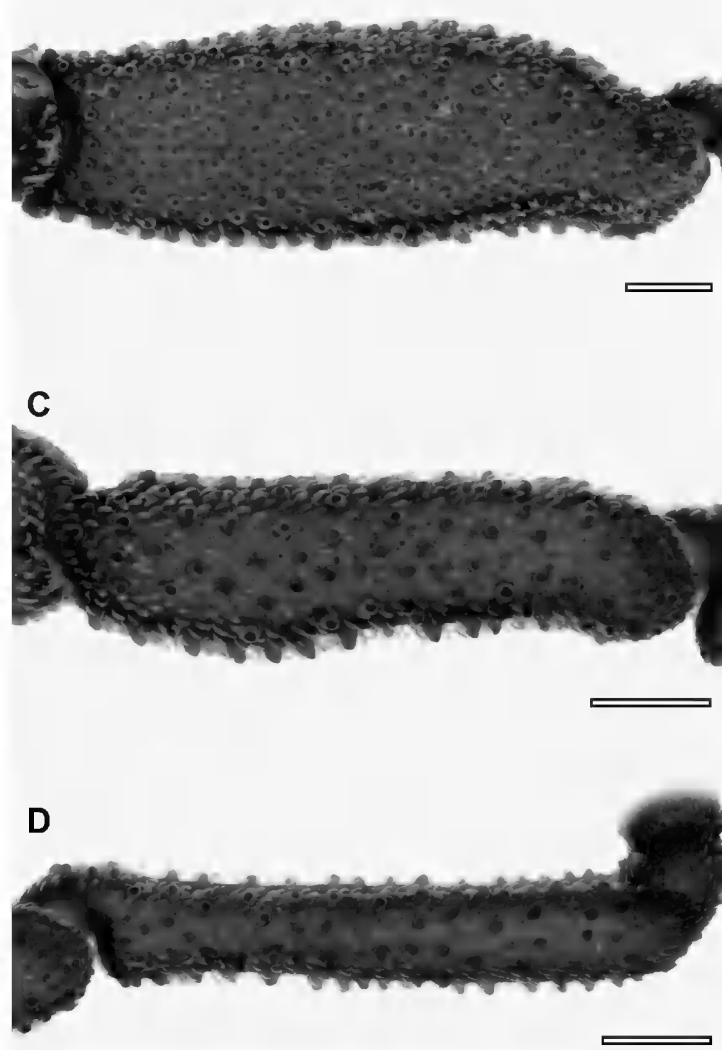

FIGURE 26. Ricinoides westermannii (Guérin-Méneville, 1838), neotype ô (ZMB 7013), leg II femur, dorsal (A) and prolateral (B) aspects, tibia, prolateral aspect $(\mathbf{C})$, and metatarsus, prolateral aspect (D). Scale bars $=0.5 \mathrm{~mm}$.
Cucullus: Cucullus broadened laterally, wider than long; ventrolateral margins rounded (fig. 9D); ventral margin predominantly linear in anterior aspect, shallowly bilobate in ventral aspect, posterior surface with median row of small denticulations; anterior surface shallowly convex, without ventral compressed surface; pair of moderately developed sublateral longitudinal sulci; ventral part unmodified anteromedially.

Chelicerae: Manus dorsal surface with medium-sized toothlike process distally. Movable finger longer than fixed finger, tooth row comprising seven small teeth; sharp prodorsal longitudinal carina parallel to tooth row (opposite fixed finger); mucron with shallow but distinct prolateral excavation (opposite fixed finger) delimited by two parallel longitudinal carinae. Fixed finger tooth row comprising four small teeth, distalmost larger but not markedly so.

Coxosternal region: Tritosternum very small, barely visible, not abutting coxae of legs I (fig. 11D); coxae of legs II and IV abutting one another medially along entire length, coxae of legs III slightly separated medially; coxae of legs II, anterior and posterior margins subparallel, not perpendicular to median axis, slightly inclined anteriorly; coxae of legs II, posterior margin V-shaped medially; suture between coxae of legs II approximately $4 \times$ length of suture between coxae of legs III and IV.

Opisthosoma: Opisthosoma oblong, elongate. Posterodorsal and posteroventral margins without spiniform granules (figs. 14D, 17D) but with some tuberose granules. Tergites X-XIII each comprising median and lateral sclerites; median sclerites of tergites XI-XIII each with paired, shallow submedian depressions near anterior margins; lateral margins of median sclerites converging posteriorly on tergite XI and, to lesser extent, XII, subparallel on XIII; median sclerite of tergite XI and, to lesser extent, XII wider than long, of XIII longer than wide, rectangular; margins of lateral sclerites adjacent to tergal longitudinal membranes predominantly linear, tergal membranes relatively broad. Sternites XI-XIII each with pair of shallow submedian depres- 


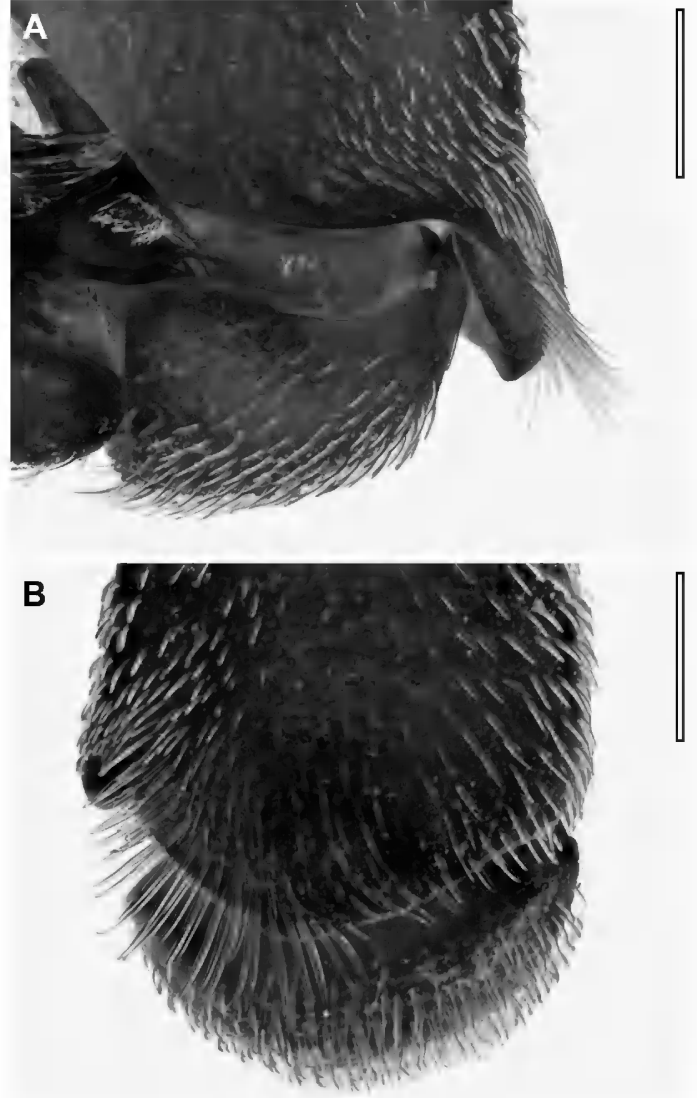

FIGURE 27. Ricinoides iita, sp. nov., holotype $\delta^{+}$ (USNM), leg III metatarsus, distal part, prolateral (A) and ventral (B) aspects. Scale bars $=0.25 \mathrm{~mm}$.

sions similar to tergites (fig. 17D). Pygidium, basal segment parallel to longitudinal axis of opisthosoma; opening narrow, slightly compressed laterally, width two fifths lateral width of segment at its base; posterior border narrow; dorsal surface with V-shaped notch; ventral surface with subtle notch.

Pedipalps: Femur globose, length approximately $2 \times$ depth. Tibia longer than femur; predominantly linear (fig. 20D); not noticeably robust but slightly swollen proximally; margins subparallel in lateral aspect, narrowing distally in dorsal aspect; apical longitudinal carinae absent. Movable finger approximately $2 \times$ length of fixed finger.

Legs: Leg II longest, femur markedly incrassate (figs. 23B, D). Legs III and IV femora nar- rowest and similar in width, femora width (at midline) increasing in order leg IV $\approx$ III $<$ I $<<$ II; dorsal surface with longitudinal sulcus most distinct on leg IV. Leg I tibia without ventral apophyses; metatarsus subcircular in cross section, with deep proventral depression in proximal half and without prominent ventral excrescence (fig. 21D). Leg II tibia with very large ventromedian apophysis proximally (fig. 23F), markedly hook shaped, with moderately acute apex, entirely covered with tuberose granules; tibia ventral surface with some moderately long setae but without distinct setal pad; metatarsus without ventrosubmedian concavity, with moderate subproximal depression and marked submedian excrescence ventrally (fig. $23 \mathrm{H}$ ); first to third tarsomeres short, subequal, fourth approximately $2 \times$ length of preceding tarsomeres; all tarsomeres movable. Leg III metatarsus not swollen, with moderate concavity dorsodistally; proventral surface without apical brushlike row of setae; prodorsal proximal sulcus present; metatarsus, metatarsal process, and tarsus precisely fitting together to completely encase copulatory apparatus when tarsus retracted; metatarsal process situated basally near tibia, robust, tapering and slightly laterally compressed, longitudinal axis sinuous, apex pointing retrolaterally; lamina cyathiformis of second tarsomere approximately as deep as long, with pointed apex; subdistal (third) tarsomere with acute dorsodistal process. Leg IV tarsus not swollen. Legs III and IV terminal tarsomere apex, dorsal margin sublinear, covering ungues. Leg I tarsus and legs IIIV terminal tarsomeres without ventrodistal papillae.

Copulatory apparatus: Fixed process, PL lobe relatively narrow and dorsoventrally compressed (figs. 29D, H). Distal lobular region, primary a lobe long, narrow, laterally compressed (figs. 29B, D, F, H, J, 33D); origin slightly prolateral, curving toward ventral surface; dorsal margin smooth, ventral margin slightly irregular. Primary $\beta$ lobe medium sized, distinctly bicuspid, with $\beta_{1}$ and $\beta_{2}$ pointed and widely separated. rsd 
lobe medium sized, pronounced, associated with distinct subdistal emargination. Secondary $p d$ lobe comprising moderately broad, elevated surface; secondary $r d$ lobe comprising cluster of approximately five small spines. Movable process slender, slightly flexible, narrowing distally; apex simple, entire.

Supplementary Description of Female: Based on paralectotypes stored with the lectotype (MSNG). Resembles male except as noted.

Measurements: Total length $6.24 \mathrm{~mm}$ (table 4).

Carapace: Carapace wider than long. Posteromedian moundlike excrescence absent (fig. 7C).

Cucullus: Ventrolateral margins rounded; ventral margin predominantly linear in anterior aspect.

Coxosternal region: Coxae of legs II and IV abutting one another medially along entire length, coxae of legs III abutting along anterior two thirds (fig. 12C); coxae of legs II, posterior margin V-shaped medially.

Opisthosoma: Opisthosoma oval, not as elongate as in male (figs. 15C, 18C). Tergites XI and XII, median sclerites wider than long; XIII, median sclerite longer than wide. Opening of basal segment of pygidium narrow, slightly compressed laterally.

Legs: Leg I metatarsus without proximal depression proventrally. Leg II femur unmodified, longer than but similar in shape to femora of other legs; tibia without ventromedian apophysis or long setae ventrally; metatarsus without subproximal depression or submedian excrescence ventrally.

Spermathecae: Anterior wall of bursa copula trix with pair of medium-sized, slightly pigmented, rounded areas. Anterior surface with eight hard sacculiform structures sinistrally and six dextrally, variable in size (fig. 34C). Spermathecae follicular, each comprising soft, elongate tube terminating in tapering duct, situated submedially on anterior surface of bursa copulatrix adjacent to dorsal margin. Posterior genital lip as in figure $34 \mathrm{C}$.

Distribution: The type series of $R$. feae originates from two localities in Guinea-Bissau (fig. 5),
Rio Cacine $\left(11^{\circ} 00^{\prime} \mathrm{N} 15^{\circ} 09^{\prime} \mathrm{W}\right)$, an estuarine area in the Tombali Region, and Bolama $\left(11^{\circ} 34^{\prime} 37^{\prime \prime} \mathrm{N}\right.$ $\left.15^{\circ} 28^{\prime} 44^{\prime \prime} \mathrm{W}\right)$, a city on the island of the same name, that is part of the Bolama-Bijagós Archipelago in the Bolama Region. Recent records of $R$. feae from the vicinity of Bambadinca, in the Bafatá Region (Murienne et al., 2013; Fernández and Giribet, 2015) were misidentified (see Ricinoides $\mathrm{sp}$.). A record of $R$. feae from Guinea (Harvey, 2003) requires confirmation.

\section{Ricinoides iita, sp. nov.}

Figures 5, 6E, 9E, 10C, 11E, 14E, 17E, 20E, 21E, 24A, C, E, G, 27, 30A, C, E, G, I, 33E, tables $1,2,4$

Type Material: Holotype ô (USNM), NIGERIA: Oyo: Ibaden [Ibadan], International Institute of Tropical Agriculture (I.I.T.A.) $\left[07^{\circ} 30^{\prime} \mathrm{N} 03^{\circ} 53^{\prime} \mathrm{E}\right]$, iv.1973, B. Critchley, pitfall. Two microvials contain the following detached pieces: sinistral leg I, dextral leg III, and copulatory apparatus.

Diagnosis: The male of $R$. iita resembles the males of $R$. afzelii, R. atewa, and R. kakum in the modified ventral part of the cucullus. It resembles the male of $R$. afzelii in possessing an apical brushlike row of yellowish setae on the proventral surface of the metatarsus of leg III (fig. 27) and the femur of leg IV being wider than the femur of leg III, and deeper than the femur of leg I, characters unique to the two species. The male of $R$. iita is unique among the four species in the anteromedian elevation on the cucullus (fig. 10C), the tubercles on the ventral surface of the pedipalp tibia not being noticeably enlarged or arranged in distinct rows (fig. 20E), the femur of leg IV being wider than the femur of leg I, and the femur of leg II being less incrassate (figs. 24A, C, table 4). Additionally, the structure of the fixed process of the male copulatory apparatus is unique in $R$. iita (figs. 30A, C, E, G, I, 33E), as the a lobe is subcircular in cross-section and curved retrolaterally, and $\beta_{2}$ of the $\beta$ lobe is fingerlike and larger 
than $\beta_{1}$ (table 2). Finally, the carapace of $R$. itta possesses the smallest dorsolateral translucent areas of the four species.

Eтymology: The specific epithet is a noun in apposition taken from the acronym of the type locality, the International Institute of Tropical Agriculture (I.I.T.A.), in Ibadan, Nigeria.

Description of Male: Based on the holotype (USNM).

Measurements: Total length $9.74 \mathrm{~mm}$ (table 4).

Coloration: Soma and appendages predominantly dark brown, almost black. Carapace dorsolateral translucent areas yellowish. Opisthosomal tergal and pleural membranes dark yellow, hyaline. Cheliceral manus yellow; fingers, finger dentition, and manus toothlike process dark.

Setation: Surfaces densely covered with short, translucent, bristlelike setae, slightly expanded but not navicular, length similar to height of surrounding tuberose granules (figs. 6E, 14E). Polygonal setae absent.

Tegument surface macrosculpture: Tegument very irregular, without cuticular pits. Carapace, cucullus, opisthosomal sclerites, legs, and, to lesser extent, coxal region covered with coarse, rounded tuberose granules, evenly spaced apart, not clustered together (figs. 6E, 9E, 11E, 14E, 21E, 24A, C, E, G). Opisthosoma, pleural membranes finely and densely granular; tergal membranes more sparsely granular. Pedipalp femur dorsal, prolateral, and retrolateral surfaces finely granular; tibia with elevated oval tubercles distally (fig. 20E), not noticeably enlarged or arranged in distinct rows.

Carapace: Carapace wider than long, broadest between coxae of legs II and III; trapezoidal, lateral margins curved, narrowing anteriorly (fig. $6 \mathrm{E})$; anterior margin linear in dorsal aspect; posterior margin slightly procurved; median longitudinal sulcus, paired posterior marginal transverse sulci, and paired anterolateral longitudinal sulci distinct; paired lateral depressions aligned with coxae of legs II; posteromedian moundlike excrescence absent; dorsolateral translucent areas entirely smooth, small, aligned with intersection between coxae of legs I and II, visible in dorsolateral aspect.
Cucullus: Cucullus broadened laterally, wider than long; ventrolateral margins rounded (fig. 9E); ventral margin predominantly linear in anterior aspect, shallowly bilobate in ventral aspect, posterior surface worn, unclear if median row of denticulations present; anterior surface shallowly convex, without ventral compressed surface; pair of moderately developed sublateral longitudinal sulci; ventral part with moderate anteromedian elevation, visible in ventral aspect (fig. 10C), anteromedian knoblike tubercle absent.

Chelicerae: Manus dorsal surface with large toothlike process distally. Movable finger longer than fixed finger, tooth row comprising six small teeth; sharp prodorsal longitudinal carina parallel to tooth row (opposite fixed finger); mucron with shallow but distinct prolateral excavation (opposite fixed finger) delimited by two parallel longitudinal carinae. Fixed finger tooth row comprising four small teeth.

Coxosternal region: Tritosternum very small, barely visible, not abutting coxae of legs I (fig. 11E); coxae of legs II and IV abutting one another medially along entire length, coxae of legs III abutting along anterior two-thirds; coxae of legs II, anterior and posterior margins almost parallel, slightly narrowing medially, not perpendicular to median axis, inclined anteriorly; coxae of legs II, posterior margin U-shaped medially; suture between coxae of legs II approximately $2 \times$ length of suture between coxae of legs III and IV.

Opisthosoma: Opisthosoma oval, longer than wide, broadest at tergite XII. Posterodorsal and posteroventral margins without spiniform granules (figs. 14E, 17E). Tergites X-XIII each comprising median and lateral sclerites; median sclerites of tergites XI-XIII each with paired, shallow submedian depressions near anterior margins; lateral margins of median sclerites converging posteriorly on tergite XI and, to lesser extent, XII, subparallel on XIII; median sclerites of tergites XI and XII wider than long, of XIII approximately as wide as long, square; margins of lateral sclerites adjacent to tergal longitudinal membranes predominantly linear, tergal membranes narrow. Sternites XI-XIII each with pair of shallow submedian depressions similar to 

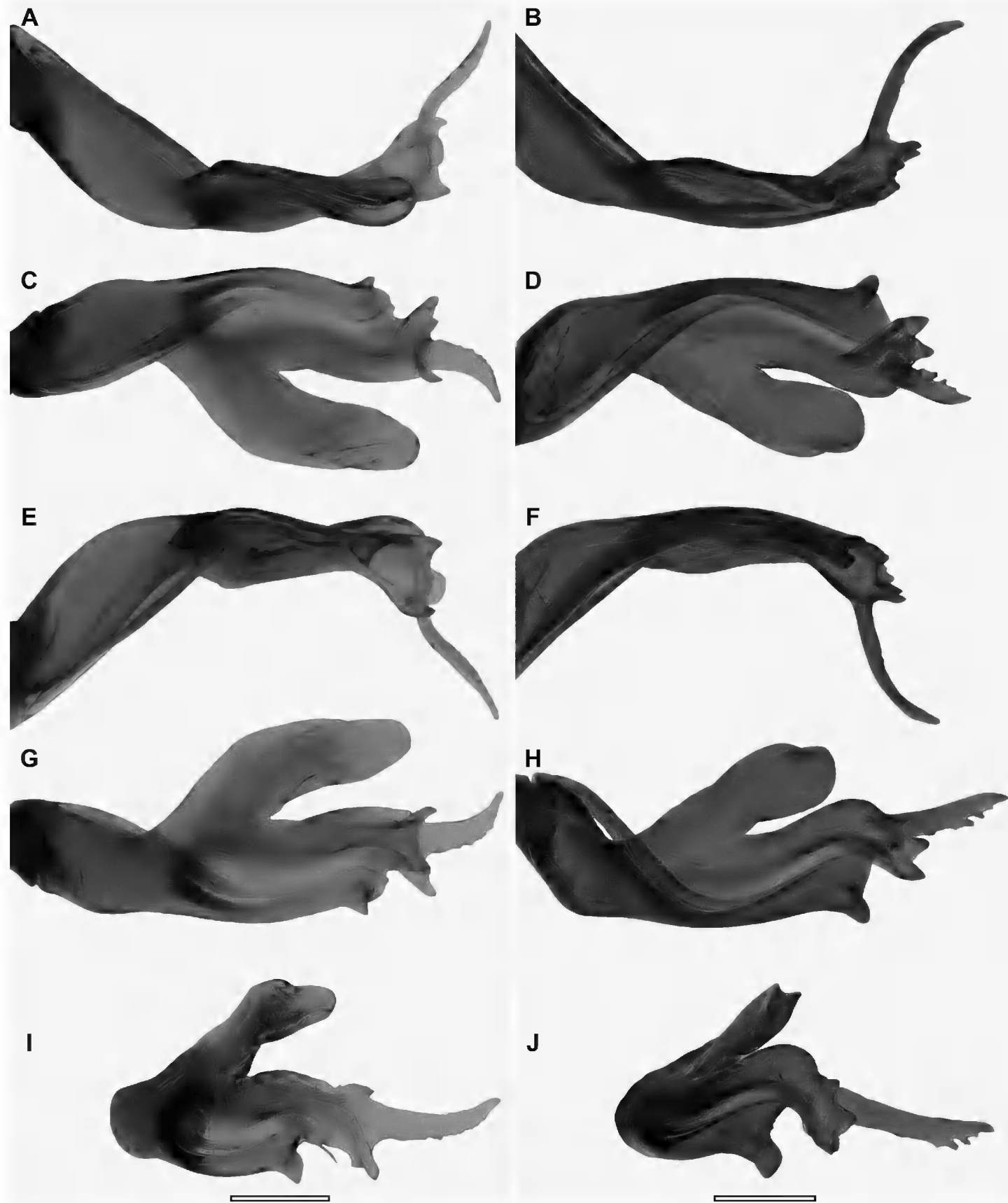

FIGURE 28. Ricinoides Ewing, 1929, leg III copulatory apparatus, prolateral (A, B), dorsal (C, D), retrolateral $(\mathbf{E}, \mathbf{F})$, ventral $(\mathbf{G}, \mathbf{H})$, and frontal $(\mathbf{I}, \mathbf{J})$ aspects. A, C, E, G, I. Ricinoides afzelii (Thorell, 1892), $\widehat{\sigma}$ (BMNH 13588948). B, D, F, H, J. Ricinoides atewa Naskrecki, 2008, holotype ơ (AMNH IZC 324855). Scale bars = $0.25 \mathrm{~mm}$. 

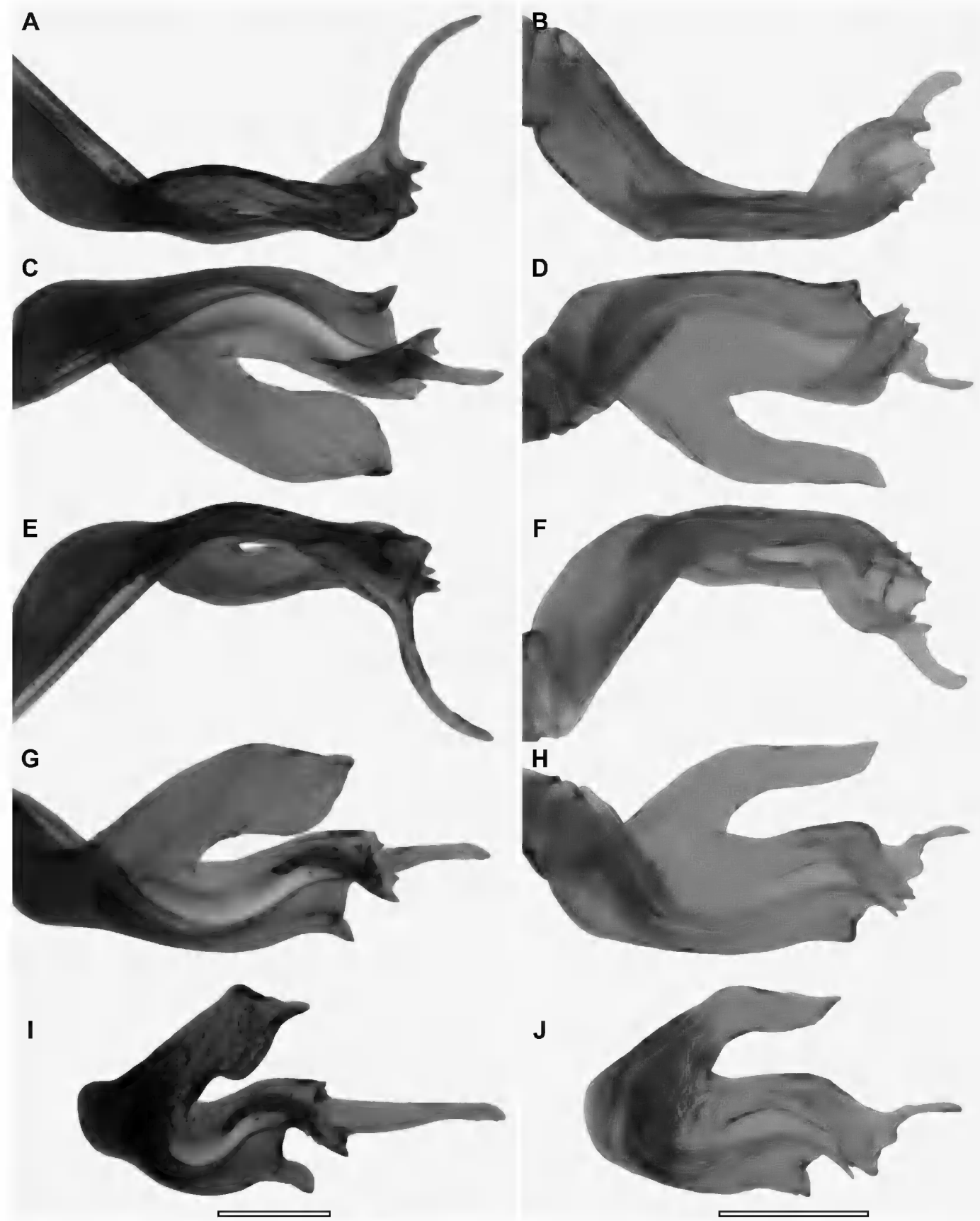

FIGURE 29. Ricinoides Ewing, 1929, leg III copulatory apparatus, prolateral (A, B), dorsal (C, D), retrolateral $(\mathbf{E}, \mathbf{F})$, ventral $(\mathbf{G}, \mathbf{H})$, and frontal $(\mathbf{I}, \mathbf{J})$ aspects. A, C, E, G, I. Ricinoides eburneus, sp. nov., holotype $\delta^{\star}$ (MRAC 230.162). B, D, F, H, J. Ricinoides feae (Hansen, 1921), lectotype ơ (MSNG). Scale bars $=0.25 \mathrm{~mm}$. 

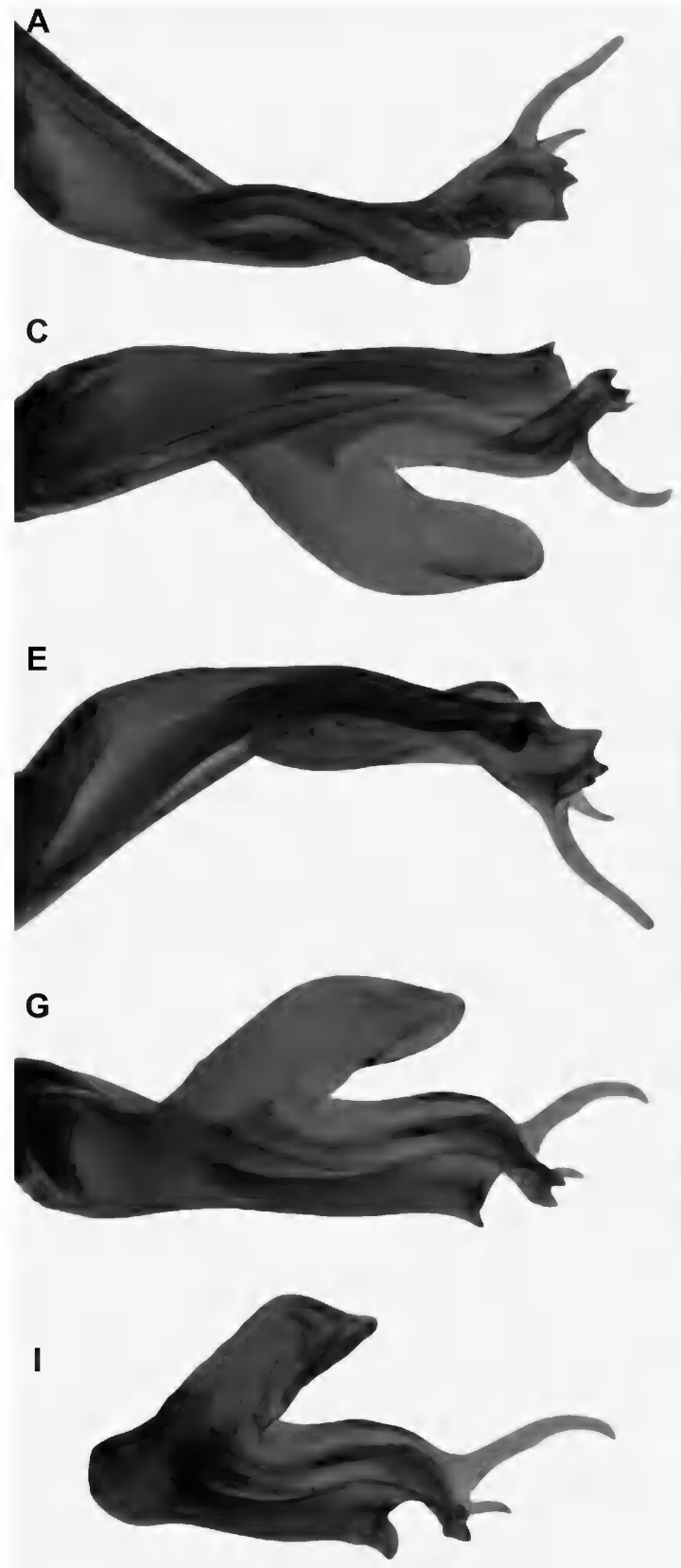

$\mathbf{J}$

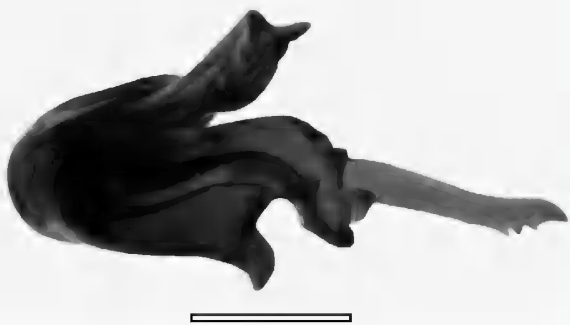

FIGURE 30. Ricinoides Ewing, 1929, leg III copulatory apparatus, prolateral (A, B), dorsal (C, D), retrolateral (E, F), ventral (G, H), and frontal (I, J) aspects. A, C, E, G, I. Ricinoides iita, sp. nov., holotype ô (USNM). B, D, F, H, J. Ricinoides kakum, sp. nov., holotype ơ (MRAC 217.183). Scale bars $=0.25 \mathrm{~mm}$. 

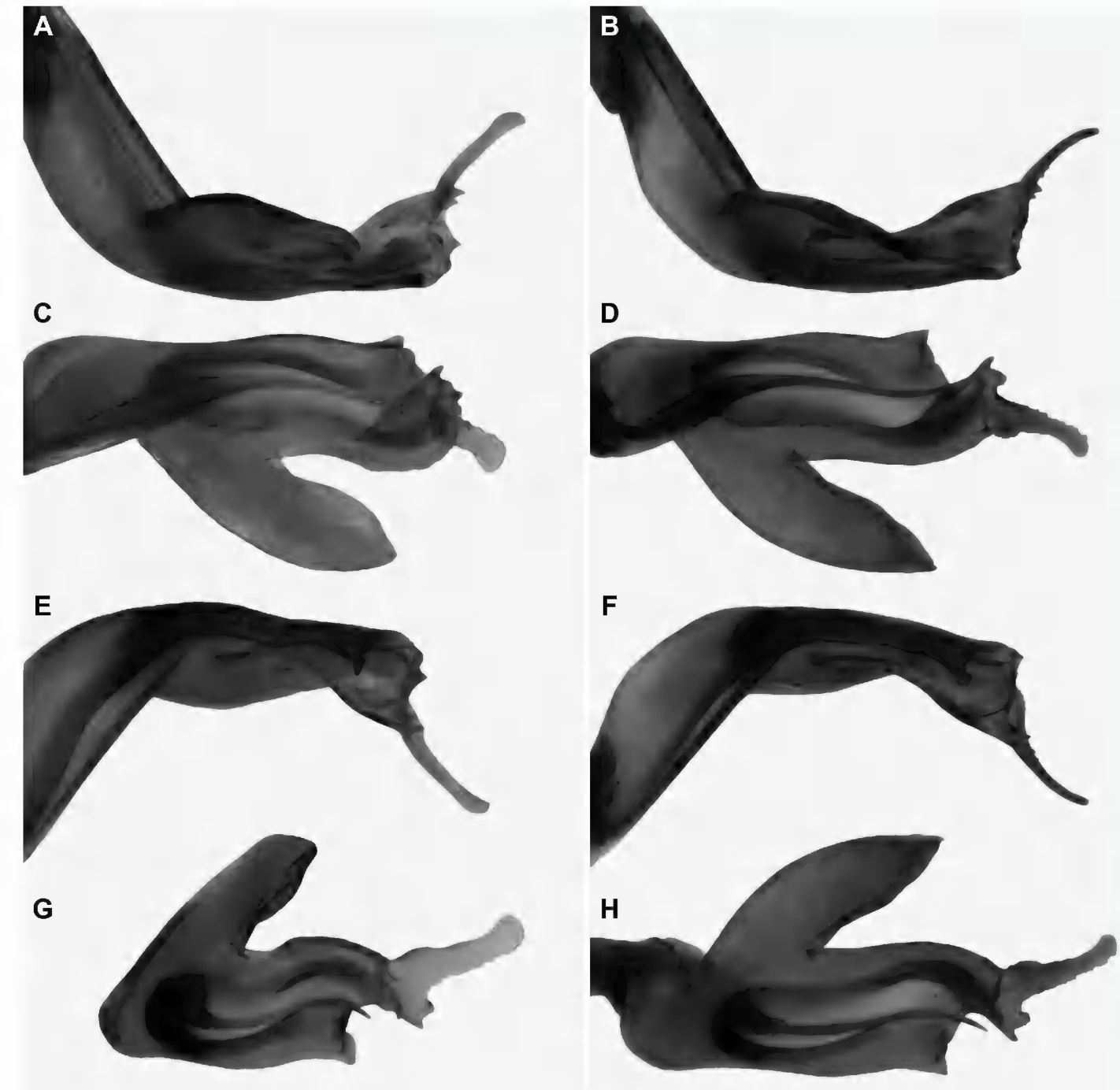

I
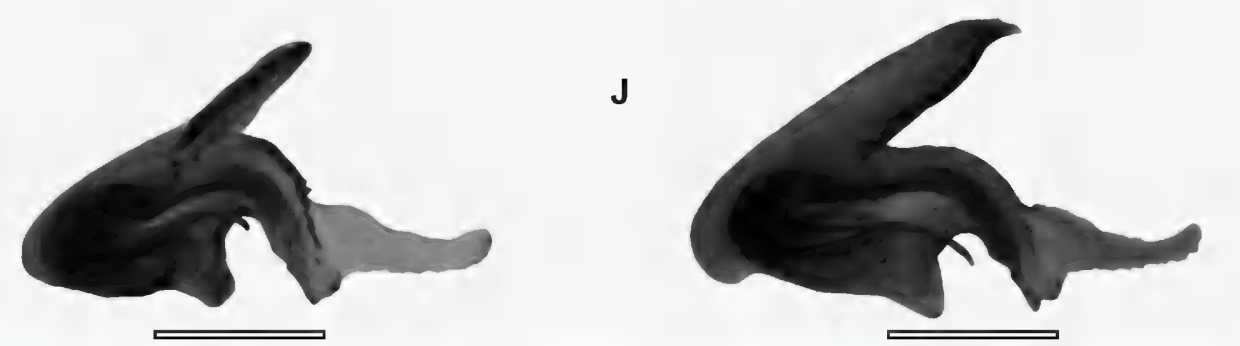

FIGURE 31. Ricinoides Ewing, 1929, leg III copulatory apparatus, prolateral (A, B), dorsal (C, D), retrolateral $(\mathrm{E}, \mathrm{F})$, ventral (G, H), and frontal (I, J) aspects. A, C, E, G, I. Ricinoides nzerekorensis, sp. nov., paratype $\sigma^{\widehat{t}}$ (MRAC 209.286). B, D, F, H, J. Ricinoides taii, sp. nov., holotype ô (MRAC 233.458). Scale bars $=0.25 \mathrm{~mm}$. 

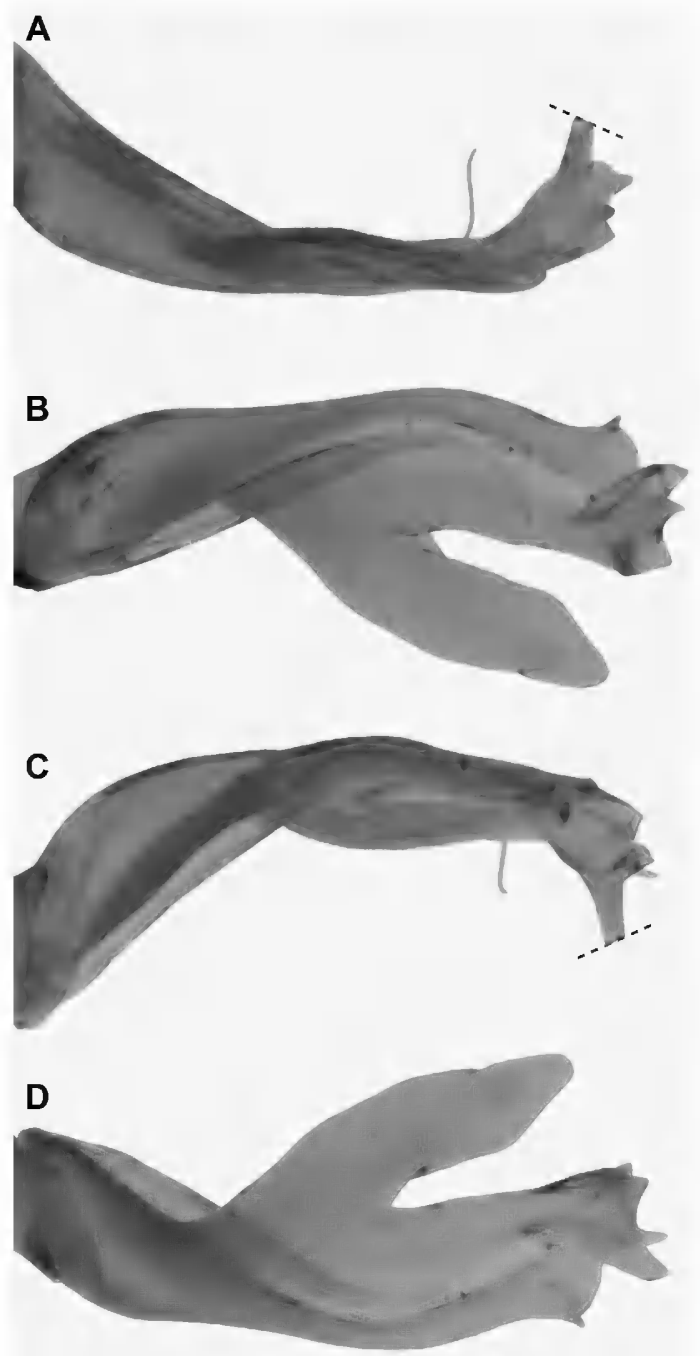

E

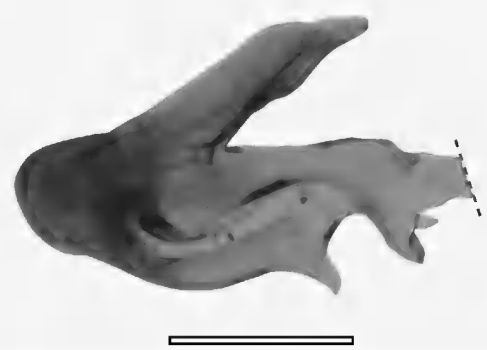

FIGURE 32. Ricinoides westermannii (Guérin-Méneville, 1838), neotype ơ (ZMB 7013), leg III copulatory apparatus, prolateral (A), dorsal (B), retrolateral (C), ventral (D), and frontal (E) aspects. Scale bars $=0.25 \mathrm{~mm}$. tergites (fig. 17E). Pygidium, basal segment parallel to longitudinal axis of opisthosoma; opening very narrow, compressed laterally, width approximately one third lateral width of segment at its base; posterior border narrow; dorsal surface with V-shaped notch; ventral surface entire.

Pedipalps: Femur globose, length approximately $2 \times$ depth. Tibia longer than femur; predominantly linear, slightly curving ventrally (fig. $20 \mathrm{E}$ ); robust along entire length, margins parallel in dorsal aspect and, to lesser extent, lateral aspect; apical longitudinal carinae absent. Movable finger approximately $2 \times$ length of fixed finger.

Legs: Leg II longest, femur markedly incrassate (figs. 24A, C). Femora width (at midline) increasing in order leg III $<$ I $<$ IV $<<$ II; dorsal surface with longitudinal sulcus distinct on all legs. Leg I tibia without ventral apophyses; metatarsus subcircular in cross section, with deep proventral depression in proximal third and without prominent ventral excrescence (fig. 21E). Leg II tibia with large ventromedian apophysis proximally (fig. 24E), not markedly hook shaped, with pointed apex, entirely covered with tuberose granules; tibia and metatarsus without pad of long translucent setae ventrally; metatarsus with very shallow subproximal depression but without ventrosubmedian concavity or excrescence (fig. 24G); first to third tarsomeres short, subequal, fourth approximately $2 \times$ length of preceding tarsomeres; all tarsomeres movable. Leg III metatarsus not swollen, with moderate concavity dorsodistally; proventral surface with apical brushlike row of long, yellowish setae (fig. 27); prodorsal proximal sulcus present; metatarsus, metatarsal process, and tarsus precisely fitting together to completely encase copulatory apparatus when tarsus retracted; metatarsal process situated basally near tibia, robust, tapering and slightly laterally compressed, longitudinal axis sinuous, apex pointing retrolaterally; lamina cyathiformis of second tarsomere longer than deep, with pointed apex; subdistal (third) tarsomere with acute dorsodistal process. Leg IV tarsus not swollen. Legs III and IV terminal tarsomere apex, dorsal margin sublinear, covering ungues. Leg I tarsus and legs II-IV terminal tarsomeres without ventrodistal papillae. 
Copulatory apparatus: Fixed process, PL lobe moderately expanded and dorsoventrally compressed (figs. 30C, G). Distal lobular region, primary a lobe very long and narrow, subcircular in cross-section (figs. 30A, C, E, G, I, 33E); origin slightly prolateral, curving toward retrolateral surface; margins smooth. Primary $\beta$ lobe medium sized, distinctly bicuspid, with $\beta_{2}$ fingerlike, larger than $\beta_{1}$, which is pointed. $r$ sd lobe medium sized, pronounced, associated with distinct subdistal emargination. Secondary $p d$ and $r d$ lobes well developed, pointed; $p d$ situated adjacent to $\beta$ and $r d$ lobes. Movable process slender, slightly flexible, narrowing distally; apex simple, entire.

FeMALE: Unknown.

Distribution: This species is known only from the type locality in the state of Oyo, Nigeria (fig. 5).

\section{Ricinoides kakum, sp. nov.}

Figures 4B, F, 5, 6F, 7D, 9F, 11F, 12D, 14F, 15D, 17F, 18D, 20F, 21F, 24B, D, F, H, 30B, D, F, H, J, 33F, 34D, tables $1,2,4$

Type Material: Holotype $\hat{0}, 2 q$ paratypes (MRAC 217.183), GHANA: Central Region: Kakum Forest [Kakum National Park, 05⒉ $21^{\prime} \mathrm{N}$ $\left.01^{\circ} 23^{\prime} \mathrm{W}\right]$, 8.xi.2005, L. Baert, R. Jocqué, and D. de Bakker, primary forest, pitfall. A microvial contains the following detached pieces of the holotype: sinistral leg III distal region with copulatory apparatus, and dextral copulatory apparatus.

Diagnosis: Ricinoides kakum most closely resembles $R$. atewa, with which it shares several characters of the male, including a group of slightly elevated granules anteromedially on the ventral part of the cucullus (fig. 10B) and moderately enlarged tubercles in the distal half of the ventral surface of the pedipalp tibia (fig. 20F). The fixed process of the male copulatory apparatus of $R$. kakum resembles that of $R$. atewa in the laterally expanded $P L$ lobe (figs. 30D, H), a character also shared by $R$. eburneus, and the distinct subdistal serrations on the retrolateral margin of the a lobe (figs. 30D, H, J), which is unique to R. kakum and $R$. atewa (table 2). The lateral sclerites of tergite $\mathrm{X}$ are obsolete and the tergal membranes broad in $R$. kakum (figs. 14F, 15D), whereas the lateral sclerites of tergite $\mathrm{X}$ are well developed and the tergal membranes narrow, in $R$. atewa. Additionally, the moderately enlarged tubercles in the distal half of the ventral surface of the pedipalp tibia comprise a single retroventral row in the male of $R$. kakum, unlike the male of $R$. atewa, in which the tubercles comprise two (proventral and retroventral) rows.

Етумоlogy: The specific epithet is a noun in apposition taken from the type locality, Kakum National Park, Ghana.

Description of Male: Based on the holotype (MRAC 217.183).

Measurements: Total length $8.11 \mathrm{~mm}$ (table 4).

Coloration: Soma and appendages predominantly dark reddish brown, almost black. Carapace dorsolateral translucent areas yellowish. Opisthosomal tergal and pleural membranes yellow, hyaline. Cheliceral manus yellow; fingers, finger dentition, and manus toothlike process dark.

Setation: Surfaces densely covered with short, translucent, bristlelike setae, slightly expanded but not navicular, length similar to height of surrounding tuberose granules (figs. 6F, 14F). Polygonal setae absent.

Tegument surface macrosculpture: Tegument very irregular, without cuticular pits. Carapace, cucullus, opisthosomal sclerites, legs, and, to lesser extent, coxal region covered with coarse, rounded tuberose granules, evenly spaced apart, not clustered together (figs. $6 \mathrm{~F}, 9 \mathrm{~F}, 11 \mathrm{~F}, 14 \mathrm{~F}, 21 \mathrm{~F}$, 24B, D, F, H). Opisthosoma, pleural membranes finely and densely granular; tergal membranes more sparsely granular. Pedipalp femur dorsal, prolateral, and retrolateral surfaces finely granular; tibia with elevated oval tubercles distally (fig. 20F), some moderately enlarged and arranged into retroventral row.

Carapace: Carapace wider than long, broadest between coxae of legs II and III; trapezoidal, lateral margins curved, narrowing anteriorly (fig. 6F); anterior margin linear in dorsal aspect; posterior margin slightly procurved; median longitudinal sulcus, paired posterior marginal trans- 
verse sulci, and paired anterolateral longitudinal sulci distinct; paired lateral depressions aligned with coxae of legs II; posteromedian moundlike excrescence absent; dorsolateral translucent areas entirely smooth, medium sized, aligned with intersection between coxae of legs I and II, visible in dorsolateral aspect.

Cucullus: Cucullus broadened laterally, wider than long; ventrolateral margins rounded (fig. $9 \mathrm{~F}$ ); ventral margin predominantly linear in anterior aspect, shallowly bilobate in ventral aspect, posterior surface, median row of denticulations worn; anterior surface shallowly convex, without ventral compressed surface; pair of moderately developed sublateral longitudinal sulci; ventral part with anteromedian group of slightly elevated granules, without anteromedian knoblike tubercle or elevation.

Chelicerae: Manus dorsal surface with large toothlike process distally. Movable finger longer than fixed finger, tooth row comprising six small teeth (markedly worn); sharp prodorsal longitudinal carina parallel to tooth row (opposite fixed finger); mucron with shallow but distinct prolateral excavation (opposite fixed finger) delimited by two parallel longitudinal carinae. Fixed finger tooth row comprising three or four small teeth.

Coxosternal region: Tritosternum very small, barely visible, not abutting coxae of legs I (fig. $11 \mathrm{~F})$; coxae of legs II-IV abutting one another medially along entire length; coxae of legs II, anterior and posterior margins almost parallel, slightly narrowing medially, not perpendicular to median axis, inclined anteriorly; coxae of legs II, posterior margin $U$-shaped medially; suture between coxae of legs II approximately $2 \times$ length of suture between coxae of legs III and $1.5 \times$ length of suture between coxae of legs IV.

Opisthosoma: Opisthosoma oval, longer than wide, broadest at tergite XII. Posterodorsal and posteroventral margins without spiniform granules (figs. 14F, 17F). Tergites XI-XIII each comprising median and lateral sclerites; tergite $\mathrm{X}$ with median sclerite, lateral sclerites obsolete, reduced to tiny sclerotized spots; median sclerites of tergites XI-XIII each with paired, shallow submedian depressions near anterior margins; lateral margins of median sclerites converging posteriorly on tergite XI and, to lesser extent, XII, slightly converging anteriorly on XIII; median sclerites of tergites XI-XIII wider than long, rectangular; margins of lateral sclerites adjacent to tergal longitudinal membranes rounded, tergal membranes broad. Sternites XIXIII each with pair of shallow submedian depressions similar to tergites (fig. 17F). Pygidium, basal segment parallel to longitudinal axis of opisthosoma; opening very narrow, compressed laterally, width approximately one third lateral width of segment at its base (fig. $4 \mathrm{~F}$ ); posterior border narrow; dorsal surface with V-shaped notch; ventral surface entire.

Pedipalps: Femur globose, length approximately $2 \times$ depth. Tibia longer than femur; almost entirely linear (fig. 20F); robust along entire length, margins parallel in dorsal and lateral aspects; apical longitudinal carinae absent. Movable finger approximately $2 \times$ length of fixed finger.

Legs: Leg II longest, femur markedly incrassate (figs. 24B, D). Femora width (at midline) increasing in order leg IV $<$ III $<$ I $<<$ II; dorsal surface with longitudinal sulcus most distinct on leg IV. Leg I tibia without ventral apophyses; metatarsus subcircular in cross-section, with deep proventral depression in proximal half and without prominent ventral excrescence (figs. $4 \mathrm{~B}, 21 \mathrm{~F}$ ). Leg II tibia with large ventromedian apophysis proximally (fig. 24F), not markedly hook shaped, with pointed apex, entirely covered with tuberose granules; tibia and metatarsus without pad of long translucent setae ventrally; metatarsus with shallow subproximal depression but without ventrosubmedian concavity or excrescence (fig. 24H); first to third tarsomeres short, subequal, fourth approximately $2 \times$ length of preceding tarsomeres; all tarsomeres movable. Leg III metatarsus not swollen, with moderate concavity dorsodistally; proventral surface without apical brushlike row of setae; prodorsal proximal sulcus present; metatarsus, metatarsal process, and tarsus precisely fitting together to completely encase copulatory appara- 

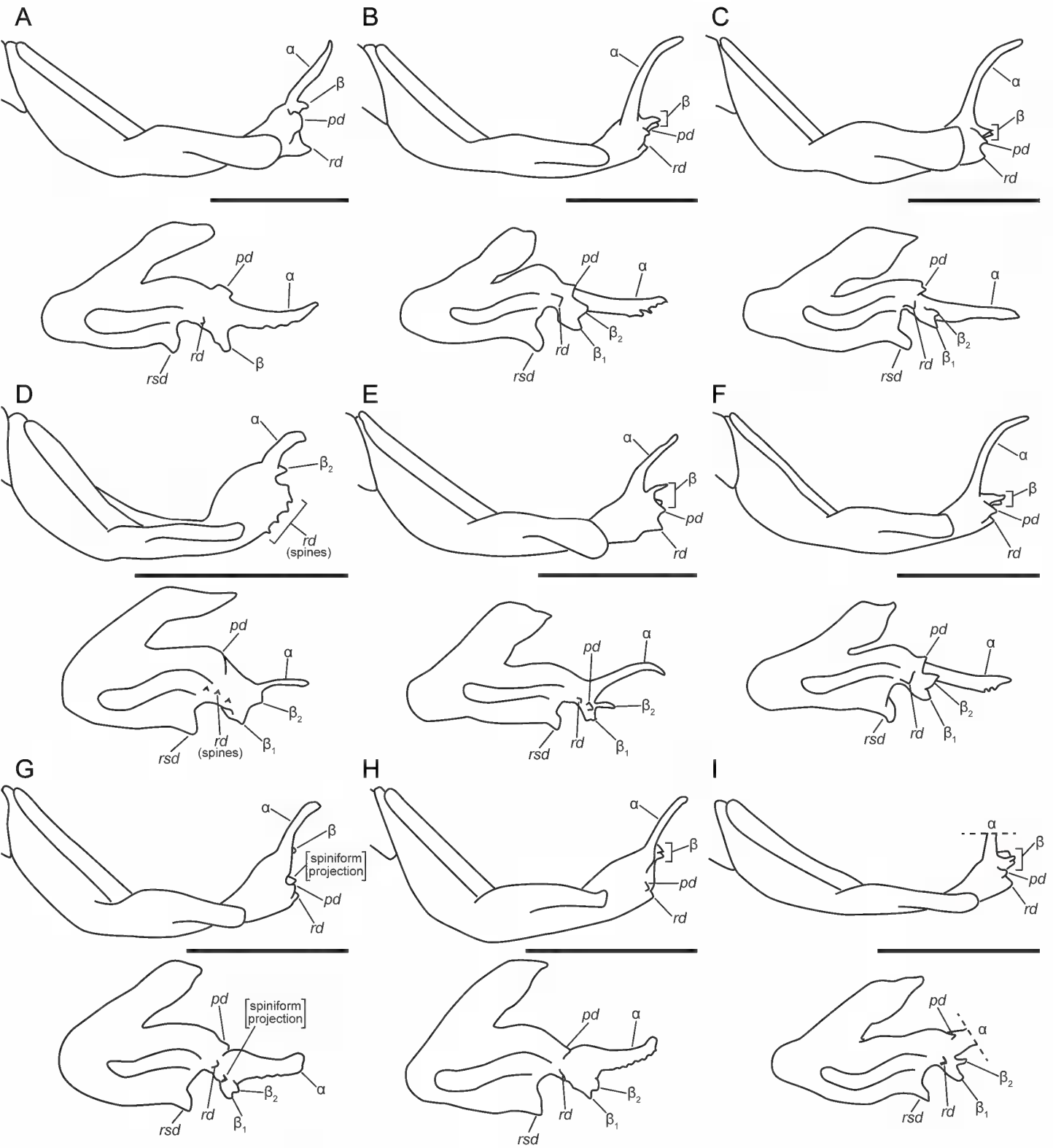

FIGURE 33. Ricinoides Ewing, 1929, leg III, male copulatory apparatus, prolateral and ventral aspects. A. Ricinoides afzelii (Thorell, 1892), ô (BMNH 13588948). B. Ricinoides atewa Naskrecki, 2008, holotype $\hat{\sigma}$ (AMNH IZC 324855). C. Ricinoides eburneus, sp. nov., holotype ơ (MRAC 230.162). D. Ricinoides feae (Hansen, 1921), lectotype $\widehat{o}$ (MSNG). E. Ricinoides iita, sp. nov., holotype $\hat{o}$ (USNM). F. Ricinoides kakum, sp. nov., holotype ơ (MRAC 217.183). G. Ricinoides nzerekorensis, sp. nov., holotype ơ (MRAC 209.266). H. Ricinoides taii, sp. nov., holotype ô (MRAC 233.458). I. Ricinoides westermannii (Guérin-Méneville, 1838), neotype $\hat{o}$ (ZMB 7013). Scale bars $=0.5 \mathrm{~mm}$. 
tus when tarsus retracted; metatarsal process situated basally near tibia, robust, tapering and slightly laterally compressed, longitudinal axis sinuous, apex pointing retrolaterally; lamina cyathiformis of second tarsomere slightly deeper than long, with pointed apex; subdistal (third) tarsomere with acute dorsodistal process. Leg IV tarsus not swollen. Legs III and IV terminal tarsomere apex, dorsal margin sublinear, covering ungues. Leg I tarsus and legs II-IV terminal tarsomeres without ventrodistal papillae.

Copulatory apparatus: Fixed process, PL lobe greatly expanded and dorsoventrally compressed (figs. 30D, H). Distal lobular region, primary a lobe very long, narrow, dorsoventrally compressed distally and, to lesser extent, proximally (figs. 30B, D, F, H, J, 33F); origin submedial, curving toward ventral surface; prolateral margin smooth, retrolateral margin with distinct subdistal serrations. Primary $\beta$ lobe medium sized, distinctly bicuspid, with $\beta_{1}$ and $\beta_{2}$ pointed. rsd lobe medium sized, pronounced, associated with distinct subdistal emargination. Secondary $p d$ and $r d$ lobes well developed, pointed. Movable process slender, slightly flexible, narrowing distally; apex simple, entire.

Supplementary Description of Female: Based on paratypes (MRAC 217.183). Resembles male except as noted.

Measurements: Total length $8.00 \mathrm{~mm}$ (table 4).

Tegument surface macrosculpture: Pedipalp tibia with oval tubercles on ventral surface smaller than in male.

Carapace: Posteromedian moundlike excrescence absent (fig. 7D).

Cucullus: Ventral part without group of elevated granules anteromedially; ventrolateral margins rounded; ventral margin predominantly linear in anterior aspect.

Coxosternal region: Coxae of legs II-IV abutting one another medially along entire length (fig. 12D); coxae of legs II, posterior margin U-shaped medially.

Opisthosoma: Opisthosoma oval (figs. 15D, 18D). Tergites XI-XIII, median sclerites wider than long; XIII, lateral margins of median scler- ite converging slightly anteriorly. Opening of basal segment of pygidium very narrow, compressed laterally.

Legs: Leg I metatarsus without proximal depression proventrally. Leg II femur unmodified, longer than but similar in shape to femora of other legs; tibia without ventromedian apophysis; metatarsus without subproximal depression ventrally.

Spermathecae: Anterior wall of bursa copulatrix with pair of medium-sized, slightly pigmented, rounded areas. Anterior surface with eight hard sacculiform structures sinistrally and five dextrally, variable in size, some markedly elongate (fig. 34D). Spermathecae follicular, each comprising soft, elongate tube terminating in tapering duct, situated submedially on anterior surface of bursa copulatrix adjacent to dorsal margin. Posterior genital lip as in figure 34D.

Distribution: This species is known only from the type locality, Kakum National Park, in the Central Region of Ghana (fig. 5).

Additional Material Examined: GHANA: Central Region: Kakum Forest [Kakum National Park, $05^{\circ} 21^{\prime} \mathrm{N} 01^{\circ} 23^{\prime} \mathrm{W}$ ], Kuntan trail, $159 \mathrm{~m}, 14-25 . x i .2005$, R. Jocqué, D. de Bakker, and L. Baert, secondary forest, pitfall, 1 \% (MRAC 217.210).

\section{Ricinoides nzerekorensis, sp. nov.}

Figures 4D, E, 5, 7E, 8A, 9G, 12E, 13A, 15E, 16A, 18E, 19A, 20G, 21G, 25A, C, E, G, 31A, C, E, G, I, 33G, 34E, tables 1, 2, 5

Ricinoides afzelii (Thorell, 1892): Tuxen, 1974:

91-96 (misidentification, material from Nzérékoré), 90, 92, 93, 95, figs. 2-4, 6-7, 9-17; Harvey, 2003: 183 (part); Naskrecki, 2008: 58, 62, figs. 14-19 (misidentification).

Type Material: Holotype $ð$ (MRAC 209.266), GUINEA: Nzérékoré Region: Forêt Classée de Ziama [Ziama Forest Reserve, $07^{\circ} 42^{\prime} \mathrm{N} 08^{\circ} 25^{\prime} \mathrm{W}$ ], 31.iii.1999, D. Flomo, rainforest, pitfall. The vial containing the holotype includes a microvial with the detached sinistral leg III and copulatory apparatus. Paratypes: tritonymph (MRAC 209.265), same data as holo- 
A
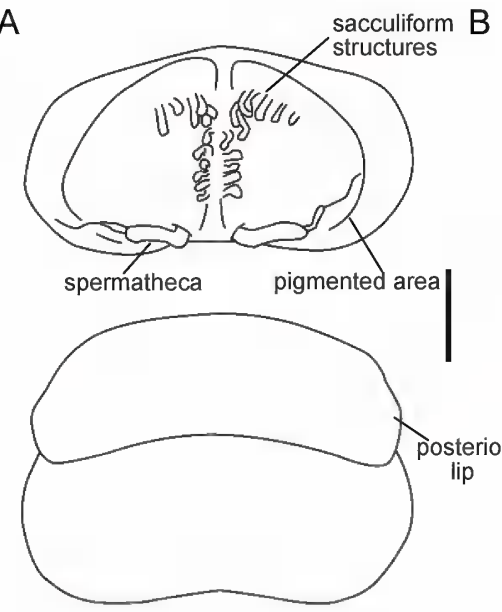

$\mathrm{D}$

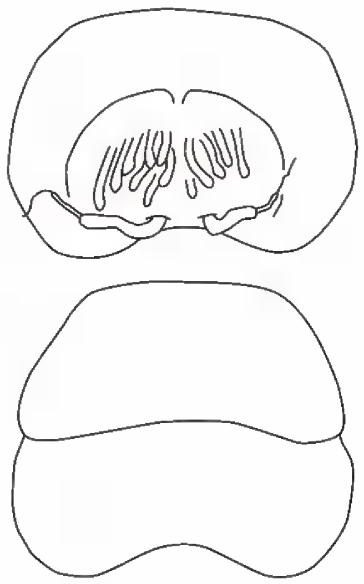

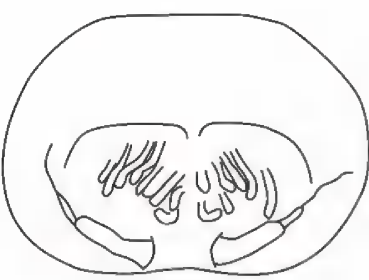

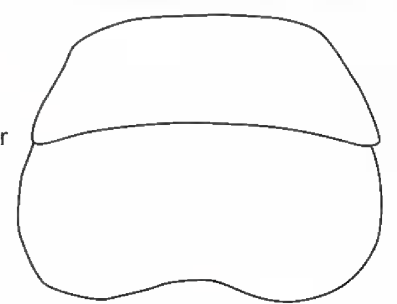

$\mathrm{E}$

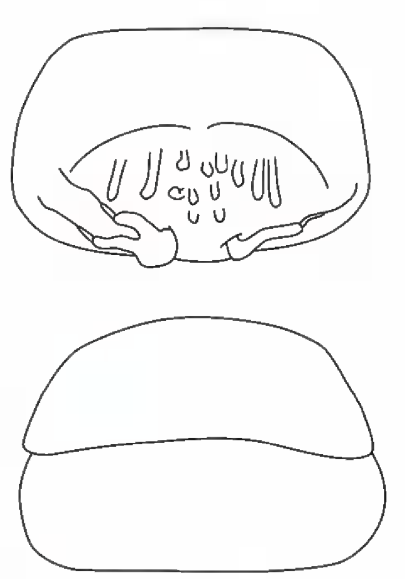

C

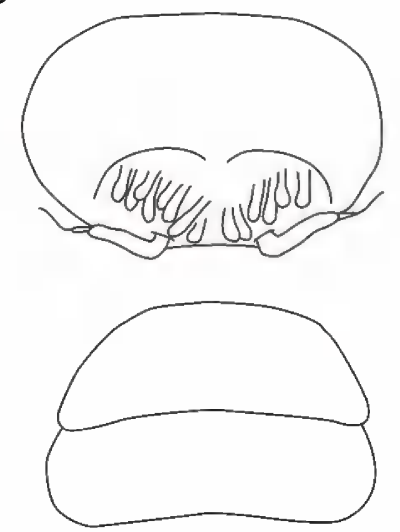

$\mathrm{F}$

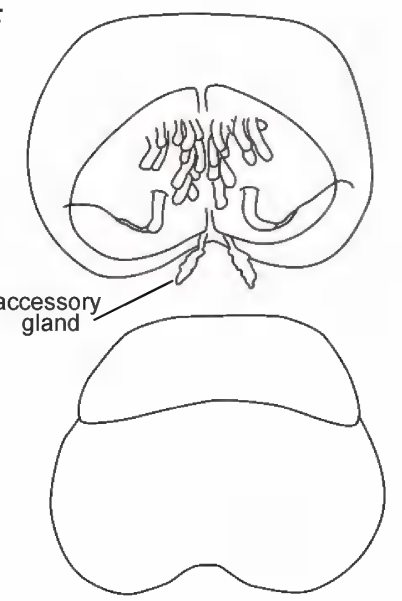

FIGURE 34. Ricinoides Ewing, 1929, female genital sclerites. Anterior wall of bursa copulatrix, anterior aspect (above), posterior genital lip and wall of bursa copulatrix, posterior aspect (below). A. Ricinoides afzelii (Thorell, 1892), $\subsetneq$ (BMNH 13588949). B. Ricinoides atewa Naskrecki, 2008, ㅇ (AMNH IZC 324883). C. Ricinoides feae (Hansen, 1921), paralectotype + (MSNG), Rio Cacine, Guinea-Bissau. D. Ricinoides kakum, sp. nov., paratype q (MRAC 217.183). E. Ricinoides nzerekorensis, sp. nov., paratype $q$ (MRAC 209.267). F. Ricinoides taii, sp. nov., paratype + (MRAC 233.482). Accessory glands only visible in F. Scale bars $=0.25 \mathrm{~mm}$.

type; 1 ơ (MRAC 209.280), same data, except: 13.iv.1999; 1 \& (MRAC 209.264), 22.v.1999; 1 o (MRAC 209.293), 1 §, 1 ? (MRAC 209.273), 4 (MRAC 209.274, 278, 279, 283), 4.vi.1999; 1 ๙ (MRAC 209.263), 17.vi.1999; 1 ઈ (MRAC 209.270), tritonymph (MRAC 209.288), 30. vi.1999; 1 우 (MRAC 209.267), 13.vii.1999; 1 주 (MRAC 209.275), 2 \& (MRAC 209.262, 291), 26.vii.1999; 1 \& (MRAC 209.277), 4.ix.1999; 1 ऊิ (MRAC 209.289), 2 우 (MRAC 209.281, 285), 16.ix.1999; 1 ơ (MRAC 209.272), 29.ix.1999; 1 o (MRAC 209.286), 1 q (MRAC 209.518), 18.xi.1999; 1 ô (MRAC 209.506), 1 ô, 1 क (MRAC 209.507), 3 q (MRAC 209.510, 511, 513), tritonymph (MRAC 209.276), 1.xii.1999; 1 ô (MRAC 209.509), 1 (MRAC 209.508), 14. xii.1999; 1 đ (MRAC 209.514), 9.i.2000; 1 ㅇ (MRAC 209.505), 22.i.2000; 1 ऊ (MRAC 209.516), 4.ii.2000; tritonymph (MRAC 209.515), 17.ii.2000; 1 q (MRAC 210.140), 18.iii.2000. 
Diagnosis: Ricinoides nzerekorensis most closely resembles $R$. taii, with which it shares several unique characters of the fixed process of the male copulatory apparatus (table 2), including a thumb-shaped a lobe, with the prolateral margin sinuous and basally expanded, and the $p d$ and $r d$ lobes weakly developed (figs. 31A, C, E, G, I, 33G). The male of R. nzerekorensis may be recognized from that of $R$. taii by the structure of leg II, specifically the moderately to very large ventromedian apophysis on the tibia (fig. 25E), the presence of a pad of bristlelike setae on the ventral surfaces of the tibia and metatarsus, and the markedly incrassate femur (figs. 25A, C, table 5); and the copulatory apparatus, specifically the presence of a spiniform projection on the prolateral border of the subdistal emargination (fig. 33G), and the small $p d$ and $r d$ lobes.

Eтумоlogy: The specific epithet is a latinized gentilicium referring to the occurrence of this species in the Nzérékoré Region of Guinea.

Description of Male: Based on the holotype (MRAC 209.266).

Measurements: Total length $8.27 \mathrm{~mm}$ (table 5).

Coloration: Soma and appendages predominantly dark red. Carapace dorsolateral translucent areas yellowish. Opisthosomal tergal and pleural membranes yellow, hyaline. Cheliceral manus yellow; fingers, finger dentition, and manus toothlike process dark.

Setation: Surfaces densely covered with short, translucent, bristlelike setae, slightly expanded but not navicular, approximately as long as height of the surrounding tuberose granules (figs. 8A, 16A). Polygonal setae absent.

Tegument surface macrosculpture: Tegument very irregular, without cuticular pits. Carapace, cucullus, opisthosomal sclerites, legs, and, to lesser extent, coxal region covered with coarse, rounded tuberose granules, evenly spaced apart, not clustered together (figs. 8A, 9G, 13A, 16A, 21G, 25A, C, E, G). Opisthosoma, pleural membranes finely and densely granular; tergal membranes more sparsely granular. Pedipalp femur retrolateral surface and, to lesser extent, dorsal surface, finely granular, prolateral surface almost completely smooth; tibia with elevated oval tubercles distally (fig. 20G), not noticeably enlarged or arranged in distinct rows.

Carapace: Carapace wider than long, broadest between coxae of legs II and III; trapezoidal, lateral margins curved, narrowing anteriorly (fig. $8 \mathrm{~A})$; anterior margin linear in dorsal aspect; posterior margin slightly procurved; median longitudinal sulcus, paired posterior marginal transverse sulci, and paired anterolateral longitudinal sulci distinct; paired lateral depressions aligned with coxae of legs II; posteromedian moundlike excrescence absent; dorsolateral translucent areas entirely smooth, medium sized, aligned with intersection between coxae of legs I and II, visible in dorsolateral aspect.

Cucullus: Cucullus broadened laterally, wider than long; ventrolateral margins rounded (fig. $9 \mathrm{G}$ ); ventral margin predominantly linear in anterior aspect, shallowly bilobate in ventral aspect, posterior surface with median row of small denticulations; anterior surface shallowly convex, without ventral compressed surface; pair of moderately developed sublateral longitudinal sulci; ventral part unmodified anteromedially.

Chelicerae: Manus dorsal surface with large toothlike process distally. Movable finger longer than fixed finger, tooth row comprising six small teeth; sharp prodorsal longitudinal carina parallel to tooth row (opposite fixed finger); mucron with shallow but distinct prolateral excavation (opposite fixed finger) delimited by two parallel longitudinal carinae. Fixed finger tooth row comprising five small teeth.

Coxosternal region: Tritosternum very small, barely visible, not abutting coxae of legs I (fig. 13A); coxae of legs II and IV abutting one another medially along entire length, coxae of legs III abutting along anterior two thirds; coxae of legs II, anterior and posterior margins almost parallel, slightly narrowing medially, not perpendicular to median axis, inclined anteriorly; coxae of legs II, posterior margin approximately $\mathrm{V}$-shaped medially; suture between coxae of legs II approximately $2 \times$ length of suture between 


\section{TABLE 5}

Measurements (mm) for Three Species of West African Ricinulei: Ricinoides nzerekorensis, sp. nov., Ricinoides taii, sp. nov., and Ricinoides westermannii (Guérin-Méneville, 1838)

Material deposited in the Musée Royal de l'Afrique Centrale (MRAC), Tervuren, Belgium, the Natural History Museum of Denmark, University of Copenhagen (ZMUC), and the Museum für Naturkunde der Humboldt-

Universität, Berlin (ZMB). Abbreviations: L, length; W, width; $H$, height.

\begin{tabular}{|c|c|c|c|c|c|c|c|c|}
\hline \multirow{4}{*}{$\begin{array}{l}\text { Type / sex } \\
\text { Collection }\end{array}$} & & \multicolumn{4}{|c|}{ R. nzerekorensis } & \multicolumn{2}{|c|}{ R. taii } & \multirow{4}{*}{$\begin{array}{c}\text { R. westermannit } \\
\text { Neotype } \delta \\
\text { ZMB } \\
7013\end{array}$} \\
\hline & & Holotype $\delta$ & Paratype $q$ & $\delta^{5}$ & $q^{5}$ & Holotype $\delta$ & Paratype $q$ & \\
\hline & & MRAC & MRAC & ZMUC & ZMUC & MRAC & MRAC & \\
\hline & & 209.266 & 209.267 & & & 233.458 & 233.482 & \\
\hline \multicolumn{2}{|l|}{ Total body $\mathrm{L}^{1}$} & 8.3 & 8.2 & 9.4 & - & 7.5 & 8.6 & 7.9 \\
\hline \multirow[t]{2}{*}{ Cucullus } & $\mathrm{L}$ & 1.8 & 1.9 & 2.1 & - & 1.7 & 1.9 & 1.7 \\
\hline & $\mathrm{W}^{2}$ & 2.9 & 2.8 & 2.9 & - & 2.4 & 2.8 & 2.8 \\
\hline \multirow[t]{2}{*}{ Carapace } & $\mathrm{L}$ & 3.1 & 3.0 & 3.9 & - & 2.7 & 3.0 & 2.9 \\
\hline & $\mathrm{W}^{2}$ & 3.3 & 3.3 & 4.4 & - & 2.9 & 3.4 & 3.2 \\
\hline \multirow[t]{2}{*}{ Opisthosoma } & $\mathrm{L}^{1}$ & 5.2 & 5.2 & 5.4 & 4.8 & 4.8 & 5.5 & 5.0 \\
\hline & $\mathrm{W}^{2}$ & 3.8 & 4.2 & 4.2 & 4.2 & 3.8 & 4.1 & 3.4 \\
\hline \multirow[t]{2}{*}{ Median sclerite XI } & $\mathrm{L}$ & 1.7 & 1.7 & 2.2 & 1.5 & 1.5 & 1.7 & 1.7 \\
\hline & $W^{2}$ & 2.6 & 2.9 & 3.2 & 2.9 & 2.5 & 2.8 & 2.4 \\
\hline \multirow[t]{2}{*}{ Median sclerite XII } & $L$ & 1.5 & 1.5 & 1.9 & 1.4 & 1.4 & 1.6 & 1.6 \\
\hline & $\mathrm{W}^{2}$ & 2.1 & 2.2 & 2.7 & 2.3 & 2.1 & 2.3 & 2.0 \\
\hline \multirow[t]{2}{*}{ Median sclerite XIII } & $\mathrm{L}$ & 1.6 & 1.7 & 2.2 & 1.6 & 1.6 & 1.8 & 1.6 \\
\hline & $\mathrm{W}^{2}$ & 1.5 & 1.6 & 2.1 & 1.7 & 1.6 & 1.8 & 1.5 \\
\hline \multirow[t]{4}{*}{ Pedipalp } & Femur L & 1.5 & 1.4 & 1.6 & - & 1.3 & 1.4 & 1.5 \\
\hline & Femur $\mathrm{H}^{3}$ & 0.7 & 0.6 & 0.9 & - & 0.6 & 0.6 & 0.6 \\
\hline & Tibia L & 2.3 & 2.3 & 2.4 & - & 2.1 & 2.3 & 2.4 \\
\hline & Tibia $\mathrm{H}^{4}$ & 0.3 & 0.3 & 0.4 & - & 0.3 & 0.3 & 0.3 \\
\hline \multirow[t]{7}{*}{ Leg I } & Femur L & 1.7 & 1.5 & 1.9 & 1.5 & 1.5 & 1.6 & 1.9 \\
\hline & Femur $\mathrm{W}^{4}$ & 0.9 & 0.6 & 0.9 & 0.6 & 0.6 & 0.6 & 0.6 \\
\hline & Femur $\mathrm{H}^{4}$ & 0.9 & 0.6 & 1.0 & 0.7 & 0.6 & 0.7 & 0.8 \\
\hline & Patella L & 1.5 & 1.3 & 1.7 & 1.2 & 1.2 & 1.2 & 1.3 \\
\hline & Tibia L & 1.2 & 1.1 & 1.2 & 1.2 & 1.0 & 1.1 & 1.2 \\
\hline & Metatarsus L & 1.9 & 1.8 & 2.2 & 1.9 & 1.7 & 1.9 & 2.0 \\
\hline & Tarsus L & 0.8 & 0.6 & 0.7 & 0.7 & 0.7 & 0.7 & 0.7 \\
\hline \multirow[t]{7}{*}{ Leg II } & Femur L & 3.3 & 2.7 & 3.7 & 3.2 & 2.7 & 3.0 & 3.4 \\
\hline & Femur $\mathrm{W}^{4}$ & 1.5 & 0.5 & 1.9 & 0.6 & 0.7 & 0.6 & 0.9 \\
\hline & Femur $\mathrm{H}^{4}$ & 2.0 & 0.7 & 2.5 & 0.7 & 0.9 & 0.8 & 1.2 \\
\hline & Patella L & 1.9 & 1.6 & 2.2 & 1.7 & 1.6 & 1.7 & 1.9 \\
\hline & Tibia L & 1.9 & 1.7 & 2.2 & 1.9 & 1.7 & 1.9 & 2.1 \\
\hline & Metatarsus L & 2.9 & 2.6 & 3.3 & 2.7 & 2.7 & 2.8 & 3.1 \\
\hline & Tarsus L & 2.6 & $2.4^{6}$ & 3.0 & 2.3 & 2.2 & 2.5 & 2.5 \\
\hline \multirow[t]{7}{*}{ Leg III } & Femur L & 2.2 & 1.9 & 2.3 & 2.0 & 2.0 & 1.9 & 2.3 \\
\hline & Femur $\mathrm{W}^{4}$ & 0.6 & 0.5 & 0.7 & 0.6 & 0.6 & 0.5 & 0.6 \\
\hline & Femur $\mathrm{H}^{4}$ & 0.6 & 0.6 & 0.7 & 0.6 & 0.6 & 0.6 & 0.5 \\
\hline & Patella L & 1.5 & 1.3 & 1.5 & 1.3 & 1.3 & 1.3 & 1.3 \\
\hline & Tibia L & 1.3 & 1.0 & 1.4 & 1.1 & 1.3 & 1.1 & 1.4 \\
\hline & Metatarsus L & 1.8 & 1.6 & 2.0 & 1.6 & 1.7 & 1.6 & 1.8 \\
\hline & Tarsus L & 2.4 & 1.4 & 2.6 & 1.3 & 2.2 & - & 2.2 \\
\hline \multirow[t]{7}{*}{ Leg IV } & Femur L & 2.4 & 2.2 & 2.6 & 2.3 & 2.2 & 2.3 & 2.6 \\
\hline & Femur $\mathrm{W}^{4}$ & 0.6 & 0.5 & 0.6 & 0.5 & 0.5 & 0.5 & 0.5 \\
\hline & Femur $\mathrm{H}^{4}$ & 0.7 & 0.6 & 0.7 & 0.6 & 0.6 & 0.6 & 0.5 \\
\hline & Patella L & 1.4 & 1.3 & 1.5 & 1.3 & 1.2 & 1.3 & 1.3 \\
\hline & Tibia L & 1.2 & 1.1 & 1.4 & 1.2 & 1.1 & 1.2 & 1.2 \\
\hline & Metatarsus L & 1.9 & 1.8 & 2.1 & 1.9 & 1.7 & 1.9 & 1.9 \\
\hline & Tarsus L & 1.8 & 1.7 & 2.0 & 1.6 & 1.5 & - & - \\
\hline
\end{tabular}

${ }^{1}$ Excludes pygidium and cucullus.

${ }^{2}$ Maximum width.

${ }^{3}$ Maximum height.

${ }^{4}$ Midline.

${ }^{5}$ Nzérékoré, Guinea.

${ }^{6}$ Leg II tarsus deformed, measurement provided for paratype $q$ (MRAC 209.278). 
coxae of legs IV and $3 \times$ length of suture between coxae of legs III.

Opisthosoma: Opisthosoma oval, longer than wide, broadest at tergite XII. Posterodorsal and posteroventral margins without spiniform granules (figs. 16A, 19A). Tergites X-XIII each comprising median and lateral sclerites; median sclerites of tergites XI-XIII each with paired, shallow submedian depressions near anterior margins; lateral margins of median sclerites converging posteriorly on tergite XI and, to lesser extent, XII, subparallel on XIII; median sclerites of tergites XI and XII wider than long, of XIII approximately as wide as long, square; margins of lateral sclerites adjacent to tergal longitudinal membranes predominantly linear, tergal membranes narrow. Sternites XI-XIII each with pair of shallow submedian depressions similar to tergites (fig. 19A). Pygidium, basal segment parallel to longitudinal axis of opisthosoma; opening very narrow, compressed laterally, width approximately one third lateral width of segment at its base; posterior border narrow; dorsal surface with V-shaped notch; ventral surface entire.

Pedipalps: Femur globose, length approximately $2 \times$ depth. Tibia longer than femur; almost entirely linear (fig. 20G); robust along entire length, margins parallel in dorsal aspect and, to lesser extent, lateral aspect; apical longitudinal carinae absent. Movable finger approximately $2 \times$ length of fixed finger.

Legs: Leg II longest, femur markedly incrassate (figs. 25A, C). Legs III and IV femora narrowest and similar in width, femora increasing in width (at midline) in order leg IV = III $<$ I $<<$ II; dorsal surface with longitudinal sulcus most distinct on leg IV. Leg I tibia without ventral apophyses; metatarsus subcircular in cross section, with deep proventral depression in proximal half and without prominent ventral excrescence (fig. 21G). Leg II tibia with very large ventromedian apophysis proximally (fig. 25E), markedly hook shaped, with acute apex, entirely covered with tuberose granules; tibia and metatarsus with distinct pad of moderately long, translucent bristlelike setae (less than half depth of metatarsus) ventrally (figs. 25E,
G); metatarsus without ventrosubmedian concavity, with moderate subproximal depression and marked submedian excrescence ventrally (fig. $25 \mathrm{G}$ ); first to third tarsomeres short, subequal, fourth approximately $2 \times$ length of preceding tarsomeres; all tarsomeres movable. Leg III metatarsus not swollen, with moderate concavity dorsodistally; proventral surface without apical brushlike row of setae; prodorsal proximal sulcus present; metatarsus, metatarsal process, and tarsus precisely fitting together to completely encase copulatory apparatus when tarsus retracted; metatarsal process situated basally near tibia, robust, tapering and slightly laterally compressed, longitudinal axis sinuous, apex pointing retrolaterally; lamina cyathiformis of second tarsomere approximately as deep as long, with slightly pointed apex; subdistal (third) tarsomere with acute dorsodistal process (fig. 4D). Leg IV tarsus not swollen. Legs III and IV terminal tarsomere apex, dorsal margin sublinear, covering ungues. Leg I tarsus and legs II-IV terminal tarsomeres without ventrodistal papillae.

Copulatory apparatus: Fixed process, $P L$ lobe moderately expanded and dorsoventrally compressed (figs. 31C, G). Distal lobular region, primary a lobe long, thumb shaped, dorsoventrally compressed (figs. 31A, C, E, G, I, 33G); origin submedial, curving toward ventral surface; prolateral margin basally expanded, sinuous, smooth; retrolateral margin slightly irregular. Primary $\beta$ lobe medium sized, distinctly bicuspid, with $\beta_{1}$ and $\beta_{2}$ pointed. rsd lobe medium sized, pronounced, associated with distinct subdistal emargination; prolateral border of subdistal emargination with distinct spiniform projection. Secondary $p d$ and $r d$ lobes small. Movable process slender, slightly flexible, narrowing distally; apex simple, entire.

Supplementary Description of Female: Based on the paratype (MRAC 209.267). Resembles male except as noted.

Measurements: Total length $8.16 \mathrm{~mm}$ (table 5).

Tegument surface macrosculpture: Pedipalp femur dorsal, prolateral, and retrolateral surfaces finely granular. 
Carapace: Posteromedian moundlike excrescence absent (fig. 7E).

Cucullus: Ventrolateral margins rounded; ventral margin predominantly linear in anterior aspect.

Coxosternal region: Coxae of legs II-IV abutting one another medially along entire length (fig. 12E); coxae of legs II, posterior margin approximately $\mathrm{V}$-shaped medially.

Opisthosoma: Opisthosoma oval (figs. 4E, 15E, 18E). Tergites XI and XII, median sclerites wider than long; XIII, median sclerite slightly longer than wide. Opening of basal segment of pygidium very narrow, compressed laterally.

Pedipalps: Tibia entirely linear.

Legs: Leg I metatarsus without proximal depression proventrally. Leg II femur unmodified, longer than but similar in shape to femora of other legs; tibia without ventromedian apophysis; tibia and metatarsus without ventral pad of translucent setae; metatarsus without subproximal depression or submedian excrescence ventrally.

Spermathecae: Anterior wall of bursa copulatrix with pair of medium-sized, slightly pigmented, rounded areas. Anterior surface with six hard sacculiform structures sinistrally and seven dextrally, variable in size, some markedly elongate (fig. 34E). Spermathecae follicular, double sinistrally, each comprising soft, elongate tube terminating in tapering duct, situated submedially on anterior surface of bursa copulatrix adjacent to dorsal margin. Posterior genital lip as in fig. 34E.

Distribution: This species has been recorded from several localities in the southern part of the Nzérékoré Region of Guinea (fig. 5).

ReMARKs: Naskrecki (2008) reported a male and female of $R$. afzelii from two localities in Guinea, Forêt Classée Diecke and Mt. Bero, situated geographically near the type locality of $R$. nzerekorensis. The copulatory apparatus of the male from Forêt Classée Diecke, illustrated in Naskrecki's (2008: 62) figs. 14-18, is inconsistent with the male copulatory apparatus of $R$. afzelii, but closely resembles that of $R$. nzerekorensis, to which this specimen is referred. The female from Mt. Bero is also referred to R. nzerekorensis based on Naskrecki's (2008) determination that it was conspecific with the male.

Additional Material Examined: GUINEA: Nzérékoré Region: Mount Nimba Strict Nature Reserve $\left[07^{\circ} 38^{\prime} \mathrm{N} 08^{\circ} 25^{\prime} \mathrm{W}\right]$ : Bangala Forest, $609 \mathrm{~m}$, 7.iii.2012, A. Henrard, C. Allard, P. Bimou and M. Sidibé, soil litter, sieving, 1 tritonymph (MRAC 238.829); Fouenyi Forest, 573 m, 1.iii.2012, A. Henrard, C. Allard, P. Bimou and M. Sidibé, soil litter, sieving, 2 o, 1 deutonymph (MRAC 239.116); Gbié, Miau River, 469 m, 15.iii.2012, A. Henrard, C. Allard, P. Bimou and M. Sidibé, near clearance zone, near river, litter, sieving, 1 deutonymph (MRAC 238.761), same data, except: 16.iii.2012, 1 tritonymph (MRAC 238.765); Gouan Forest (mid-one), 2-11.x.2011, D. van den Spiegel and A. Henrard, soil litter near cliffs, pitfall, 1 ( 9 (MAC 238.168); Heyétouna Forest, 687 m, 18.iii.2012, A. Henrard, C. Allard, P. Bimou and M. Sidibé, soil litter, sieving, 1 tritonymph (MRAC 238.767); Yeï Forest, 601 m, 5.iii.2012, A. Henrard, C. Allard, P. Bimou and M. Sidibé, soil litter, sieving, 1 deutonymph (MRAC 238.763). Nzérékoré [07 $45^{\prime} \mathrm{N}$ $08^{\circ} 49^{\prime} \mathrm{W}$ ], 10-25.iv.1957, S. v. H. Olsen, on forest floor, 1 đ (ZMUC), same data, except 15.v.1961 (or 15.iv.1961), 1 ㅇ (ZMUC).

Ricinoides taii, sp. nov.

Figures 5, 7F, 8B, 9H, 12F, 13B, 15F, 16B, 18F, 19B, 20H, 21H, 25B, D, F, H, 31B, D, F, H, J, $33 \mathrm{H}, 34 \mathrm{~F}$, tables $1,2,5$

Type Material: Holotype ơ (MRAC 233.458), paratype + (MRAC 233.482), CÔTE D'IVOIRE: Montagnes and Bas-Sassandra Districts: Forêt de Taï [Taï National Park, $05^{\circ} 41^{\prime} \mathrm{N} 06^{\circ} 56^{\prime} \mathrm{W}$ ], D. van den Spiegel and A. Kablan, pitfall. The membranous tissues of the specimens are weakened and some body parts broken. The vial containing the holotype includes the following detached pieces: both legs IV, opisthosoma, sinistral pedipalp, distal part of sinistral leg III, and copulatory appara tus. The dextral copulatory apparatus is missing. The female is in similar condition, with all the pieces contained in the same vial.

DiAgnosis: Ricinoides taii most closely resembles $R$. nzerekorensis, with which it shares several unique characters of the fixed process of the male copulatory apparatus (table 2), including a thumb- 
shaped a lobe, with the prolateral margin sinuous and basally expanded, and the $p d$ and $r d$ lobes weakly developed (figs. 31B, D, F, H, J, 33H). The male of $R$. taii may be recognized from that of $R$. nzerekorensis by the structure of leg II, specifically the small ventromedian apophysis on the tibia (fig. 25F), the absence of a pad of bristlelike setae on the ventral surfaces of the tibia and metatarsus, and the less incrassate femur (figs. 25B, D, table 5); and the copulatory apparatus, specifically the absence of a distinct spiniform projection on the prolateral border of the subdistal emargination (fig. $33 \mathrm{H}$ ), and the vestigial $p d$ and $r d$ lobes, represented by slightly elevated ridges.

EтумоLоgy: The specific epithet is a noun in apposition taken from the type locality, Taï National Park, Côte d'Ivoire.

Description of MALE: Based on the holotype (MRAC 233.458).

Measurements: Total length $7.51 \mathrm{~mm}$ (table 5).

Coloration: Soma and appendages predominantly dark brown, almost black. Carapace dorsolateral translucent areas yellowish. Opisthosomal tergal and pleural membranes yellow, hyaline. Cheliceral manus yellow; fingers, finger dentition, and manus toothlike process dark.

Setation: Surfaces densely covered with short, translucent, bristlelike setae, slightly expanded but not navicular, length similar to height of surrounding tuberose granules (figs. 8B, 16B). Polygonal setae absent.

Tegument surface macrosculpture: Tegument very irregular, without cuticular pits. Carapace, cucullus, opisthosomal sclerites, legs, and, to lesser extent, coxal region covered with coarse, rounded tuberose granules, evenly spaced apart, not clustered together (figs. $8 \mathrm{~B}, 9 \mathrm{H}, 13 \mathrm{~B}, 16 \mathrm{~B}$, $21 \mathrm{H}, 25 \mathrm{~B}, \mathrm{D}, \mathrm{F}, \mathrm{H})$. Opisthosoma, pleural membranes finely and densely granular; tergal membranes more sparsely granular. Pedipalp femur dorsal, prolateral, and retrolateral surfaces finely granular; tibia with elevated oval tubercles distally (fig. 20H), not noticeably enlarged or arranged in distinct rows.

Carapace: Carapace wider than long, broadest between coxae of legs II and III; trapezoidal, lat- eral margins curved, narrowing anteriorly (fig. $8 \mathrm{~B})$; anterior margin linear in dorsal aspect; posterior margin slightly procurved; median longitudinal sulcus, paired posterior marginal transverse sulci, and paired anterolateral longitudinal sulci distinct; paired lateral depressions aligned with coxae of legs II; posteromedian moundlike excrescence absent; dorsolateral translucent areas entirely smooth, medium sized, aligned with intersection between coxae of legs I and II, visible in dorsolateral aspect.

Cucullus: Cucullus broadened laterally, wider than long; ventrolateral margins rounded (fig. $9 \mathrm{H})$; ventral margin predominantly linear in anterior aspect, shallowly bilobate in ventral aspect, posterior surface with median row of small denticulations; anterior surface shallowly convex, without ventral compressed surface; pair of moderately developed sublateral longitudinal sulci; ventral part unmodified anteromedially.

Chelicerae: Manus dorsal surface with large toothlike process distally. Movable finger longer than fixed finger, tooth row comprising seven small teeth; sharp prodorsal longitudinal carina parallel to tooth row (opposite fixed finger); mucron with shallow but distinct prolateral excavation (opposite fixed finger) delimited by two parallel longitudinal carinae. Fixed finger tooth row comprising five small teeth.

Coxosternal region: Tritosternum very small, barely visible, not abutting coxae of legs I (fig. 13B); coxae of legs II-IV abutting one another medially along entire length; coxae of legs II, anterior and posterior margins subparallel, not perpendicular to median axis, inclined anteriorly; coxae of legs II, posterior margin V-shaped medially; suture between coxae of legs II approximately $2 \times$ length of suture between coxae of legs IV and $3 \times$ length of suture between coxae of legs III.

Opisthosoma: Opisthosoma oval, longer than wide, broadest at tergite XII. Posterodorsal and posteroventral margins without spiniform granules (figs. 16B, 19B). Tergites X-XIII each comprising median and lateral sclerites; median sclerites of tergites XI-XIII each with paired, shallow submedian depressions near anterior 
margins; lateral margins of median sclerites converging posteriorly on tergite $\mathrm{XI}$ and, to lesser extent, XII, subparallel on XIII; median sclerites of tergites XI and XII wider than long, of XIII approximately as wide as long, square; margins of lateral sclerites adjacent to tergal longitudinal membranes predominantly linear, tergal membranes narrow. Sternites XI-XIII each with pair of shallow submedian depressions similar to tergites (fig. 19B). Pygidium, basal segment parallel to longitudinal axis of opisthosoma; opening very narrow, compressed laterally, width approximately one third lateral width of segment at its base; posterior border narrow; dorsal surface with $\mathrm{V}$-shaped notch; ventral surface entire.

Pedipalps: Femur globose, length slightly more than $2 \times$ depth. Tibia longer than femur; almost entirely linear (fig. 20H); robust along entire length, margins parallel in dorsal aspect and, to lesser extent, lateral aspect; apical longitudinal carinae absent. Movable finger approximately $2 \times$ length of fixed finger.

Legs: Leg II longest, femur moderately incrassate (figs. 25B, D). Femora width (at midline) increasing in order leg IV $<$ III = I < II; dorsal surface with longitudinal sulcus distinct on all legs. Leg I tibia without ventral apophyses; metatarsus subcircular in cross-section, with moderate proventral depression in proximal half and without prominent ventral excrescence (fig. $21 \mathrm{H}$ ). Leg II tibia with small ventromedian apophysis proximally (fig. $25 \mathrm{~F}$ ), forming slight protrusion covered with tuberose granules; tibia and metatarsus without pad of long translucent setae ventrally; metatarsus without ventrosubmedian concavity, with very shallow subproximal depression and obsolete submedian excrescence ventrally (fig. $25 \mathrm{H}$ ); first to third tarsomeres short, subequal, fourth approximately $2 \times$ length of preceding tarsomeres; all tarsomeres movable. Leg III metatarsus not swollen, with moderate concavity dorsodistally; proventral surface without apical brushlike row of setae; prodorsal proximal sulcus present; metatarsus, metatarsal process, and tarsus precisely fitting together to completely encase copulatory apparatus when tarsus retracted; metatarsal process situated basally near tibia, robust, tapering and slightly laterally compressed, longitudinal axis sinuous, apex pointing retrolaterally; lamina cyathiformis of second tarsomere approximately as deep as long, with pointed apex; subdistal (third) tarsomere with acute dorsodistal process. Leg IV tarsus not swollen. Legs III and IV terminal tarsomere apex, dorsal margin sublinear, covering ungues. Leg I tarsus and legs II-IV terminal tarsomeres without ventrodistal papillae.

Copulatory apparatus: Fixed process, $P L$ lobe moderately expanded and dorsoventrally compressed (figs. 31D, H). Distal lobular region, primary a lobe long, thumb shaped, dorsoventrally compressed (figs. 31B, D, F, H, J, 33H); origin submedial, curving toward ventral surface; prolateral margin basally expanded, sinuous; prolateral and retrolateral margins slightly irregular. Primary $\beta$ lobe medium sized, distinctly bicuspid, with $\beta_{1}$ and $\beta_{2}$ pointed. rsd lobe medium sized, pronounced, associated with distinct subdistal emargination. Secondary $p d$ and $r d$ lobes vestigial, represented by slightly elevated ridges. Movable process slender, slightly flexible, narrowing distally; apex simple, entire.

Supplementary Description of Female: Based on the paratype (MRAC 233.482). Resembles male except as noted.

Measurements: Total length $8.60 \mathrm{~mm}$ (table 5).

Carapace: Posteromedian moundlike excrescence absent (fig. 7F).

Cucullus: Ventrolateral margins rounded; ventral margin predominantly linear in anterior aspect.

Coxosternal region: Coxae of legs II-IV abutting one another medially along entire length (fig. 12F); coxae of legs II, posterior margin $\mathrm{V}$-shaped medially.

Opisthosoma: Opisthosoma oval (figs. 15F, 18F). Tergites XI and XII, median sclerites wider than long; XIII, median sclerite approximately as wide as long. Opening of basal segment of pygidium very narrow, compressed laterally. 
Pedipalps: Tibia entirely linear.

Legs: Leg I metatarsus without proximal depression proventrally. Leg II femur unmodified, longer than but similar in shape to femora of other legs; tibia without ventromedian apophysis; metatarsus without subproximal depression or submedian excrescence ventrally.

Spermathecae: Anterior wall of bursa copulatrix with pair of medium-sized, slightly pigmented, rounded areas. Anterior surface with 12 hard sacculiform structures sinistrally and 11 dextrally, variable in size (fig. 34F). Spermathecae follicular, each comprising soft, elongate tube terminating in tapering duct, situated submedially on anterior surface of bursa copulatrix, well separated from dorsal margin. Posterior genital lip as in figure $34 \mathrm{~F}$.

Distribution: Ricinoides taii is known only from the type locality, Tai National Park, in the Montagnes and Bas-Sassandra districts of Côte d'Ivoire (fig. 5). It is one of three ricinuleid species recorded from the national park, the others being $R$. eburneus and R. megahanseni.

\section{Ricinoides westermannii (Guérin-Méneville, 1838)}

Figures 4A, 5, 8C, 10A, 13C, 16C, 19C, 20I, 21I, $26,32,33$, tables $1,2,5$

Cryptostemma westermannii Guérin-Méneville, 1838: 11, 12; Lucas, 1838: 353, 354, pl. 539, figs. 7, 7a; Gervais, 1844: 131, pl. 47, fig. 4; Fritsch, 1904: 32, fig. 36; Hansen and Sørensen, 1904: 149, 150, pl. 7, figs. 3a, b, pl. 8, figs. 1a-f; Moritz and Fischer, 1980: 139. Cryptostemma westermanni: Börner, 1902: 442, fig. 8; Hansen, 1930: unpaginated, pl. 15, fig. 9a.

Cryptostemma plebejum Hansen and Sørensen, 1904: 148, pl. 8, figs. 2a-f; Moritz and Fischer, 1980: 139 (synonymized by Legg, 1978b: 124).

Ricinoides westermannii (Guérin-Méneville, 1838): Harvey, 2003: 184 (part, material from Togo only).
Ricinoides westermanni: Ewing, 1929: 597; Kästner, 1932: 107, fig. 144; Bolívar y Pieltain, 1942: 201; Savory, 1964: 197, fig. 100; Tuxen, 1974: 102, 103, figs. 1d, 34-38; Savory, 1977: 215, fig. 87; Legg, 1978b: 124 (part, material from Togo only); 1982: 288-290, figs. 1a-c (misidentification); Harvey, 1984: 205-207, figs. 1-9 (misidentification).

Ricinoides plebejum (Hansen and Sørensen, 1904): Ewing, 1929: 597; Bolívar y Pieltain, 1942: 201; Tuxen, 1974: 105.

Type Material Examined: Cryptostemma westermannii: Neotype ô (ZMB 7013), TOGO: Bismarckbourg [Centrale Region: $08^{\circ} 10^{\prime} 39^{\prime \prime} \mathrm{N}$ $00^{\circ} 41^{\prime} 15^{\prime \prime} \mathrm{E}$ ], 16.vii.1893, Büttner. Two microvials contain the following detached pieces: cucullus, both chelicerae and pedipalps, some segments and tarsomeres of legs II and III, and sinistral copulatory apparatus. The following body regions are missing: second to fifth tarsomeres of both legs IV, dextral leg III metatarsus, tarsus, and copulatory apparatus. Cryptostemma plebejum: Holotype tritonymph (ZMB 7834), TOGO: Misahöhe [Plateaux Region: Misahohél Missahohé, $06^{\circ} 57^{\prime} \mathrm{N} 00^{\circ} 35^{\prime} \mathrm{E}$ ], 24.vi.1894, E. Baumann.

Diagnosis: Ricinoides westermannii differs from the other eight species in being the only species in which a ventromedian apophysis is absent on the tibia of leg II in the male (fig. $26 \mathrm{C})$ and $\beta_{1}$ is noticeably larger than $\beta_{2}$ in the $\beta$ lobe of the fixed process of the male copulatory apparatus (figs. 32, 33I). The male of $R$. westermannii differs further from the males of all other species, except $R$. feae, in the relatively unmodified pedipalp tibia (fig. 20I), which is markedly robust in the other species, and in the width of the opening of the pygidium basal segment, which is approximately two fifths the lateral width of the segment at its base, but narrower laterally in the other species. The male of $R$. westermannii differs from that of $R$. feae in several respects, including the structure of the copulatory apparatus (table 2). 
Redescription of Male: Based on the neotype (ZMB 7013).

Measurements: Total length $7.89 \mathrm{~mm}$ (table 5).

Coloration: Color faded; soma and appendages uniform pale chestnut coloration. Cheliceral manus yellow; fingers, finger dentition, and manus toothlike process dark.

Setation: Surfaces densely covered with short, translucent, bristlelike setae, slightly expanded but not navicular, length similar to height of surrounding tuberose granules (figs. 8C, 16C). Polygonal setae absent.

Tegument surface macrosculpture: Tegument very irregular, without cuticular pits. Carapace, cucullus, opisthosomal sclerites, legs, and, to lesser extent, coxal region covered with coarse, rounded tuberose granules, evenly spaced apart, not clustered together (figs. 8C, 10A, 13C, 16C, 21I, 26). Opisthosoma, pleural membranes finely and densely granular; tergal membranes more sparsely granular. Pedipalp femur dorsal, prolateral, and retrolateral surfaces finely granular; tibia with elevated oval tubercles distally (fig. 20I).

Carapace: Carapace wider than long, broadest between coxae of legs II and III; trapezoidal, lateral margins curved, narrowing anteriorly (fig. $8 \mathrm{C}$ ); anterior margin linear in dorsal aspect; posterior margin slightly procurved; median longitudinal sulcus, paired posterior marginal transverse sulci, and paired anterolateral longitudinal sulci distinct; paired lateral depressions aligned with coxae of legs II; posteromedian moundlike excrescence absent; dorsolateral translucent areas entirely smooth, medium sized, aligned with intersection between coxae of legs I and II, visible in dorsolateral aspect.

Cucullus: Cucullus broadened laterally, wider than long; ventrolateral margins rounded (fig. $10 \mathrm{~A}$ ); ventral margin predominantly linear in anterior aspect, shallowly bilobate in ventral aspect, posterior surface with median row of small denticulations; anterior surface shallowly convex, without ventral compressed surface; pair of moderately developed sublateral longitudinal sulci; ventral part unmodified anteromedially.
Chelicerae: Manus dorsal surface with large toothlike process distally. Movable finger longer than fixed finger, tooth row comprising seven small teeth (two basalmost teeth extremely small in both chelicerae); sharp prodorsal longitudinal carina parallel to tooth row (opposite fixed finger); mucron with shallow but distinct prolateral excavation (opposite fixed finger) delimited by two parallel longitudinal carinae. Fixed finger tooth row comprising four or five small teeth.

Coxosternal region: Tritosternum very small, barely visible, not abutting coxae of legs I (fig. 13C); coxae of legs II-IV abutting one another medially along entire length; coxae of legs II, anterior and posterior margins almost parallel, slightly narrowing medially, not perpendicular to median axis, inclined anteriorly; coxae of legs II, posterior margin $\mathrm{V}$-shaped medially; suture between coxae of legs II approximately $2 \times$ length of suture between coxae of legs III and $1.5 \times$ length of suture between coxae of legs IV.

Opisthosoma: Opisthosoma oval, longer than wide, broadest at tergite XII. Posterodorsal and posteroventral margins without spiniform granules (figs. 16C, 19C). Tergites X-XIII each comprising median and lateral sclerites; median sclerites of tergites XI-XIII each with paired, shallow submedian depressions near anterior margins; lateral margins of median sclerites converging posteriorly on tergite XI and, to lesser extent, XII, subparallel on XIII; median sclerites of tergites XI and XII wider than long, of XIII approximately as wide as long, square; margins of lateral sclerites adjacent to tergal longitudinal membranes predominantly linear, tergal membranes narrow. Sternites XI-XIII each with pair of shallow submedian depressions similar to tergites (fig. 19C). Pygidium, basal segment parallel to longitudinal axis of opisthosoma; opening narrow, slightly compressed laterally, width two fifths lateral width of segment at its base; posterior border narrow; dorsal surface with V-shaped notch; ventral surface entire.

Pedipalps: Femur globose, length slightly more than $2 \times$ depth. Tibia longer than femur; entirely linear (fig. 20I); not noticeably robust or swollen proximally, margins subparallel in dorsal 
and lateral aspects; apical longitudinal carinae absent. Movable finger approximately $2 \times$ length of fixed finger.

Legs: Leg II longest, femur markedly incrassate (figs. 26A, B). Femora width (at midline) progressively increasing in order leg IV $<$ III $<$ I $<<$ II; dorsal surface with longitudinal sulcus distinct on all legs (fig. 4A). Leg I tibia without ventral apophyses; metatarsus subcircular in cross section, with moderate proventral depression in proximal half and without prominent ventral excrescence (fig. 21I). Leg II tibia without ventromedian apophysis (fig. 26C); tibia and metatarsus without pad of long translucent setae ventrally; metatarsus with shallow subproximal depression but without ventrosubmedian concavity or excrescence (fig. 26D); first to third tarsomeres short, subequal, fourth approximately $2 \times$ length of preceding tarsomeres; all tarsomeres movable. Leg III metatarsus not swollen, with moderate concavity dorsodistally; proventral surface without apical brushlike row of setae; prodorsal proximal sulcus present; metatarsus, metatarsal process, and tarsus precisely fitting together to completely encase copulatory apparatus when tarsus retracted; metatarsal process situated basally near tibia, robust, tapering and slightly laterally compressed, longitudinal axis sinuous, apex pointing retrolaterally; lamina cyathiformis of second tarsomere slightly longer than deep, with pointed apex; subdistal (third) tarsomere with acute dorsodistal process. Leg IV tarsus unknown (legs IV incomplete, second to fifth tarsomeres missing). Leg III (and presumably leg IV) terminal tarsomere apex, dorsal margin sublinear, covering ungues. Leg I tarsus and legs II and III terminal tarsomeres without ventrodistal papillae (legs IV incomplete, second to fifth tarsomeres missing).

Copulatory apparatus: Fixed process, PL lobe moderately expanded and dorsoventrally compressed (figs. 32B, D). Distal lobular region, primary a lobe broken, missing part lost (figs. 32, 33I); Tuxen's (1974: 102) figure 38 suggests the lobe is long, narrow, and curving toward ventral surface, but is uninformative about the shape of its margins. Primary $\beta$ lobe medium sized, distinctly bicuspid, with $\beta_{1}$ and $\beta_{2}$ pointed, and $\beta_{1}$ noticeably larger. $r s d$ lobe medium sized, pronounced, associated with distinct subdistal emargination. Secondary $p d$ and $r d$ lobes well developed, pointed. Movable process slender, slightly flexible, narrowing distally; apex simple, entire.

Female: Unknown. The specimen described by Harvey (1984) as the female of $R$. westerman$n i i$, is probably conspecific with $R$. atewa.

Distribution: The type locality of $R$. westermannii, Bismarckbourg $\left(08^{\circ} 10^{\prime} 39^{\prime \prime} \mathrm{N} 00^{\circ} 41^{\prime} 15^{\prime \prime} \mathrm{E}\right)$, is situated in the Centrale Region of Togo, whereas the type locality of its junior synonym, $R$. plebejum, Misahöhe (Misahohé/Missahohé, 06 $57^{\circ} \mathrm{N}$ $00^{\circ} 35^{\prime} \mathrm{E}$ ), mispelled "Misalishe" in various works (e.g., Tuxen, 1974; Harvey, 2003), is situated in the Plateaux Region of Togo (fig. 5). Ricinoides westermannii has also been reported from Côte d'Ivoire and Ghana (Legg, 1978b, 1982; Harvey, 1984, 2003), but these records are doubtful, considering the narrow geographical distributions of most ricinuleid species. The reports by Legg (1978b, 1982), based on two deutonymphs and two tritonymphs from Man, Côte d'Ivoire (MHNG) and a tritonymph from Tafo, Ghana (AMNH IZC 324953), all of which were examined during the present investigation, cannot be confirmed because adult males are presently unknown from these localities. Harvey's (1984) report of $R$. westermannii from Mt. Atewa, Ghana, the type locality of $R$. atewa, is probably conspecific with the latter.

\section{Ricinoides sp.}

Figures 3, 5

Ricinoides feae (Hansen, 1921): Murienne et al., 2013: 2, figs. 1, 2 (misidentification);

Fernández and Giribet, 2015: 6, 7

(misidentification).

Ricinoides aff. feae (Hansen, 1921): Murienne et al., 2013: 2, figs. 1, 2; Fernández and Giribet, 2015: 7.

Ricinoides afzelii (Thorell, 1892) or Ricinoides feae (Hansen, 1921): Penney et al., 2009: 66-68, figs. $2,3$. 
REMARKs: The phylogenetic analyses of Murienne et al. (2013) and Fernández and Giribet (2015) included material, misidentified as $R$. feae, from Guinea-Bissau. Comparison with the type specimens of $R$. feae indicate that these specimens belong to a closely related, undescribed species. Unfortunately, the specimens were carelessly damaged in the process of DNA extraction: legs were removed from the adults and the male copulatory apparatus broken, eliminating or damaging the structures necessary for diagnosis and description. Consequently, the description of this species is postponed until intact material becomes available. The male specimen from the Gambia is unsuitable for description as the sinistral leg III is abnormal and the dextral copulatory apparatus damaged. Although a complete comparison of all the taxonomically informative characters cannot be conducted, given the condition of the few males available, all these specimens are presumed to belong to the same undescribed species. They are also probably conspecific with the specimens reported by Penney et al. (2009) from two other Gambian localities: Abuko Nature Reserve $\left(13^{\circ} 23^{\prime} 28.38^{\prime \prime} \mathrm{N} 16^{\circ} 39^{\prime} 00.18^{\prime \prime} \mathrm{W}\right)$ and Bijilo Forest Park $\left(13^{\circ} 26^{\prime} 16^{\prime \prime} \mathrm{N} 16^{\circ} 43^{\prime} 32^{\prime \prime} \mathrm{W}\right)$. These specimens, which Penney et al. (2009) regarded as likely belonging to either $R$. afzelii or $R$. feae, were not collected, however, and photographs of the habitus of the live animals are the only record available.

MATERIAL EXAMINED: THE GAMBIA: Lower River: Kiang West, Keneba $\left[13^{\circ} 19^{\prime} 52^{\prime \prime} \mathrm{N} 16^{\circ} 00^{\prime} 34^{\prime \prime} \mathrm{W}\right]$, 8.viii.1957, D.H. Murphy, moist litter in secondary forest, 1 o (BMNH 13588975 old 1958.10.7.1), 31.vii.1957, D.H. Murphy, deciduous litter in relict riverine forest, 1 o, 1 larva (BMNH 13588976 old 1958.10.7.2-3), 4. ix.1957, 1 ㅇ, 1 tritonymph, 1 larva (BMNH 14041443 old 1958.10.7.4-6), 19.i.1958, 2 protonymphs (BMNH 14041444 old 1958.10.7.7-8). Western Region: Brikama [13 $16^{\prime} \mathrm{N} 16^{\circ} 39^{\prime} \mathrm{W}$ ], 12.vii.1993, P. Olivier, border of primary forest, 2 (MRAC 177.186). GUINEA-BISSAU: Bafatá Region: Bambadinca, property of Riverzoo Farm, $12^{\circ} 00^{\prime} 09^{\prime \prime} \mathrm{N} 14^{\circ} 53^{\prime} 25.9^{\prime \prime} \mathrm{W}, 29 . v i .2005$, J. Huff and V. Vignoli, secondary growth bordered by river and grass savannah, leaf litter sifting, 3 tritonymphs, 6 deutonymphs, 10 protonymphs (AMCC [LP 4664]);
Bambadinca, $19 \mathrm{~km} \mathrm{~S}, 11^{\circ} 53^{\prime} 03.9^{\prime \prime} \mathrm{N} 14^{\circ} 50^{\prime} 08.5^{\prime \prime} \mathrm{W}$, 1.vii.2005, J. Huff and V. Vignoli, wet savannah with marginal secondary rainforest, leaf litter sifting, 1 ot (AMCC [LP 4662]), 1 tritonymph, 1 deutonymph (AMCC [LP 4663]); Bambadinca, $22 \mathrm{~km} \mathrm{S,} 12^{\circ} 04^{\prime} 53.6^{\prime \prime} \mathrm{N}$ $14^{\circ} 48^{\prime} 03.7^{\prime \prime} \mathrm{W}, 30 . v i .2005$, J. Huff and V. Vignoli, mango plantation behind village, leaf litter sifting, $1 \delta, 1$ ㅇ (AMCC [LP 4661]), 4 tritonymphs, 1 deutonymph, 5 protonymphs, 2 larvae (AMCC [LP 4658]), $12^{\circ} 04^{\prime} 53.6^{\prime \prime} \mathrm{N} 14^{\circ} 48^{\prime} 03.7^{\prime \prime} \mathrm{W}, 2 . v i i .2005$, J. Huff and V. Vignoli, wet forest with permanent pond, under log, 1 o (AMCC [LP 4660]). SENEGAL: Kédougou Region: Kédougou, W along road to Salemata, $12^{\circ} 33^{\prime} 10.6^{\prime \prime} \mathrm{N}$ $12^{\circ} 13^{\prime} 39.4^{\prime \prime} \mathrm{W}, 4 . v i i .2005$, J. Huff and V. Vignoli, sparse forest with small boulders, hand collected under rocks and logs, 1 \& (AMCC [LP 4659]).

\section{ACKNOWLEDGMENTS}

R.B.-T. was supported by a Theodore Roosevelt Postdoctoral Research Fellowship from the AMNH Richard Gilder Graduate School (RGGS) and U.S. National Science Foundation (NSF) grant DEB 1655050 to L.P. C.E.S. was supported for a nineweek internship in the 2019 NSF-funded Research Experiences for Undergraduates program at the AMNH, during which part of this project was conducted under the supervision of R.B.-T. R.B.-T. thanks John J. Flynn (Dean of the RGGS), Rebecca Johnson (RGGS Director of Administration), David A. Grimaldi (Acting Chair, Division of Invertebrate Zoology), and Edward Gaughan (Invertebrate Zoology Administrative Assistant) for support and assistance during the COVID-19 pandemic, when this work was completed. The authors thank the curators and managers of institutional collections who loaned material for study: Janet Beccaloni and Danniella Sherwood (BMNH), Petra Sierwald and Crystal A. Maier (FMNH), Peter J. Schwendinger (MHNG), Christophe Allard and Rudy Jocqué (MRAC), Maria Tavano (MSNG), Julia Stigenberg (NHRS), Hannah Wood and Dana M. DeRoche (USNM), Jason A. Dunlop (ZMB), Nikolaj Scharff and Jan Pedersen (ZMUC); Jeremy Huff and Valerio Vignoli for fieldwork in GuineaBissau and Senegal in 2005 (supported by NSF grant EAR 0228699 to L.P.); Andrew K. Smith and Morgan Hill for access to imaging equipment at the 
AMNH Microscopy and Imaging Facility; Martín J. Ramírez and Fabián Tricárico for access to the scanning-electron microscope at the MACN; Steve R. Davis (AMNH) for discussions on morphological characters; Steve Thurston (AMNH) for assistance with preparing the plates for this contribution; Piotr Naskrecki for the image on the cover; Elena Babicz for the image in figure 1; Pío A. Colmenares, Stephanie F. Loria, and Louis N. Sorkin for logistical assistance at the AMNH; Oscar F. Francke and Leonardo S. Carvalho for helpful comments on an earlier version of the manuscript.

\section{REFERENCES}

Armas, L.F., de. 2017. Cuatro especies nuevas de Pseudocellus de Cuba (Arachnida: Ricinulei). Revista Ibérica de Aracnología 30: 87-99.

Ballesteros, J.A., and P.P. Sharma. 2019. A critical appraisal of the placement of Xiphosura (Chelicerata) with account of known sources of phylogenetic error. Systematic Biology 68 (6): 896-917.

Ballesteros, J.A., C.E. Santibáñez-López, L. Kováč, E, Gavish-Regev, and P.P. Sharma. 2019. Ordered phylogenomic subsampling enables diagnosis of systematic errors in the placement of the enigmatic arachnid order Palpigradi. Proceedings of the Royal Society B, Biological Sciences 286: 1-9.

Bolívar y Pieltain, C. 1942. Estudio de un ricinulideo de la Caverna de Cacahuamilpa, Guerrero, Mex. (Arachnida). Revista de la Sociedad Mexicana de Historia Natural 2: 197-209.

Börner, C. 1902. Arachnologische Studien (II und III). Zoologischer Anzeiger 25: 433-466.

Botero-Trujillo, R., and E. Flórez. 2017. Two new ricinuleid species from Ecuador and Colombia belonging to the peckorum species-group of Cryptocellus Westwood (Arachnida, Ricinulei). Zootaxa 4286 (4): 483-498.

Botero-Trujillo, R., and A. Valdez-Mondragón. 2016. A remarkable new species of the magnus speciesgroup of Cryptocellus (Arachnida, Ricinulei) from Ecuador, with observations on the taxonomy of the New World genera. Zootaxa 4107 (3): 321-337.

Cokendolpher, J.C. 2000. First Cryptocellus from Suriname (Ricinulei). Memorie della Società Entomologica Italiana 78 (2): 515-520.

Cokendolpher, J.C., and T. Enríquez. 2004. A new species and records of Pseudocellus (Arachnida: Ricinulei: Ricinoididae) from caves in Yucatán, Mexico and Belize. Texas Memorial Museum, Speleological Monographs 6: 95-99.

Dubinin, V.B. 1962. Podtip Chelicerophora. Khelitseronosnye chlenistonogie [Subphylum Chelicerophora. Chelicerate arthropods]. In B.B. Rohdendorf (editor), Osnovy paleontologii [Fundamentals of paleontology]: 375-530. Moscow: Academy of Sciences of the U.S.S.R. [in Russian]

Dumitresco, M., and I. Juvara-Balş. 1977a. L'importance de la structure des organes copulateurs femelles dans la systématique des Ricinulei. Travaux de l'Institute de Spéologie "Émile Racovitza" 16: 259-261.

Dumitresco, M., and I. Juvara-Balş. 1977b. Position systematique de Heteroricinoides bordoni n. g. n. sp. dans la famille Ricinuleididae (Arachnida). Boletín de la Sociedad Venezolana de Espeleologia 7 (14): 147-180.

Dunlop, J.[A.] 1994. Ricinuleids. Journal of the British Tarantula Society 10: 55-58.

Dunlop, J.A. 1996. Evidence for a sister group relationship between Ricinulei and Trigonotarbida. Bulletin of the British Arachnological Society 10 (6): 193-204.

Ewing, H.E. 1929. A synopsis of the American arachnids of the primitive order Ricinulei. Annals of the Entomological Society of America 22: 583-600.

Fernández, R., and G. Giribet. 2015. Unnoticed in the tropics: phylogenomic resolution of the poorly known arachnid order Ricinulei (Arachnida). Royal Society Open Science 2: 1-13.

Fritsch, A. 1904. Palaeozoische Arachniden. Prague: A. Fric.

García, L.F., E. Torrado-León, G. Talarico, and A.V. Peretti. 2015. First characterization of the behavioral repertory in a ricinuleid: Cryptocellus narino Platnick \& Paz 1979 (Arachnida, Ricinulei, Ricinoididae). Journal of Insect Behavior 28: 447-459.

Gertsch, W.J. 1971. Three new ricinuleids from Mexican caves (Arachnida, Ricinulei). Bulletin of the Association for Mexican Cave Studies 4: 127-135.

Gertsch, W.J., and S. Mulaik. 1939. Report on a new ricinuleid from Texas. American Museum Novitates 1037: 1-5.

Gervais, P. 1844. Ordre V. Phalangides. In C.A. Walckenaer (editor), Histoire naturelle des insectes. Aptères, vol. 3. Paris: Librairie Encyclopédique de Rôret.

Guérin-Méneville, F.E. 1838. Note sur l'Acanthodon et sur le Cryptostemme, nouveaux genres d'arachnides. Revue Zoologique 1: 10-14.

Hansen, H.J. 1921. The Pedipalpi, Ricinulei, and Opiliones (exc. Op. Laniatores) collected by Mr. Leonardo Fea in tropical West Africa and adjacent 
islands. In Studies on Arthropoda, vol. 1: 1-55. Copenhagen: Gyldendalske Boghandel.

Hansen, H.J. 1930. On the comparative morphology of the appendages in the Arthropoda. B. Crustacea (supplement), Insecta, Myriopoda, and Arachnida. In Studies on Arthropoda, vol. 3: 1-376. Copenhagen: Gyldendalske Boghandel.

Hansen, H.J., and W. Sørensen. 1904. On two orders of Arachnida. Cambridge, U.K.: Cambridge University Press.

Harvey, M.S. 1984. The female of Ricinoides westermannii (Guérin-Méneville), with notes on those of $R$. afzelii (Thorell) and R. karschii (Hansen \& Sørensen) (Ricinulei). Bulletin of the British Arachnological Society 6 (5): 205-210.

Harvey, M.S. 2003. Catalogue of the smaller arachnid orders of the world. Collingwood, Victoria, Australia: CSIRO Publishing.

Kaestner, A. 1968. Arthropod relatives, Chelicerata, Myriapoda. In Invertebrate zoology, vol. 2. New York: Wiley.

Karsch, F. 1892. Ueber Cryptostemma Guér. als einzigen recenten Ausläufer der fossilen Arachnoideen-Ordnung der Meridogastra Thor. Berliner Entomologische Zeitschrift 37: 25-32.

Kästner, A. 1932. Ricinulei Thorell. In W. Kükenthal, Handbuch der Zoologie, 3 (2) (4): 99-116. Berlin and Leipzig: Walter de Gruyter.

Kennaugh, J.H. 1968. An examination of the cuticle of three species of Ricinulei (Arachnida). Journal of Zoology (London) 156: 393-404.

Legg, G. 1976a. The external morphology of immature stages of Ricinoides karschi (Arachnida: Ricinulei). Bulletin of the British Arachnological Society 3 (9): 243-248.

Legg, G. 1976b. The external morphology of a new species of ricinuleid (Arachnida) from Sierra Leone. Zoological Journal of the Linnean Society 59: 1-58.

Legg, G. 1977. Sperm transfer and mating in Ricinoides hanseni (Ricinulei: Arachnida). Journal of Zoology (London) 182: 51-61.

Legg, G. 1978a. Two new ricinuleids from W. Africa (Arachnida: Ricinulei) with a key to the adults of the genus Ricinoides. Bulletin of the British Arachnological Society 4 (2): 89-99.

Legg, G. 1978b. The status of Ricinoides plebejus and a note on R. afzelii (Ricinulei, Arachnida). Bulletin of the British Arachnological Society 4 (3): 124-125.

Legg, G. 1982. Some Ricinulei (Arachnida) from Ivory Coast, including a new species and a note on the immature stages of Ricinoides westermanni (Hansen
\& Sørensen). Revue Suisse de Zoologie 89 (2): $287-$ 296.

Lucas, H. 1838. Phalangiens. In F.-E. Guerin (editor), Dictionnaire pittoresque d'histoire naturelle et des phénomènes de la nature, vol. 7: 349-354. Paris: Au Bureau de Souscription.

Millot, J. 1945a. La constitution de l'abdomen des Ricinulei (Arachnides). Bulletin de la Société Entomologique de France 59: 72-74.

Millot, J. 1945b. Lanatomie interne des Ricinulei (Arachnides). Annales des Sciences Naturelles, Zoologie 11 (7): 1-29.

Millot, J. 1949a. Classe de Arachnides (Arachnida). I. - Morphologie générale et anatomie interne. In P.-P. Grassé (editor), Traité de zoologie, vol. 6: 263-319. Paris: Masson et Cie.

Millot, J. 1949b. Ordre des Ricinuléides. In P.-P. Grassé (editor), Traité de zoologie, vol. 6: 744-760. Paris: Masson et Cie.

Moritz, M., and S.C. Fischer. 1980. Die Typen der Arachniden-Sammlung des Zoologischen Museums Berlin. II. Uropygi, Amblypygi, Schizomida, Ricinulei, Solifuga. Mitteilung aus dem Zoologischen Museum in Berlin 56: 137-154.

Murienne, J., L.R. Benavides, L. Prendini, G. Hormiga, and G. Giribet. 2013. Forest refugia in Western and Central Africa as 'museums' of Mesozoic biodiversity. Biology Letters 9: 2-7.

Naskrecki, P. 2008. A new ricinuleid of the genus Ricinoides Ewing (Arachnida, Ricinulei) from Ghana. Zootaxa 1698: 57-64.

Penney, D., Y. Marusik, C.P. Wheater, and A.M. Langan. 2009. First Gambian Ricinulei (Arachnida: Ricinoididae): northernmost African record for the order. Zootaxa 2021: 66-68.

Petrunkevitch, A. 1913. A monograph of the terrestrial Palaeozoic Arachnida of North America. Transactions of the Connecticut Academy of Arts and Sciences 18: 1-137.

Petrunkevitch, A. 1955. Arachnida. In R.C. Moore (editor), Treatise on invertebrate paleontology. Part P. Arthropoda. 2. Chelicerata with sections on Pycnogonida and Palaeoisopus: 42-162. Lawrence, KS: Geological Society of America and University of Kansas Press.

Platnick, N.I. 1980. On the phylogeny of Ricinulei. In J. Gruber (editor), Verhandlungen 8. Internationaler Arachnologen-Kongress abgehalten an der Universität für Bodenkultur, Wien, 7-12 Juli, 1980: 349353. Vienna: H. Egermann.

Pollock, J. 1966. Secret life of the ricinulid. Animals (London) 8: 402-405. 
Pollock, J. 1967. Notes on the biology of Ricinulei (Arachnida). Journal of the West African Science Association 12: 19-22.

Santibáñez-López, C.E., et al. 2018. Integration of phylogenomics and molecular modeling reveals lineage-specific diversification of toxins in scorpions. PeerJ 6: 1-23.

Savory, T.H. 1964. Arachnida. London: Academic Press. Savory, T.H. 1977. Arachnida, 2nd ed. London: Academic Press.

Selden, P.A. 1992. Revision of the fossil ricinuleids. Transactions of the Royal Society of Edinburgh: Earth Sciences 83: 595-634.

Selden, P.A., and J.A. Dunlop. 1998. Fossil taxa and relationships of chelicerates. In G. Edgecombe (editor), Arthropod fossils and phylogeny: 303-331. New York: Columbia University Press.

Sharma, P.P., et al. 2014. Phylogenomic interrogation of Arachnida reveals systemic conflicts in phylogenetic signal. Molecular Biology and Evolution 31 (11): 2963-2984.

Sharma, P.P., R. Fernández, L.A. Esposito, E. GonzálezSantillán, and L. Monod. 2015. Phylogenomic resolution of scorpions reveals multilevel discordance with morphological phylogenetic signal. Proceedings of the Royal Society B, Biological Sciences 282: $1-10$.

Sharma, P.P., et al. 2018. A revised dated phylogeny of scorpions: phylogenomic support for ancient divergence of the temperate Gondwanan family Bothriuridae. Molecular Phylogenetics and Evolution 122: 37-45.

Teruel, R. 2018. Two remarkable new species of Pseudocellus Platnick, 1980 (Ricinulei: Ricinoididae) from eastern Cuba. Ecologica Montenegrina 19: 73-88.

Thorell, T. 1892. On an apparently new arachnid belonging to the family Cryptostemmoidae, Westw. Kungliga Svenska Vetenskaps-akademiens Handlingar 17: 1-18.

Tuxen, S.L. 1974. The African genus Ricinoides (Arachnida, Ricinulei). Journal of Arachnology 1: 85-106.

Valdez-Mondragón, A., and O.F. Francke. 2011. Four new species of the genus Pseudocellus (Arachnida: Ricinulei: Ricinoididae) from Mexico. Journal of Arachnology 39: 365-377.

Valdez-Mondragón, A., and O.F. Francke. 2013. Two new species of ricinuleids of the genus Pseudocellus (Arachnida: Ricinulei: Ricinoididae) from southern Mexico. Zootaxa 3635 (5): 545-556.
Valdez-Mondragón, A., and A.R. Juárez-Sánchez. 2021. A new epigean species of ricinuleid of the genus Pseudocellus (Arachnida: Ricinulei: Ricinoididae) from a tropical sub-deciduous forest in Oaxaca, Mexico. Journal of Arachnology 48: 329-338.

Valdez-Mondragón, A., O.F. Francke, and R. BoteroTrujillo. 2018. New morphological data for the order Ricinulei with the description of two new species of Pseudocellus (Arachnida: Ricinulei: Ricinoididae) from Mexico. Journal of Arachnology 46: 114-132.

Valdez-Mondragón, A., M.R. Cortez-Roldán, and E.F. Campuzano-Granados. 2020. On the Mexican ricinuleids: a new species of the genus Pseudocellus (Arachnida: Ricinulei: Ricinoididae) from the cloud forest of Chiapas, Mexico. Revista Mexicana de Biodiversidad 91: 1-12.

Westwood, J.O. 1874. Thesaurus entomologicus oxoniensis. Oxford: Clarendon Press.

Whalen, N., and P. Selden. 2020. A new, giant ricinuleid (Arachnida, Ricinulei), from the Pennsylvanian of Illinois, and the identification of a new, ontogenetically stable, diagnostic character. Journal of Paleontology. [doi: 10.1017/jpa.2020.104]

Wunderlich, J. 2012. Description of the first fossil Ricinulei in amber from Burma (Myanmar), the first report of this arachnid order from the Mesozoic and from Asia, with notes on the related extinct order Trigonotarbida. In J. Wunderlich (editor), Beiträge zur Araneologie 7, Fifteen papers on extant and fossil spiders (Araneae): 233-244. Hirschberg, Germany: Joerg Wunderlich.

Wunderlich, J. 2015. New and rare fossil Arachnida in Cretaceous Burmese amber (Amblypygi, Ricinulei and Uropygi: Thelephonida [sic]). In J. Wunderlich (editor), Beiträge zur Araneologie 9, Spinnen des erdmittelalters: 409-436. Hirschberg, Germany: Joerg Wunderlich.

Wunderlich, J. 2017. New extinct taxa of the arachnid order Ricinulei, based on new fossils preserved in mid Cretaceous Burmese amber. In J. Wunderlich (editor), Beiträge zur Araneologie 10, Ten papers on fossil and extant Spiders (Araneae): 48-71. Hirschberg, Germany: Joerg Wunderlich.

Zakhvatkin, A.A. 1952. Razdelenie kleshcher (Acarina) na otriâdy i ikh polozhenie v sisteme Chelicerata [Division of mites (Acarina) into orders and their position in the system of Chelicerata]. Parazitologicheskii Sbornik Zoologicheskii Institut Akademii Nauk SSSR 14: 5-46. [in Russian] 